\title{
8 Raumreferenzierung und -belegung
}

Zusammenfassung: Im Kapitel wird dargelegt, welche musterhaften raumbezogenen Formen kolonialer Referenzierung und -belegung durch Namenvergabeprozesse festzustellen sind. Für den quantitativ untergeordneten Bestand an Einzelbenennungen rücken die spezifisch kolonialen Kommemorationen solcher Inventare z. T. in den Hintergrund. Der maßgebliche Hauptanteil ist dagegen innerhalb von Kolonialclustern zu verorten, für die eindeutige zeitliche Distributionen festzustellen sind. Auch in clusterbezogener Perspektive sind dominante Konstruktionsmuster herauszustellen. Darüber hinaus werden die für gebündelte koloniale Namenvergaben festzustellenden Georeferenzierungen dargelegt, die der kolonialrevisionistischen Propaganda in den 1920ern und 1930er Jahren entsprechen. Die Kolonialcluster der drei annektierten Städte weisen partielle Übereinstimmungen (Pabianitz [Pabianice] und Königshütte [Chorzów]), aber auch Abweichungen (Lodz bzw. Litzmannstadt [€ódź]) auf, die vor dem Hintergrund der städtebezogenen Umbenennungsprozesse durch die Nationalsozialisten diskutiert werden.

Die Berücksichtigung der historischen Positionierung kolonial motivierter Straßenbenennungen in die unmittelbare Raumdeskription führt zu weiteren Erkenntnissen der damit versprachlichten kolonisatorischen Gewissheiten. Dementsprechend wurde jedes einzelne SN-Token hinsichtlich raumlinguistischer Aspekte annotiert, also danach, ob der kolonial motivierte Straßenname als Einzelbenennung oder innerhalb eines themenkohärenten Kolonialclusters verfügt wurde. Neben Hinweisen in historischen Adressbüchern, administrativen Texten u. dgl. geben insbesondere historische Stadtpläne Aufschluss über die räumliche Verortung der Namen. Für das erstellte Gesamtinventar können hinsichtlich der beiden Formen von Raumbelegung folgende Distributionen herausgestellt werden:

Tab. 22: Raumbezogene Formen kolonialer Referenzierung und -belegung.

\begin{tabular}{lll}
\hline & Einzelbenennungen & innerhalb von Kolonialclustern \\
\hline Anzahl an SN-Token & 72 & 455 \\
Distributionen & ca. $19 \%$ & ca. $86 \%$ \\
\hline
\end{tabular}

Kolonial motivierte Straßennamen, die als Einzelbenennungen in den öffentlichen Raum verfügt wurden, stellen ein zahlenmäßig untergeordnetes Phänomen dar. Prototypisch ist dagegen die gebündelte Verfügung mehrerer SNToken als themenkohärente Kolonialcluster für parallele, sich kreuzende und/

Ә Open Access. (C) 2021 Verena Ebert, publiziert von De Gruyter. (c))BY-ND Dieses Werk ist lizenziert unter der Creative Commons Attribution-NoDerivatives 4.0 International Lizenz.

https://doi.org/10.1515/9783110718133-009 
oder in unmittelbarer räumlicher Nähe zueinander liegende Straßenzüge. Im Folgenden wird diskutiert, welche historischen Formen kommemorativer Raumreferenzierung und -belegung mit kolonial motivierten Namenvergabepraktiken als Einzelbenennungen bzw. Clusterbenennungen bis 1945 in ortsübergreifendnationaler Perspektive festzustellen sind.

\subsection{Einzelbenennungen}

Für das Teilinventar an 72 singulären SN-Token können aus raumlinguistischer Perspektive drei unterschiedliche Formen kolonial motivierter Einzelbenennungen ausgemacht werden:

- Singuläre ortsbezogene Einzelbenennungen (a)

- Zwei und mehr voneinander unabhängige ortsbezogene Einzelbenennungen (b)

- Singuläre oder zwei und mehr voneinander unabhängige ortsbezogene Einzelbenennungen neben Kolonialclustern (c)

Die drei unterschiedlichen Formen kolonial motivierter Namenvergabepraktiken als Einzelbenennungen erfolgen in drei Tabellen, in denen jede Einzelbenennung mit dem jeweiligen Verfügungsort dargelegt wird. Es folgen Nachweise darüber, in welchen Quellengattungen die jeweiligen SN-Token erhoben werden konnten. Im Anschluss an die jeweiligen tabellarisch aufgezeigten drei Formen von Einzelbenennungen werden die Inventare im ortsübergreifenden Zugriff im Hinblick auf prototypische Strukturen und den damit intendierten kommemorativen Funktionen unter Einbezug ihrer Benennungszeiträume untersucht.

\subsubsection{Inventare}

Singuläre ortsbezogene Einzelbenennungen konnten in historischen Adressbüchern, Stadtplänen u. dgl. für folgende Orte erhoben werden:

Tab. 23: Singuläre ortsbezogene Einzelbenennungen (a).

\begin{tabular}{lll}
\hline Stadt & SN-Token & Literaturnachweise \\
\hline Altena & Karl-Peters-Str. & Weidner. $^{143}$ \\
\hline
\end{tabular}

143 https:/www.lwl.org/westfaelische-geschichte/nstopo/strnam/Begriff_27_Orte.html, Abruf am 28/06/2019. 


\begin{tabular}{|c|c|c|}
\hline Stadt & SN-Token & Literaturnachweise \\
\hline Amberg & Lüderitzplatz & Adressbuch Amberg (1938 II: 50). \\
\hline Asch $[A \check{c}]$ & Lüderitzstr. & Adressbuch Asch (1941 II: 43). \\
\hline $\begin{array}{l}\text { Brandenburg an der } \\
\text { Havel }\end{array}$ & Gustav-Nachtigal-Str. & $\begin{array}{l}\text { Stadtplan Brandenburg an der Havel } \\
\text { (1955). }{ }^{144}\end{array}$ \\
\hline Erfurt & Wissmannstr. & $\begin{array}{l}\text { Wohnungsanzeiger Erfurt (1919), Adressbuch } \\
\text { Erfurt (1924 IV: 212), Blaha et al. (1992: 43). }\end{array}$ \\
\hline Frankfurt/Oder & Wißmannstr. & $\begin{array}{l}\text { Adressbuch Frankfurt/Oder (1929 II: 263), } \\
\text { Stadtplan Frankfurt/Oder (1937). }\end{array}$ \\
\hline Glatz [Kłodzko] & Lettow-Vorbeck-Str. & $\begin{array}{l}\text { Adressbuch Glatz (1937 II: 111), Gierich } \\
(1982: 110) .\end{array}$ \\
\hline Hildesheim & Karl-Peters-Str. & Stadtplan Hildesheim (1940). \\
\hline Iglau [Jihlava] & Lüderitzgasse & $\begin{array}{l}\text { Stadtplan Iglau (1943), Kalousková (ange- } \\
\text { nommen). }\end{array}$ \\
\hline Iserlohn & Karl-Peters-Str. & Weidner. ${ }^{145}$ \\
\hline Kaiserslautern & Karl-Peters-Str. & Stadtverwaltung Kaiserslautern (2001: 31). \\
\hline Karlsbad [Karlovy Vary] & $\begin{array}{l}\text { Herrmann-von- } \\
\text { Wissmann-Str. }\end{array}$ & $\begin{array}{l}\text { Stadtplan Karlsbad (1940), Kalousková } \\
\text { (angenommen). }\end{array}$ \\
\hline Kattowitz [Katowice] & Lettow-Vorbeck-Str. & Stadtplan Kattowitz $(1940,1942)$. \\
\hline Leslau [Włocławek] & Karl-Peters-Str. & Stadtplan Leslau (1942). \\
\hline Lüneburg & Karl-Peters-Str. & Reinecke (2007: 102). \\
\hline Lünen & Lettow-Vorbeck-Str. & Adressbuch Lünen (1938 II), Weidner. ${ }^{146}$ \\
\hline München Gladbach & Lettow-Vorbeck-Str. & $\begin{array}{l}\text { Stadtplan München Gladbach und Rheydt } \\
\text { (1940), Wittmann-Zenses (1998: 68). }\end{array}$ \\
\hline Oldenburg & Tangastr. & $\begin{array}{l}\text { Adressbuch Oldenburg (1940 III: 331), } \\
\text { Schohusen (1977: 245). }\end{array}$ \\
\hline Pirmasens & Dr. Carl-Peters-Str. & Hauptausschussprotokoll Pirmasens (21.1.1947). \\
\hline Saarbrücken & Lüderitzstr. & $\begin{array}{l}\text { Adressbuch Saarbrücken (1926/27 II: 497, } \\
\text { 1934/35 II: 570). }\end{array}$ \\
\hline Saarlouis bzw. Saarlautern & Von-Lettow-Vorbeck-Str. & Bungert (2014: 58). \\
\hline Schweidnitz [Świdnica] & Lüderitzufer & $\begin{array}{l}\text { Adressbuch Schweidnitz (1942 I: 147), Adler } \\
\text { (2006: 31). }\end{array}$ \\
\hline
\end{tabular}

144 Das SN-Token taucht im Adressbuch Brandenburg an der Havel (1938/39) noch nicht auf. Es ist zu vermuten, dass die Benennung noch vor 1945 erfolgte.

145 http://www.lwl.org/westfaelische-geschichte/nstopo/strnam/Begriff_27.html, Abruf am 28/06/2019.

146 https://www.lwl.org/westfaelische-geschichte/nstopo/strnam/Kommune_138.html, Abruf am 28/06/2019. 


\begin{tabular}{lll}
\hline Stadt & SN-Token & Literaturnachweise \\
\hline Siegburg & Dr. Karl-Peters-Str. & Stadtplan Siegburg (ca. 1942). \\
Stolberg (Rhld.) & Dr. Karl-Peters-Str. & Stadtplan Stolberg (1942). \\
Tübingen & Eduard-Haber-Str. & Adressbuch Tübingen (1942 III: 19), Eck \\
& & $(2017:$ 224). \\
Wiesbaden & Karl-Peters-Str. & Stadtplan Wiesbaden (1939). \\
Zerbst/Anhalt & Karl-Peters-Str. & Adressbuch Zerbst/Anhalt (1939/40 II: 232). \\
\hline
\end{tabular}

Einzelbenennungen sind sowohl für Großstädte als auch für eine vergleichbare Anzahl an Mittelstädten festzustellen. Bis auf die in Erfurt bzw. Frankfurt/Oder am Ende der faktischen Kolonialzeit bzw. in den 1920er Jahren verfügten Benennungen fallen alle weiteren singulären Namenverfügungen in die nationalsozialistische Zeit. Für die erst Ende der 1930er Jahre im Zuge des Münchener Abkommens bzw. des Polenfeldzugs annektierten Gebiete konnten koloniale Einzelbenennungen für Asch [Aš], Iglau [Jihlava] und Karlsbad [Karlovy Vary] (Kap. 4) bzw. in Kattowitz [Katowice] (Lettow-Vorbeck-Straße) und Leslau [Włoclawek] (Karl-Peters-Straße) erhoben werden.

Ein zweites Muster stellen Orte dar, für die zwei oder mehrere kolonial motivierte SN-Token als Einzelbenennungen in der unmittelbaren Raumdeskription auszumachen sind, d. h. bei den betreffenden Straßenzügen handelt sich weder um parallel angelegte oder sich kreuzende noch in der Nähe zueinander liegende Straßen. So konnten bspw. für die Mittelstadt Altenburg drei singuläre Einzelbenennungen erhoben werden. Die kolonial motivierten SN-Token Samoa- und Togoweg wurden noch in der Zwischenkriegszeit für neu angelegte Siedlungen im Zuge der Reichsheimstätten-Förderung verfügt. Die jeweiligen Straßenzüge liegen nicht in unmittelbarer Nähe:

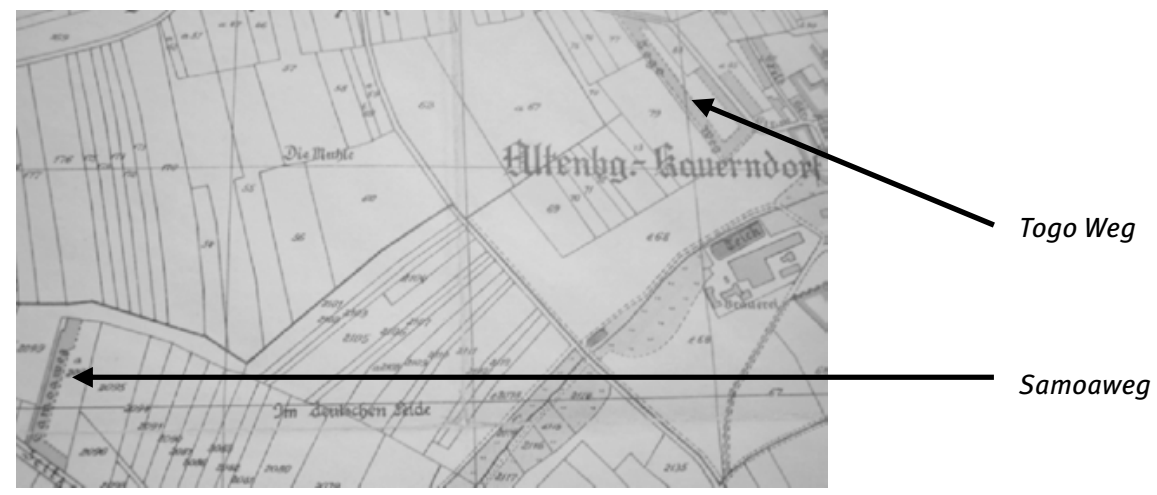

Abb. 13: Stadtplan Altenburg (1939), Ausschnitt Kauerndorf (Randsiedlung). 
Auch die in nationalsozialistischer Zeit erfolgte Benennung Lettow-VorbeckStraße erfolgte als räumlich nicht zusammenhängende Einzelbenennung in den westlich zum Stadtzentrum erschlossenen Stadtteil Neue Welt (vgl. Stadtplan Altenburg 1939). Alle zwei und mehr erhobenen Einzelbenennungen des zweiten Typs sind in folgender Tabelle mit entsprechenden Literaturnachweisen aufgeführt:

Tab. 24: Zwei und mehr voneinander unabhängige ortsbezogene Einzelbenennungen (b).

\begin{tabular}{|c|c|c|}
\hline Stadt & SN-Token & Literaturnachweise \\
\hline Altenburg & Lettow-Vorbeck-Str., Samoaweg, Togoweg & Stadtplan Altenburg (1939). \\
\hline Bad Godesberg & Gerhard-Rohlfs-Str., Karl-Peters-Str. & $\begin{array}{l}\text { Adressbuch Bad Godesberg } \\
\text { (1920 I: 41), Straßenkataster } \\
\text { der Stadt Bonn. }{ }^{147}\end{array}$ \\
\hline Chemnitz & Kamerunstraße, Wissmannstr. & $\begin{array}{l}\text { Adressbuch Chemnitz (1940 III: } \\
\text { 120), Stadtplan Chemnitz (1920). }\end{array}$ \\
\hline Danzig [Gdańsk] & $\begin{array}{l}\text { Carl-Peters-Str., Lüderitzstr., Gustav- } \\
\text { Nachtigal-Str., Von-Wissmann-Str. }\end{array}$ & $\begin{array}{l}\text { Adressbuch Danzig (1942 II: } \\
\text { 80, 135, 242, 382). }\end{array}$ \\
\hline Hagen & Karl-Peters-Str., Lettow-Vorbeck-Str. & Weidner. ${ }^{148}$ \\
\hline Ludwigsburg & Lüderitzstr., Karl-Peters-Str. & $\begin{array}{l}\text { Adressbuch Ludwigsburg } \\
\text { (1943: 275). }\end{array}$ \\
\hline Oberhausen & $\begin{array}{l}\text { Karl-Peters-Str., Leutweinstr., Lüderitzstr., } \\
\text { Windhuker Str., Wissmannstr. }\end{array}$ & Stadtplan Oberhausen (1938). \\
\hline Posen [Poznań] & $\begin{array}{l}\text { Karl-Peters-Str., Lüderitzstr., Lettow-Vorbeck- } \\
\text { Str., Nachtigalstr., Wissmannstr. }\end{array}$ & Stadtplan Posen (1939). \\
\hline Solingen & Lüderitzweg, Wissmannstr. & Stadtplan Solingen (1935). \\
\hline $\begin{array}{l}\text { Waldenburg } \\
\text { [Watbrzych] }\end{array}$ & Petersstr., Wissmannstr. & Stadtplan Waldenburg (1937). \\
\hline Weimar & Lüderitzstr., Petersstr., Rohlfsstr. & $\begin{array}{l}\text { Adressbuch Weimar (1937 III: } \\
46,55,59) \text {. }\end{array}$ \\
\hline
\end{tabular}

Für Bad Godesberg, Chemnitz und Weimar sind zwei und mehrere kolonial motivierte Einzelbenennungen festzustellen, die in unterschiedlichen Zeiträumen als Einzelbenennungen verfügt wurden: Die SN-Token Gerhard-Rohlfs-

147 http://stadtplan.bonn.de/strassen_auskunft.php?strasse=2411, Abruf am 28/06/2019.

$148 \mathrm{https} / /$ www.lwl.org/westfaelische-geschichte/nstopo/strnam/Kommune_79.html, Abruf am 28/06/2019. 
Straße $e^{149}$, Wissmannstraße $e^{150}$ und Rohlfsstraße (vgl. Adressbuch Weimar 1919 V: 253) wurden noch zur faktischen Kolonialzeit verfügt. Die Einzelbenennungen Karl-Peters-Straße (Bad Godesberg), Kamerunstraße (Chemnitz) sowie Lüderitzstraße und Petersstraße (Weimar) erfolgten erst in nationalsozialistischer Zeit. Alle weiteren Einzelbenennungen erfolgten zwischen 1933 und 1945. Neben der überschaubaren Anzahl an acht Groß- und Mittelstädten konnten koloniale Einzelbenennungen des zweiten Typs auch für die im Zuge des Polenfeldzugs annektierten Orte Danzig [Gdańsk] und Posen [Poznań] erhoben werden.

Für das dritte Muster sind an ein- und demselben Ort neben Kolonialclustern (Kap. 8.2) auch ein oder mehrere kolonial motivierte SN-Token zu konstatieren, die jeweils als kolonial motivierte Einzelbenennungen in den öffentlichen Raum verfügt wurden; aus diesem Grund werden sie in folgender Tabelle inklusive einer Verortung dargelegt:

Tab. 25: Singuläre oder mehrere voneinander unabhängige Einzelbenennungen neben Kolonialclustern (c).

\begin{tabular}{|c|c|c|}
\hline Stadt & SN-Token & Literaturnachweise \\
\hline Berlin(-Kreuzberg) & Gröbenufer & $\begin{array}{l}\text { Geheimes Staatsarchiv Preußischer Kultur- } \\
\text { besitz, TA I HA Rep. } 89 \text { Nr. } 14456 \text { Bl. 191-196. }\end{array}$ \\
\hline $\begin{array}{l}\text { Bremen (Verb. Altstadt- } \\
\text { Neustadt) }\end{array}$ & Lüderitzbrücke & Stadtplan Bremen (1938). \\
\hline Bremen(-Schwachhausen) & Lüderitzstr. & Stadtplan Bremen (1938). \\
\hline Düsseldorf(-Unterbilk) & Wissmannstr. & $\begin{array}{l}\text { Stadtplan Düsseldorf (1909), Adressbuch } \\
\text { Düsseldorf (1934 III: 461). }\end{array}$ \\
\hline Hamburg(-Eimsbüttel) & Gerhard-Rohlfs-Weg & Adressbuch Hamburg (1940 III: 10). ${ }^{151}$ \\
\hline
\end{tabular}

149 Man vgl. dazu einen Ausschnitt aus der DKZ (18.3.1913: 167), aus der ersichtlich wird, dass die DKG die Benennung, wenngleich die Eingemeindung erst 1967 erfolgte, der Stadt Bonn zuspricht: „Aus Bonn schreibt man uns, daß dort eine Rohlfs-Straße vorhanden ist - zu Ehren des ehemaligen Marokko-Forschers Gerhard Rohlfs.“ Aus diesem Grund wurde die Benennung ins Inventar der vorliegenden Studie aufgenommen.

150 Das noch zur Kolonialzeit verfügte SN-Token Wissmannstraße tritt ab Ende der 1920er Jahre nicht mehr auf, weil an gleicher Stelle eine Wohnanlage entstanden ist. Herzlicher Dank geht an Dr. S. Pfalzer vom Stadtarchiv Chemnitz.

151 Der Name ist ebenfalls auf Plan 2 der im Adressbuch abgedruckten „Pläne der Hansestadt Hamburg“(http://agora.sub.uni-hamburg.de/subhh-adress/digbib/view?did=c1:654910\&p=2437, Abruf am 23/04/20) als Einzelbenennung für den Bezirk Hamburg-Eimsbüttel eingezeichnet. Darüber hinaus ist der Name in dem ein Jahr zuvor veröffentlichten Amtlichen Gebiets- und Straßenverzeichnis (vgl. Statistisches Landesamt Hamburg 01.05.1939) vermerkt. 


\begin{tabular}{|c|c|c|}
\hline Stadt & SN-Token & Literaturnachweise \\
\hline Hamburg(-Osdorf) & Togostr. & Amtlicher Anzeiger Nr. 129 (1947)..$^{152}$ \\
\hline Heilbronn(-Kernstadt) & Lettow-Vorbeck-Str. & Adressbuch Heilbronn (1936 III: 92). \\
\hline Herford(-Ottelau) & Adolf-Lüderitz-Str. & Weidner. ${ }^{153}$ \\
\hline Köln(-Neustadt) & Lettow-Vorbeck-Str. & $\begin{array}{l}\text { Adressbuch Köln (1939 IV: 432), Kaufmann et } \\
\text { al. (1996: 70-71). }\end{array}$ \\
\hline $\begin{array}{l}\text { Königsberg i. Pr. bzw. } \\
\text { Königsberg (Pr.) [Kalinin- } \\
\text { grad](-Hufen) }\end{array}$ & Wissmannstr. & Stadtplan Königsberg (ca. 1925). \\
\hline Leipzig(-Neustadt) & Wissmannstraße & $\begin{array}{l}\text { Adressbuch Leipzig (1918 II: 399), Stadtplan } \\
\text { Leipzig (ca. 1920). }\end{array}$ \\
\hline $\begin{array}{l}\text { Lodz bzw. Litzmannstadt } \\
\text { [tódź](-Nord) }\end{array}$ & Lettow-Vorbeck-Str. & $\begin{array}{l}\text { Straßenverzeichnis Litzmannstadt (1941), } \\
\text { Thiem (1941). }\end{array}$ \\
\hline Wuppertal(-Vohwinkel) & Lettow-Vorbeck-Str. & Adressbuch Wuppertal (1938 III: 253). \\
\hline
\end{tabular}

Bis auf die Mittelstädte Heilbronn und Herford beschränken sich derartige Prozesse, bei denen neben der Verfügung von gebündelten kolonial motivierten SN-Token als themenkohärente Viertel auch Einzelbenennungen festzustellen sind, auf Großstädte. Abgesehen von dem noch in der faktischen Kolonialzeit verfügten Namen in Berlin-Kreuzberg (Gröbenufer) und der Einzelbenennung in Königsberg i. Pr. bzw. Königsberg (Pr.) [Kaliningrad] (Wissmannstraße) erfolgten alle weiteren betreffenden SN-Token in nationalsozialistischer Zeit. Auch für die Großstadt Lodz bzw. Litzmannstadt [Łódź] ist auf dem Anfang der 1940er Jahre erstellten Stadtplan neben einem mit kolonialen Straßennamen belegten Viertel (Kap. 8.3) die singuläre Benennung Lettow-Vorbeck-Straße festzustellen.

\subsubsection{Strukturmuster und Diskursfunktionen}

Für koloniale Namenvergabepraktiken, die als Einzelbenennungen in den städtischen Raum verfügt wurden, sind über die drei raumlinguistischen Formen hinaus strukturbezogene Muster festzustellen: Bei dem maßgeblichen Hauptanteil derartiger singulärer Benennungen handelt es sich um deanthroponymische Konstruktionen, mit denen Kolonialakteure im öffentlichen Raum des Deut-

152 Aus dem Dokument ergeht die im gleichen Jahr erfolgte Umbenennung des SN-Tokens Togostraße, die 1933 administrativ verfügte wurde, in Tönninger Weg.

153 https://www.lwl.org/westfaelische-geschichte/nstopo/strnam/Kommune_92.html, Abruf am 28/06/2019. 
schen Reichs geehrt und/oder gewürdigt werden sollten. Dabei sind die anthroponymischen MOD-Types Peters, Lüderitz, Lettow-Vorbeck und Wissmann als quantitativ dominant herauszustellen. Die ortsübergreifend erhobenen Einzelbenennungen referieren vor allem auf Personen, die entscheidenden Anteil an der Erwerbung oder Verteidigung des deutschen Kolonialbesitzes trugen. Die Inventare sind bezüglich ihrer vorrangig anthroponymischen MOD-Types folglich als weitestgehend unmarkiert $\mathrm{zu}$ beschreiben; die entsprechenden Konstruktionen reihen sich unauffällig in die für das erstellte Gesamtinventar dargelegten hochfrequenten deanthroponymischen Muster ein (Diagramm 1). Auch die diachrone Verteilung der Einzelbenennungen auf die jeweiligen gesellschaftspolitischen Verfügungszeiträume entspricht den Distributionen, die für das erstellte Gesamtinventar kolonial motivierter Namenvergabepraktiken im Deutschen Reich zwischen 1884 und 1945 aufgezeigt wurde (Kap. 6.2); der maßgebliche Anteil an Einzelbenennungen wird in nationalsozialistischer Zeit verfügt. In einer solchen diachronen Perspektive sind Präferenzen hinsichtlich der anthroponymischen Modifikatoren auszumachen: Die wenigen noch in der faktischen Kolonialzeit ${ }^{154}$ und in der Zwischenkriegszeit ${ }^{155}$ verfügten SN-Token sollten vorrangig Herrmann von Wissmann ehren und/oder würdigen. Der Hauptanteil der zwischen 1933 und 1945 verfügten deanthroponymischen Einzelbenennungen referiert dagegen in kommemorativer Intention auf Carl Peters, Adolf Lüderitz und Paul von Lettow-Vorbeck.

Die Überprüfung der betreffenden Straßen in historischen Stadtplänen zeigt, dass die im Nationalsozialismus verfügten Einzelbenennungen nicht selten über deren koloniale Motivik hinaus kontextualisiert wurden. So ist bspw. für die mit praxonymischen Anteilen verfügte detoponymische Einzelbenennung der Tangastraße in Oldenburg festzustellen, dass diese innerhalb eines thematisch weiter gefassten Kleinclusters in Bezug auf die intendierte Kommemoration aufgeht. Mitte der 1930er Jahre wurde das SN-Token Grüner Weg mit den Benennungen Falklandstraße und Tangastraße für den nördlichen bzw. südlichen Teil des Straßenzugs überschrieben (vgl. Adressbuch Oldenburg 1940 III: 331). Beide zeitgleich in Oldenburg verfügten Straßennamen sind im Rahmen einer solchen militärischen Traditionspflege der Nationalsozialisten einzuordnen, die an die Kämpfe des Deutschen Kaiserreichs im Weltkrieg anknüpfen sollten.

154 D. s.: Gerhard-Rohlfs-Straße in Bad Godesberg (Bonn), Gröbenufer in Berlin, Wissmannstraße in Chemnitz, Wissmannstraße in Düsseldorf, Wissmannstraße in Erfurt, Wissmannstraße in Leipzig, Rohlfsstraße in Weimar.

155 D. s.: Wißmannstraße in Frankfurt/Oder, Lüderitzstraße in Saarbrücken, Wissmannstraße in Königsberg i. Pr. bzw. Königsberg (Pr.) [Kaliningrad]. 
[...] es handelt sich hier [...] um einen Verweis auf kriegerische Auseinandersetzungen [...] Hier Tanga, wo deutsche Truppen im Jahr 1914 gegen die Briten kämpften. Und dort Falkland, eine Inselgruppe im Atlantik, um die sich ebenfalls 1914 deutsche und englische Truppen eine Seeschlacht lieferten. (Fricke 2009: 8)

Einzelbenennungen, die in thematisch anders gelagerten Clustern aufgingen, können in ortsübergreifender Perspektive für Namenmuster dargelegt werden, die auf Paul von Lettow-Vorbeck referieren sollten. Nicht selten wurden die in nationalsozialistischer Zeit verfügten Einzelbenennungen mit dem anthroponymischen MOD-Type Lettow-Vorbeck zusammen mit weiteren deanthroponymischen Benennungen für Straßenzüge in nächster Nähe verfügt, die keine koloniale Benennungsmotiviken aufweisen (siehe Abb. 14).

Alle deanthroponymischen Konstruktionen wurden zeitgleich Ende der 1930er Jahre im Zuge der Tilgung älterer Straßennamen verfügt (vgl. Straßennamenverzeichnis, Stadtplan Altenburg 1939); die Umbenennungen sollten auf Personen referieren, die aus historischer Sicht wichtige militärische Führungspositionen während des Ersten Weltkriegs (Karl Litzmann ${ }^{156}$, Reinhard Scheer ${ }^{157}$, Hans von Seeckt ${ }^{158}$ ) inne hatten.

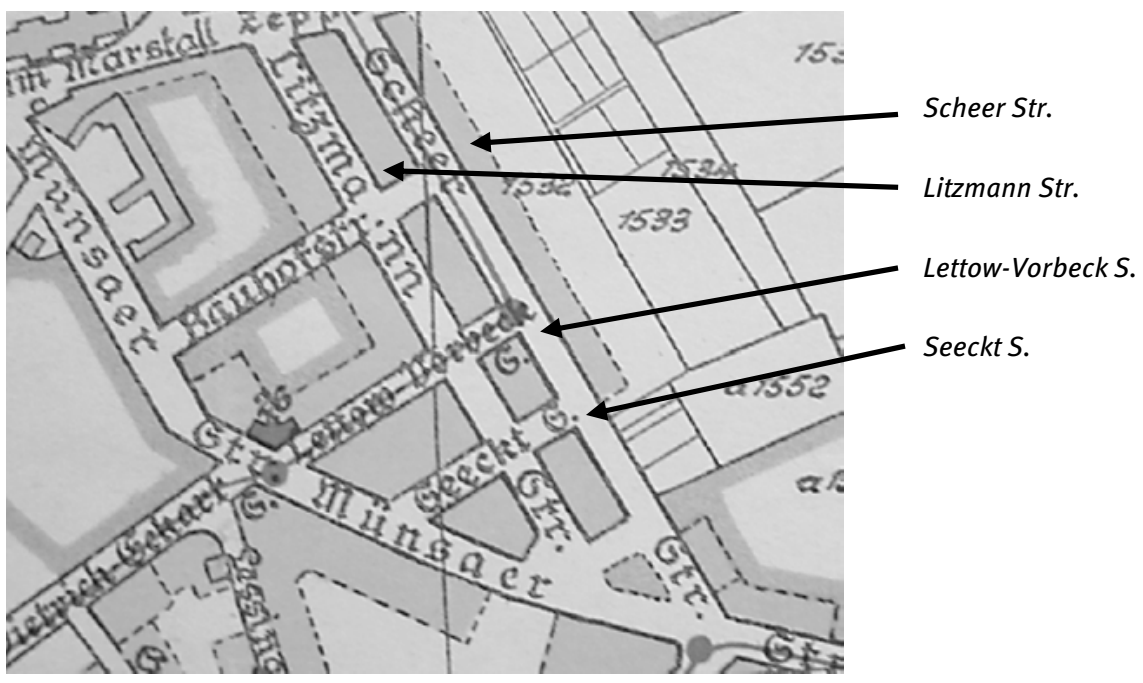

Abb. 14: Stadtplan Altenburg (1939).

156 Man vgl. dazu Kraft (1985: 715-716).

157 Man vgl. dazu Epkenhans (2005: 607).

158 Man vgl. dazu Hürten (2010: 139-140). 
In dieses Muster der kommemorativen Ehrung und/oder Würdigung ehemaliger hoher Offiziere und/oder Generäle des Ersten Weltkriegs wird auch die Umbenennung der Lettow-Vorbeck-Straße eingeordnet, die innerhalb solcher thematisch anders gelagerten bzw. weiter gefassten Clusterbenennung in Bezug auf die intendierte Kommemoration aufgeht. Auch die identischen in Heilbronn bzw. Köln verfügten Kolonialismen ${ }^{159}$ sind in unmittelbarer Umgebung zu zeitgleich erfolgten deanthroponymischen Umbenennungen $\mathrm{zu}$ verorten, die sich auf Generäle des Ersten Weltkriegs beziehen. Sie erfolgten für Straßenzüge in direkter Umgebung zu Mackensenstraße und Litzmannstraße ${ }^{160}$ bzw. zu Mackensenstraße, Litzmannstraße und Ludendorffstraße. ${ }^{161}$ Gleiches gilt bspw. auch für die LettowVorbeck-Straße in Lünen. Und auch im Stadtplan der annektierten Stadt Lodz bzw. Litzmannstadt [€ódź] (vgl. Thiem 1942) ist der Straßenzug des SN-Tokens Lettow-Vorbeck-Straße in direkter Nähe zu Straßen zu verorten, die nach hohen Offizieren und/oder Generälen des Ersten Weltkriegs benannt wurden.

Derartige ortsübergreifende Befunde zeigen, dass die städtischen Administrationen Paul von Lettow-Vorbeck in nationalsozialistischer Zeit „als Symbol in ihr Heldenpantheon eingliederten und damit endgültig der Geschichte übereigneten" (Speitkamp 2004). Die aus zeitgenössischer Sicht erfolgreich geführten Kampfhandlungen Lettow-Vorbecks als Kommandeur der Schutztruppe für Deutsch-Ostafrika werden anhand entsprechender Benennungsmotiviken in historischen Adressbüchern dargelegt. Nichtsdestotrotz stellen derartige Phänomene nur vermeintliche kolonial motivierte Einzelbenennungen dar, die in thematisch anders gelagerten Clustern mit Bezügen zu weiteren Personen, Orten u. dgl. im Ersten Weltkrieg aufgingen. Seine Rolle als führender General bei der Verteidigung der Kolonie gegen englische Alliiertentruppen ist innerhalb derartiger Clusterbenennungen insofern als desemantisiert zu beschreiben, als dass man dabei vorrangig seine Funktion des deutschen Kriegsgenerals in den Mittelpunkt rücken wollte.

159 „Lettow-Vorbeck-Straße [...] Verteidiger[s] von Deutsch-Ostafrika im Weltkriege [...]“ (Adressbuch Heilbronn 1936 III: 92). „Lettow-Vorbeck-Straße [...] seit 1918 Kommandeur der Schutztruppe in Deutsch-Ostafrika, das er von 1914-1918 in heldenhafter Weise gegen eine riesige feindliche Übermacht verteidigte“ (Adressbuch Köln 1939 IV: 432).

160 Man vgl. dazu die Verortung der Lettow-Vorbeck-Straße im entsprechenden Eintrag (Adressbuch Heilbronn III: 92): „von der Mackensen- zur Litzmannstraße“.

161 „In der NS-Zeit, 1938, wurde die Innere Kanalstraße von der Aachener Straße aus nach Norden hin in vier Abschnitte geteilt und mit den Bezeichnungen Mackensenstraße [...], Litzmannstraße [...], Ludendorffstraße [...] und Lettow-Vorbeck-Straße [...] versehen“ (Kaufmann et al. 1996: 71). 


\subsection{Cluster}

Für den Gesamtuntersuchungszeitraum wurden 455 der zwischen 1884 und 1945 erhobenen kolonialen Straßennamen als themenkohärente Cluster für parallele, sich kreuzende und/oder in unmittelbarer räumlicher Nähe zueinander liegende Straßenzüge verfügt. Dabei sind zwei rein quantitativ voneinander unterscheidbare Clustertypen festzustellen:

- Klein angelegte Kolonialcluster: 2 kolonial motivierte SN-Token für 2 in unmittelbarer Nähe zueinander liegende Straßen

- Groß angelegte Kolonialcluster: $2+x$ kolonial motivierte SN-Token für $2+x$ in unmittelbarer Nähe zueinander liegende Straßen

Die Häufigkeitsverteilung der entsprechenden Inventare auf diese beiden Typen an Kolonialclustern ist absolut eindeutig: Nur 26 SN-Token sind dem ersten Typ kolonialer Kleincluster mit zwei Benennungen zuzuschreiben. Alle weiteren 429 SN-Token wurden innerhalb groß angelegter themenkohärenter Namenviertel des zweiten Typs mit drei und mehr Benennungen verfügt.

\subsubsection{Klein angelegte Kolonialcluster}

Koloniale Namenvergabepraktiken in der Form von Kleinclustern mit nur zwei SN-Token sind für eine überschaubare Anzahl an 13 Städten zu konstatieren. Neben deren Repräsentation auf Karten sind sie auch in historischen Adressbüchern verzeichnet, in denen die kolonialen Bezeichnungsmotiviken dargelegt werden. So sind bspw. die als themenkohärentes Kleincluster für Parallelstraßen verfügten Benennungen Lüderitz- und Woermannweg in Münster-Gremmendorf erstmalig auf dem Stadtplan von 1939 festzustellen, deren koloniale Motiviken im Straßenverzeichnis des drei Jahre später herausgegebenen Einwohnerbuchs dargelegt werden (siehe Abb. 15). 


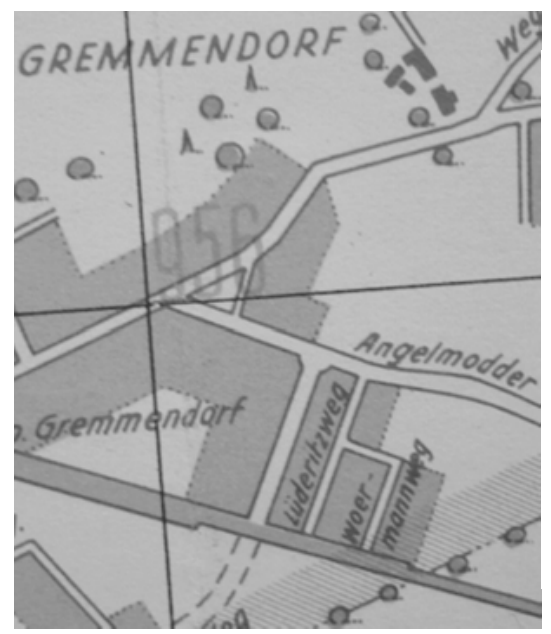

„Lüderitzweg (Südlich des Angelmodder Weges) [1939 - Bekannter Kolonialpolitiker (1834-1886), Gründer der ersten deutschen Südwestafrika-Kolonie.]“ (Adressbuch Münster 1941/42 II: 161)

„Woermannweg (früher Teil des Angelmodder Weges) [1939 - Mitbegründer der WoermannLinie, welche den deutschen Ostafrikadienst betreibt; erwarb 1884 das Mündungsgebiet des Kamerunflusses als deutschen Kolonialbesitz [...].“ (Adressbuch Münster 1941/42 II: 258)

Abb. 15: Stadtplan Münster (1939), Ausschnitt Gremmendorf.

\subsubsection{Inventare}

Die Verteilung solcher kolonialen Kleincluster auf Groß- bzw. Mittelstädte hält sich relativ die Waage. In folgender Tabelle werden die Benennungen mit Angabe der jeweiligen städtischen Bezirke, Viertel oder Siedlungen, in denen die jeweiligen zwei Benennungen zu verorten sind, aufgelistet:

Tab. 26: Ortsspezifische Verteilung von Kleinclustern.

\begin{tabular}{lll}
\hline $\begin{array}{l}\text { Stadt, weitere Infos über } \\
\text { clusterbezogene Verortung }\end{array}$ & $\begin{array}{l}\text { Innerhalb der jeweiligen Clus- } \\
\text { ter verfügte Benennungen }\end{array}$ & Literaturnachweise \\
\hline Essen-Karnap & Lüderitzwiese, Woermannstr. & $\begin{array}{l}\text { Stadtplan Essen (1942), } \\
\text { Dieckhoff (1979: 182, 295). }\end{array}$ \\
Gotha-Sundhausen & $\begin{array}{l}\text { Adolf-Lüderitz-Str., Von Lettow- } \\
\text { Vorbeck-Str. }\end{array}$ & $\begin{array}{l}\text { Stadtplan Gotha (1936), Adress- } \\
\text { buch Gotha (1941-1942 II: 264, } \\
\text { 470). }\end{array}$ \\
Köln-Ehrenfeld & Gravenreuthstr., Wissmannstr. & $\begin{array}{l}\text { Bechhaus-Gerst (2013: 237). } \\
\text { Magdeburg-Sudenburg }\end{array}$ \\
& $\begin{array}{l}\text { Gustav-Nachtigal-Str., } \\
\text { Wissmannstr. }\end{array}$ & $\begin{array}{l}\text { Adressbuch Magdeburg (1940 II: } \\
\text { 68, 207), Stadtplan Magdeburg } \\
(1937) .\end{array}$ \\
Münster-Gremmendorf & Lüderitzweg, Woermannweg & $\begin{array}{l}\text { Stadtplan Münster (1939), Ad- } \\
\text { ressbuch Münster (1941/42 II: } \\
161,258) .\end{array}$ \\
\hline
\end{tabular}




\begin{tabular}{|c|c|c|}
\hline $\begin{array}{l}\text { Stadt, weitere Infos über } \\
\text { clusterbezogene Verortung }\end{array}$ & $\begin{array}{l}\text { Innerhalb der jeweiligen Clus- } \\
\text { ter verfügte Benennungen }\end{array}$ & Literaturnachweise \\
\hline Nürnberg-Ziegelstein & Wissmannplatz, Wissmannstr. & Maas (1994: 154). \\
\hline Pirna-Feistenberg & $\begin{array}{l}\text { Dr. Carl-Peters-Str., Gustav- } \\
\text { Nachtigal-Str. }\end{array}$ & $\begin{array}{l}\text { Straßen-Verzeichnis im Adress- } \\
\text { buch Pirna (1938), Stadtplan } \\
\text { Pirna (1939). }\end{array}$ \\
\hline Saalfeld-West & $\begin{array}{l}\text { Carl-Peters-Platz, Lettow- } \\
\text { Vorbeck-Str. }\end{array}$ & Werner (2011: 33-34, 96). \\
\hline $\begin{array}{l}\text { Gmünd bzw. Schwäbisch } \\
\text { Gmünd-Rehnenhof-Wetzgau }\end{array}$ & Lüderitzweg, Petersweg & $\begin{array}{l}\text { Stadtplan Schwäbisch Gmünd } \\
\text { (1948), Stadtadressbuch Schwä- } \\
\text { bisch Gmünd }(2015: 139,166) \text {. }\end{array}$ \\
\hline $\begin{array}{l}\text { Schweinfurt-Hochfeld/ } \\
\text { Steinberg }\end{array}$ & Karl-Peters-Str., Lüderitzstr. & $\begin{array}{l}\text { Adressbuch Schweinfurt (1938 II: } \\
44,56) \text {. }\end{array}$ \\
\hline $\begin{array}{l}\text { Swinemünde } \\
\text { [Świnoujście]-Kurviertel }\end{array}$ & Karl-Peters-Str., Lüderitzstr. & $\begin{array}{l}\text { Straßenverzeichnis im Adress- } \\
\text { buch Swinemünde (1938 II: 99- } \\
\text { 100). }\end{array}$ \\
\hline Wuppertal-Barmen & Samoastr., Windhukstr. & $\begin{array}{l}\text { Adressbuch Wuppertal (1938 III: } \\
\text { 347, 447). }\end{array}$ \\
\hline Zwickau-Weißenborn & Karl-Peters-Str., Lüderitzstr. & $\begin{array}{l}\text { Adressbuch Zwickau (1940 III: } \\
\text { 118, 157), Lageplan zur Nieder- } \\
\text { hohndorfer Straße im Adress- } \\
\text { buch Zwickau (1943/44 III: 181). }\end{array}$ \\
\hline
\end{tabular}

\subsubsection{Strukturmuster und Diskursfunktionen}

Die als Kleincluster verfügten Namen weisen starke Übereinstimmungen mit kolonialen Namenvergabepraktiken als Einzelbenennungen auf: Bis auf die in Wuppertal-Barmen verfügten detoponymischen Konstruktionen weisen alle weiteren Namen anthroponymische MOD-Types auf, die für das Gesamtinventar als hochfrequent (Diagramm 1) dargelegt wurden. Darüber hinaus sind auch die innerhalb solcher Kleincluster verfügten Namen maßgeblich für die Zeit des Nationalsozialismus zu konstatieren. Nur die in Köln-Ehrenfeld verfügten Konstruktionen erfolgten noch während der faktischen Kolonialepoche des Deutschen Kaiserreichs (vgl. Bechhaus-Gerst 2013: 237). Die SN-Token Wissmannstraße und -platz mit zwei identischen Modifikator-Konstruktionen in dem zeitgleich zur Stadt Nürnberg eingemeindeten Ortsteil Ziegelstein wurden durch entsprechenden Antrag der DKG erst nach den Bestimmungen des Versailler Vertrags durchgesetzt (vgl. Maas 1994: 154). Die Verfügung der Wissmannstraße in Magdeburg-Sudenburg erfolgt am Ende der de facto-Kolonialzeit (vgl. Stadt- 
plan Magdeburg 1919). Das deanthroponymische SN-Token Gustav-NachtigalStraße kann dagegen erst in Stadtplänen nach 1933 erhoben werden.

Mit den maßgeblich im Nationalsozialismus verfügten Kleinclustern mit deanthroponymischen Konstruktionen sollten zwei Kolonialakteure aus der Zeit des Kaiserreichs durch entsprechende Namenvergabepraktiken von in unmittelbarer Nähe zueinander liegenden Straßenzügen geehrt und/oder gewürdigt werden. Trotz der gebündelten Benennungen sind im Ergebnis keine Kolonialviertel festzustellen. Die jeweiligen Benennungen wurden wie in MünsterGremmendorf für zwei relativ abgrenzbare Straßenzüge verfügt, sie sind aber mit einer ganzen Reihe weiterer Straßen in unmittelbarer Nähe zu konstatieren:

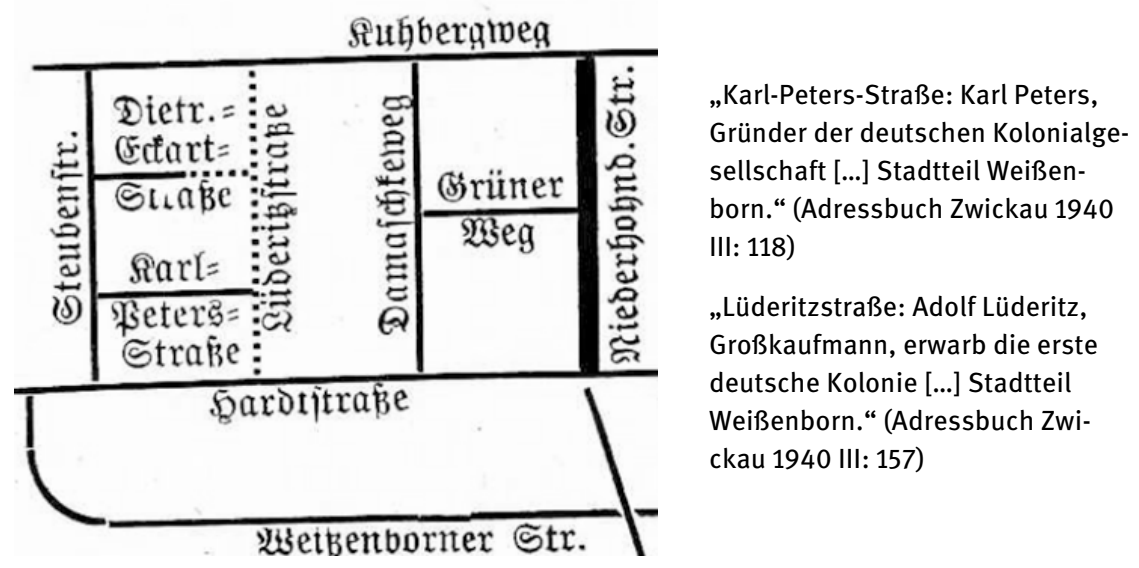

Abb. 16: Lageplan zur Niederhohndorfer Straße, Adressbuch Zwickau (1943/44 III: 181).

Im Vergleich zu der großen Zahl an kolonialen Großclustern mit drei und mehr SN-Token stellen derartige Verfügungspraktiken von nur zwei kolonial motivierten Benennungen ein völlig randständiges Phänomen dar. Es ist zu vermuten, dass die mit derartigen Namenvergaben intendierten Kommemorationen vorrangig in Adressbüchern dargelegt wurden, in denen die spezifisch kolonialen Motiviken solcher Namenverfügungen nachvollzogen werden können.

\subsubsection{Groß angelegte Kolonialcluster}

Die Vergabepraxis von drei und mehr SN-Token als themenkohärente Großcluster stellt zweifellos das ortsübergreifende Muster kolonialer Fixierungspraktiken im öffentlichen Raum des Deutschen Reichs dar: 429 SN-Token aller erhobenen ko- 
lonial motivierten Benennungen sind innerhalb solcher Namenviertel zu verorten. Groß angelegte Cluster konnten für die im Zuge des Polenfeldzugs annektierten Städte nur einzelortsbezogen erhoben werden. Sie sind ausschließlich in Stadtplänen folgender Orte festzustellen: Königshütte [Chorzów], Lodz bzw. Litzmannstadt [Łódź] und Pabianitz [Pabianice]. Die clusterbezogenen Inventare bleiben in den folgenden Ausführungen unberücksichtigt und werden separat in Kap. 8.3 dargelegt. Unter Abzug jener sind 389 Benennungen herauszustellen, die als groß angelegte Kolonialcluster für 48 Städte erhoben werden konnten. Dabei sind folgende ortstypischen Distributionen auszumachen:

Tab. 27: Ortsspezifische Verteilung von Großclustern (annektierte Gebiete ausgenommen).

\begin{tabular}{lll}
\hline & Großstädte & Mittelstädte \\
\hline Anzahl an Orten & 31 & 17 \\
Anzahl an Clustern & 43 & 17 \\
\hline
\end{tabular}

Quantitativ dominant ist die Anzahl solcher Großcluster in 31 Großstädten. Koloniale Cluster mit drei und mehr als drei Benennungen konnten darüber hinaus für 17 Mittelstädte festgestellt werden. Administrative Verfügungspraktiken von mehreren kolonialen Großclustern in unterschiedlichen Vierteln für eine Stadt sind - das zeigt nicht zuletzt die größere Summe an Clustern im Vergleich zu der Anzahl an Orten (Tab. 27) - auf Großstädte beschränkt. Für Hamburg sind innerhalb des Untersuchungszeitraums von 1884 und 1945 durch die Sichtung entsprechender Quellengattungen sogar sechs Cluster (Kleiner Grasbrook, Hamm und Horn, Ottensen, Wandsbek-West, Wandsbek-Ost, Rahlstedt) festzustellen. Die Benennungen des ersten Clusters in nächster Nähe zu den dort angelegten Hafenanlagen weisen dechoronymische und deoikonymische Konstruktionen auf. Die Namen sind auf Karten und in Straßenverzeichnissen der Einwohnerbücher mit entsprechenden Motiviken aufgeführt (siehe Abb. 17).

Auf den ersten Blick suggeriert der Stadtplanausschnitt des Hamburger Hafens, dass hier ein Cluster mit vorrangig orientierenden Namen wie bspw. AfrikaAustralia- und Indiakai und weiteren Benennungen vorliegt, die auch auf weitere Handelsziele in den afrikanischen Kolonien referieren. Durch die Sichtung zeitlich gestaffelter Stadtpläne und historischer Benennungsmotiviken ist jedoch festzustellen, dass die Benennungen Afrika-, Australia- und Indiakai zeitgleich mit der Anlegung von Hafenanlagen für Ufereinlassungen bereits Ende des 19. Jahrhunderts erfolgten; koloniale Benennungsmotiviken für jene SN-Token können nicht nachgewiesen werden (vgl. Stöllin 1925: 52, 66). Der Ausbau des Hafens ab Mitte 


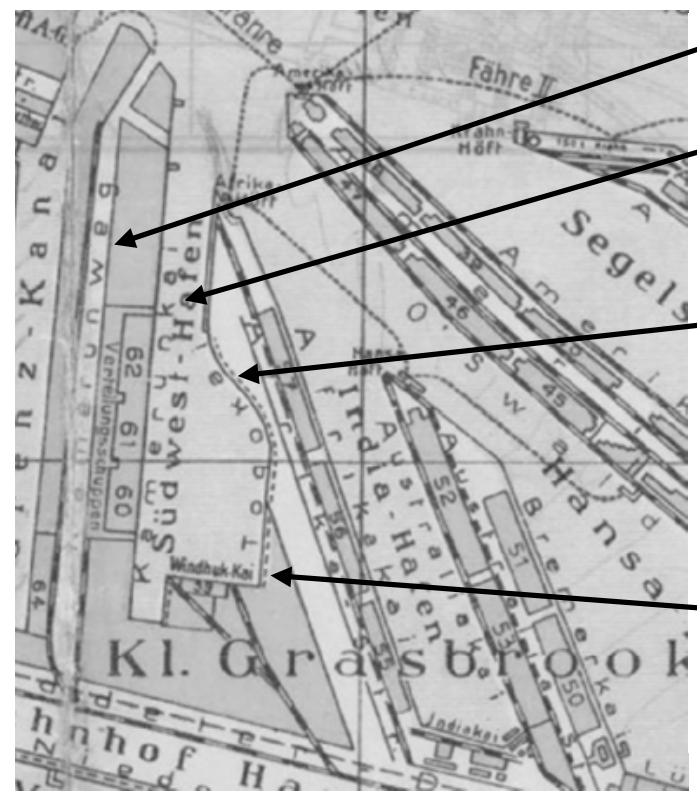

„Kamerunweg (s. Kamerunkai)“

(Stöllin 1925: 67)

„Kamerunkai: Ben. 1922 zur Erinnerung an die Deutschland durch den Vertrag von Versailles entrissene Kolonie.“(Stöllin 1925: 67)

„Togokai: Ben. 1922 im Anschluß an den auf Deutsch-Südwest-Afrika bezüglichen Namen des Südwesthafens zur Erinnerung an die Deutschland durch den Vertrag von Versailles entrissene Kolonie [...].“ (Stöllin 1925: 82)

„Windhukkai [...] Benannt zur Erinnerung an die verlorenen Kolonien.“ (Adressbuch Hamburg 1932 IV: 922)

Abb. 17: Stadtplan Hamburg (ca. 1935), Ausschnitt Kleiner Grasbrook.

der 1920er Jahre als Südwesthafen hatte die Erbauung neuer Straßenzüge zur Folge, deren Benennungen in nachweislich kolonialer Motivik verfügt wurden: Für die Zwischenkriegszeit ist für den öffentlichen Raum am Hamburger Hafen die Verfügung eines kolonialzeitbezogenes Clusters festzustellen, bei dem für drei der vier Konstruktionen der Geo-Klassifikator -kai von den älteren Benennungen in nächster Nähe übernommen wurden.

Die in der Zwischenkriegszeit verfügten Benennungen sind insofern überraschend, als dass

der Güterumschlag im Hamburger Hafen [...] sich in der Zeit von 1918 bis 1945 sehr unstetig [entwickelte]. Wirtschaft und Handel kamen durch den Krieg fast völlig zum Erliegen [...]. Erst 1928 konnte [...] das Vorkriegsergebnis von 25,5 Mio. t wieder übertroffen werden. (Kludas et al. 1988: 148)

Die im Straßenverzeichnis dargelegten Benennungsmotiviken (Abb. 17) weisen gezielte kolonialrevisionistische Argumentationsmuster der Rückforderung der „entrissene[n] Kolonie[n]“ und „verlorenen Kolonien“ auf. Es kann nur vermutet werden, dass mit den Benennungen der aus zeitgenössischer Sicht unrechtmäßige Verlust der Kolonialgebiete versprachlicht und darüber hinaus gerade dort fixiert werden sollte, wo sich die Verordnungen des Friedensvertrags auf die Hansestadt besonders stark auswirkten. 
Das zweite in Hamburg innerhalb des Untersuchungszeitraums verfügte Kolonialcluster ist im Nordosten des Bezirks Hamburg-Mitte zu verorten: In den öffentlichen Raum der aneinander angrenzenden Stadtteile Hamm und Horn wurden die vier deanthroponymischen Konstruktionen Carl-Peters Weg, EminPascha-Straße, Theodor-Weber-Reihe und Wissmannsweg für Parallelstraßen oder sich kreuzende Straßenzüge verfügt, die Kolonialakteure ehren und/oder würdigen sollten.

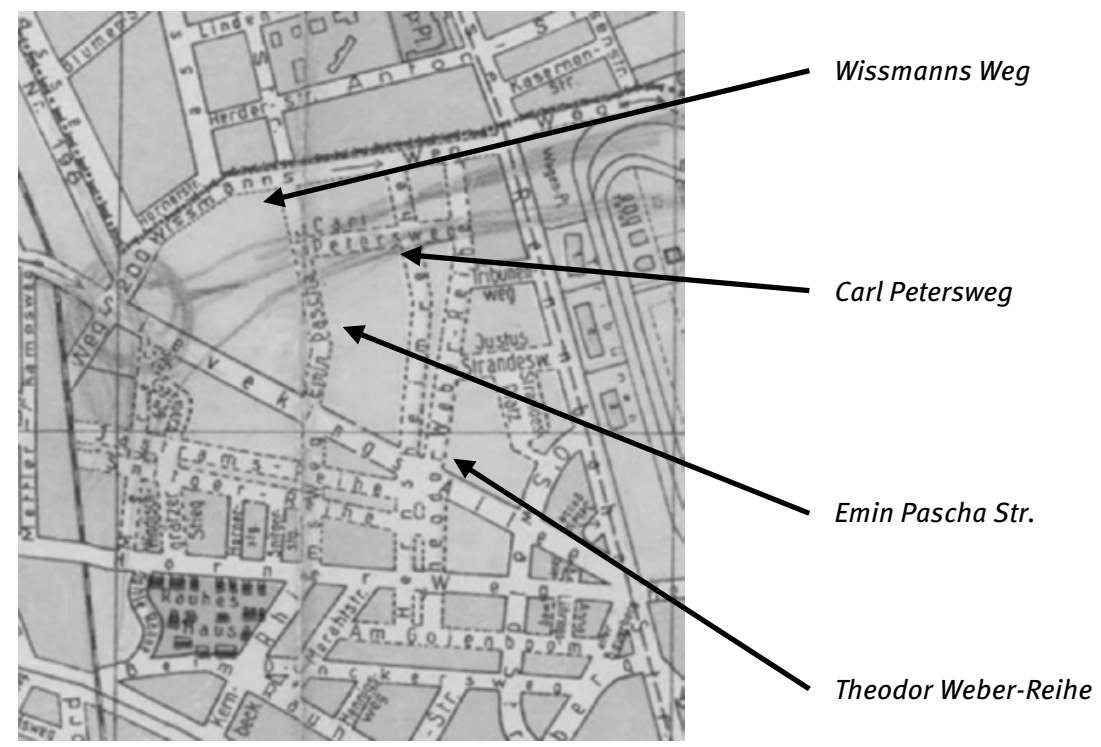

Abb. 18: Stadtplan Hamburg (ca. 1935), Ausschnitt Hamm und Horn.

Das dritte Großcluster lässt sich für den Hamburger Stadtteil Ottensen (Bezirk Altona) verorten: Wenngleich die vier SN-Token Daressalamstraße, Kamerunstraße, Otawiweg und Windhukstraße noch nicht in entsprechenden Stadtplänen vor 1945 aufzufinden sind, werden sie in Straßenverzeichnissen der zu Beginn der 1940er Jahre veröffentlichten Einwohnerbücher als Neubenennungen für zum damaligen Zeitpunkt noch unbebaute Straßenzüge aufgeführt, oder deren Verfügungszeitpunkte sind durch entsprechende amtliche Quellengattungen noch für die nationalsozialistische Zeit nachzuweisen. ${ }^{162}$

162 Daressalamstraße (vgl. Adressbuch Hamburg 1940 IV: 275) und Windhukstraße (vgl. Adressbuch Hamburg 1940 IV: 1273). In der Straßennamen-Herkunftskartei, die sich u. a. auf den Amtlichen Anzeiger und das Altonaer Amtsblatt beziehen, in denen Namenverfügungen zeitgenössisch veröffentlicht wurden, werden auch die Benennungen Kamerunstraße für 1936 und 
Drei weitere Cluster sind allesamt innerhalb des Bezirks Wandsbek zu verorten; die jeweiligen Kolonialismen wurden in den bisherigen Hamburger Namenlexika lediglich ausschnitthaft dargelegt. ${ }^{163}$ Aus diesem Grund sollen die SN-Token der jeweiligen Kolonialviertel im Folgenden dargelegt werden, die im Stadtplan des dazugehörigen Adressbuchs von 1940 erstmalig verzeichnet sind:

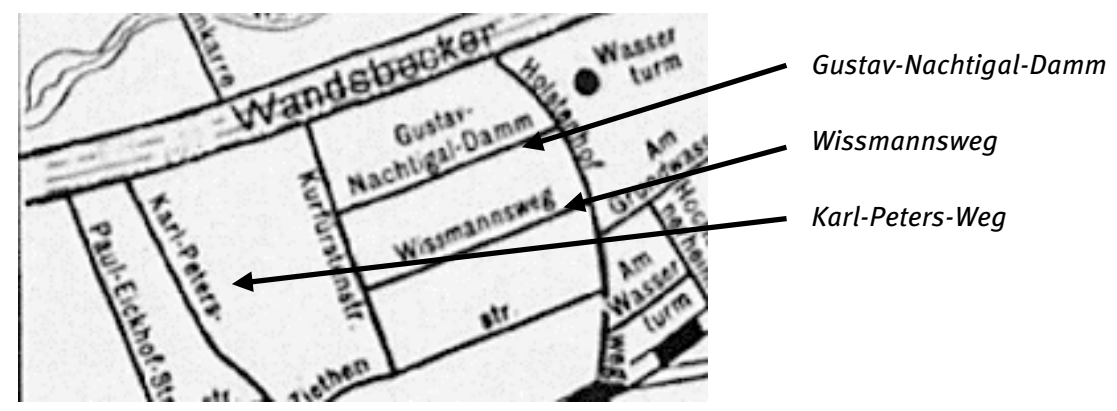

Abb. 19: Stadtplan Hamburg, Ausschnitt Wandsbek-West, im Adressbuch Hamburg (1940).

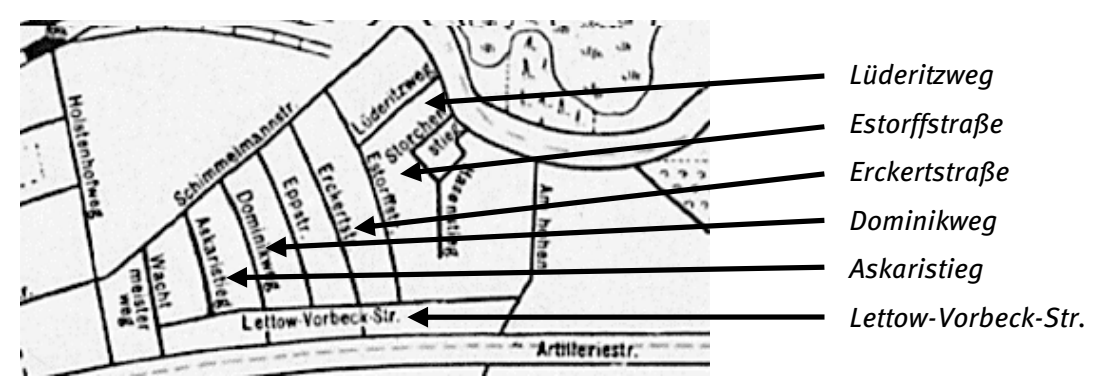

Abb. 20: Stadtplan Hamburg, Ausschnitt Wandsbek-Ost, im Adressbuch Hamburg (1940).

Otawiweg für 1942 angegeben. Die SN-Token Daressalamstraße und Kamerunstraße sind in Einwohnerbüchern zu Beginn der 1950er Jahre (vgl. Adressbuch Hamburg 1950 IV: 87, 221) aufgeführt. Das SN-Token Kamerunstraße wurde noch in den 1950er Jahren umbenannt in Harmsenstraße (vgl. Adressbuch Hamburg 1953 IV: 577), das SN-Token Daressalamstraße wurde - offenbar aufgrund der Tatsache, dass der dazugehörige Straßenzug auch in der Nachkriegszeit noch nicht bebaut wurde - getilgt.

163 In Beckershaus (1997) werden nur die SN-Token Tangastraße, Lettow-Vorbeck-Straße und Dominikweg aufgeführt. Bake (2015 I: 137) führt - unter Rückgriff auf K. Treins (Hamburgs „Kolonialviertel“, Ausstellung freedom roads!) - folgende koloniale SN-Token auf: „Askaristieg, Kameruneck, Gustav-Nachtigal-Straße, Karl-Peters-Straße, Lüderitzweg, Südwestkamp, Togoweg, Waterberg und Wißmannstraße. [...] Der Zweite Weltkrieg verhinderte allerdings die Umsetzung dieser Pläne“. 
Die SN-Token Eppstraße, Lettow-Vorbeck-Straße und Schimmelmannstraße tauchen bereits im Straßenverzeichnis des vorangegangenen Jahres (vgl. Hamburger Adressbuch 1939 IV: 297, 692, 991) als Neubenennungen auf. Benennungsmotiviken sind für die drei SN-Token nicht angegeben. Dass die koloniale Intention der Einzelbenennung Lettow-Vorbeck-Straße nur ein Jahr später weitergeführt werden sollte, legen die in gleichem Wortlaut angelegten Motiviken der beiden Umbenennungsprodukte Erckertstraße und Estorffstraße nahe:

Erckertstrasse bzw. Estorffstraße [...] [...] hervorragender Führer in uns. Kolonialkriegen, besonders in den Kämpfen um Südwest-Afrika (Herero-Aufstand 1904). (Adressbuch Hamburg 1940 IV: 354, 365)

Das dritte in Wandsbek gelegene Großcluster ist für den Stadtteil Rahlstedt auszumachen und weist acht koloniale Straßennamen (d. s.: Kameruneck, Ostafrikadamm, Somalikamp, Südwestkamp, Tangastraße, Togoweg, Waterberg, Windhuker Stieg) auf:

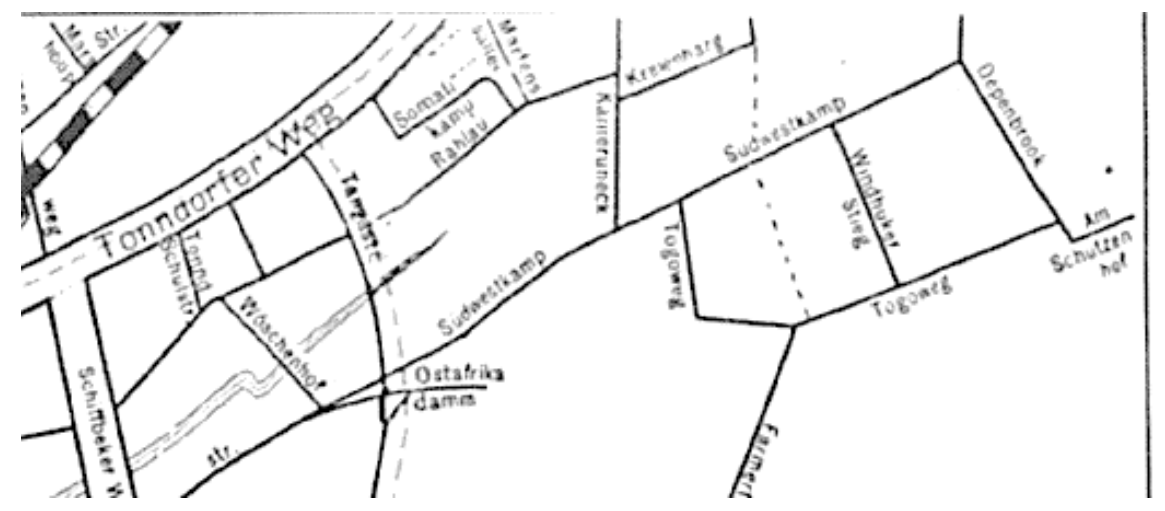

Abb. 21: Stadtplan Hamburg, Ausschnitt Rahlstedt, im Adressbuch Hamburg (1940).

Obwohl das Simplex Waterberg nicht im Stadtplan aufgeführt wird, ist das SNToken mit acht Adressen im Straßennamenverzeichnis aufgelistet mit folgendem Hinweis „(Rahlstedt/Wandsbek-Ost) Vom Kameruneck rechts: [...]“ (Adressbuch Hamburg 1940 IV: 1241).

Alle für Wandsbek-West, -Ost und -Rahlstedt dargelegten Namen sind ebenfalls im Amtlichen Gebiets- und Straßenverzeichnis (vgl. Statistisches Landesamt Hamburg 01.05.1939) aufgeführt. Im Vorwort findet sich die Information, dass im Zuge der damaligen Eingemeindungen der zuvor eigenständigen Stadt Wandsbek nach dem Groß-Hamburg-Gesetz ca. 1.600 Umbenennungen erforderlich waren. 
Wenngleich diese erst später in Kraft gesetzt werden sollten, orientierte man sich am zukünftigen Ist-Stand. ${ }^{164}$ Inwieweit zeitgenössisch eine Umsetzung der kolonialzeitbezogenen Namen in der unmittelbaren Raumdeskription durch entsprechende Beschilderung stattgefunden hat, lässt die Quellenlage nicht zu. Nichtsdestotrotz ist am Ende der 1930er Jahre für die Seite der administrativen Namengeber ein offensichtlich großes Interesse an der Sichtbarmachung von Kolonialismus und kolonialen Themen im Hamburger (Alltags-)Raum festzustellen. Auffällig ist, dass sich die MOD-Types mit den in Hamburg-Kleiner Grasbrook (Abb. 17) oder -Hamm und Horn (Abb. 18) verfügten älteren kolonialen Benennungen teilweise überschneiden (d. s.: Kamerun, Peters, Togo, Windhuk, Wissmann) was von offizieller Seite vermieden werden sollte:

a) Jeder Straßenname soll in einer Gemeinde nur einmal vorkommen. Mehrfach vorkommende Straßennamen, die sich bei Gebietsveränderungen ergeben können, sollen durch Umbenennung beseitigt werden. [...] b) (1) Straßenbezeichnungen, die sich nur in den Grundwörtern (wie Straße, Allee, Platz usw.) unterscheiden, gelten als Wiederholung. (2) Eine Wiederholung ist nur statthaft, wenn eine Straße, ein Platz, eine Brücke oder eine Grünanlage unmittelbar beieinander liegen, oder bei fortlaufenden hervorragenden Straßenzügen (Ausfallstraßen) von beträchtlicher Länge, die bei demselben Bestimmungswort (das ist der Name, nach dem die Straße benannt ist) durch die Änderung des Grundwortes in einzelne Abschnitte unterteilt werden. (Runderlaß des Reichsministers des Innern 15.7.1939) $)^{165}$

Wenngleich Hamburg zumindest zahlenmäßig das Zentrum kolonial motivierter Straßenvergabepraktiken in nationalsozialistischer Zeit darstellt, sind auch für weitere Großstädte innerhalb des gesamten Untersuchungszeitraums (18841945) mehrere Cluster festzustellen: Zwei nebeneinander existierende Kolonialcluster mit sich unterscheidenden Modifikator-Konstruktionen der jeweiligen kolonial motivierten Benennungen konnten auch für Berlin(-Dahlem und -Wedding), Bremen(-Waller Vorstadt und -Oslebshausen), Hannover(-SüdstadtBult und -Badenstedt) und Köln(-Nippes und -Ehrenfeld) erhoben werden.

Bei den zwei für Düsseldorf erhobenen groß angelegten Kolonialclustern ist eine partielle Überschneidung der Modifikatoren festzustellen. Wenngleich die kolonial motivierten Konstruktionen beider Großcluster in die nationalsozialistische Zeit zu verorten sind, lagen diese nicht zeitgleich vor: Für die Reichsaus-

164 Gleiches gilt wohl auch für die Einzelbenennung Gerhard-Rohlfs-Weg in HamburgStellingen. Herzlicher Dank geht an Y. Gerlach vom Staatsarchiv Hamburg.

165 Ein Großteil der für Wandsbek erhobenen Kolonialismen tauchen bspw. im Hamburger Adressbuch von 1949, das erstmalig nach 1945 wieder ein Straßenverzeichnis aufweist, nicht mehr auf. 
stellung „Schaffendes Volk“, die die nationalsozialistischen Wirtschaftsplanungen propagandistisch für die Öffentlichkeit zugänglich machen sollte, wurde ein Ausstellungsgelände in dem aufzuschließenden Düsseldorfer Stadtteil Golzheim angelegt, dessen Straßenzüge Namen erhalten sollten, die Kolonialakteure des Kaiserreichs ehren und/oder würdigen sollten (vgl. Kleinfeld 1996: 19): Der zeitgenössische Stadtplan zeigt für die nördlich des Ausstellungsgeländes erbauten Straßen folgende deanthroponymische Benennungen auf:

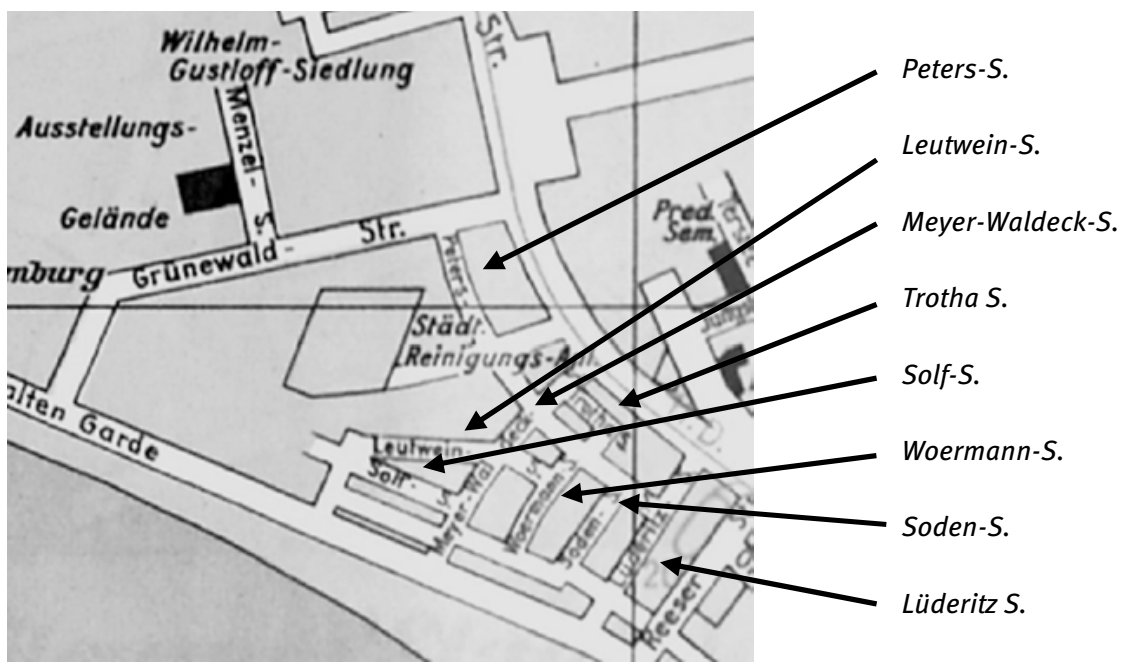

Abb. 22: Stadtplan Düsseldorf (1937), Ausschnitt Golzheim.

Kurz vor Ausstellungsbeginn wurden jene Namen jedoch wieder getilgt und durch andere Benennungen ersetzt:

Im Juni 1936 wählte man auf Vorschlag der Stadtverwaltung Namen von Kolonialpolitikern [...]. Andere Namen stammten von Gegnern des Naziregimes wie Hans Freiherr von Soden [...], der Gutachten gegen die Anwendung der Arierparagraphen erstellt hatte oder Wilhelm Solf [...], um den sich ein Kreis von Widerstandskämpfern gebildet hatte [...]. Noch rechtzeitig vor der Ausstellungseröffnung fiel auf, dass diese Namen nicht den Erfordernissen entsprechen, und so wurden die Benennungen per Beschluss vom 16.1.1937 wieder geändert. Diesmal griff man zu Namen von Personen, die der nationalsozialistischen Weltanschauung näher standen, meist beim Aufstand an der Münchener Feldherrenhalle umgekommene ,Alte Kämpfer‘ [...]. (Schäfers 2001: 279-280)

Umso überraschender ist, dass bis auf die Konstruktionen Leutwein- und Trothastraße alle der zuvor in Golzheim verfügten und wenig später getilgten deanthroponymischen Konstruktionen bereits ein Jahr danach als Benennungen 
für Straßenzüge in Urdenbach zu konstatieren sind, die auch im Adressbuch von 1940 unter Angabe der jeweiligen Benennungsmotiviken aufgelistet sind:

Lüderitzstraße (Urdenbach) Franz Lüderitz, Großkaufmann und Kolonialpolitiker, [...] verunglückt in der Küstenbrandung des Oranjeflusses; erwarb 1883 den Hafen Angra Pequena u. das Küstengebiet Lüderitzland, aus dem das Schutzgebiet Deutsch-Südwestafrika hervorging, das seit 1920 Völkerbundsmandat ist. (Adressbuch Düsseldorf 1940 III: 311)

Meyer-Waldeck-Straße (Urdenbach) Alfred Meyer Waldeck, Vizeadmiral [...] seit 1911 Gouverneur des Kiautschou-Gebietes, verteidigte Tsingtau gegen die Japaner [...]. (Adressbuch Düsseldorf 1940 III: 328)

Petersstraße (Urdenbach) Karl Peters, Afrikareisender und Kolonialpolitiker [...] erwarb 1884-85 das deutsche Schutzgebiet Ostafrika, dessen Reichskommissar er 1891-1892 gewesen ist. (Adressbuch Düsseldorf 1940 III: 365)

Sodenstraße (Urdenbach) Julius Freiherr von Soden, Staatsmann [...] seit 1885 Gouverneur von Kamerun, 1892 bis 93 von Deutsch-Ostafrika. (Adressbuch Düsseldorf 1940 III: 425)

Solfstraße (Urdenbach) Wilhelm Solf, Staatsmann [...] seit 1900 Gouverneur von Samoa, 1911 Staatssekretär des Kolonialamtes [...]. (Adressbuch Düsseldorf 1940 III: 426)

Woermannstraße (Urdenbach) Adolf Woermann, Großkaufmann und Kolonialpolitiker [...] Mitinhaber des Handelshauses Carl Woermann, gründete 1880 die Deutsch-Westafrikanische Dampferlinie, erwarb 1884 in Verbindung mit Janßen und Thormählen das Kamerungebiet, das seit 1920 Mandatsgebiet des Völkerbundes ist. (Adressbuch Düsseldorf 1940 III: 492)

Für München sind innerhalb des Untersuchungszeitraums sogar drei koloniale Großcluster für den 28. Stadtbezirk (heute Nymphenburg-Neuhausen), Bogenhausen und Trudering festzustellen (siehe Abb. 23). Nur die in nationalsozialistischer Zeit verfügten kolonial motivierten Konstruktionen für in unmittelbarer Nähe zueinander liegende Straßenzüge in Bogenhausen und Trudering liegen zeitgleich vor: Bei den in München-Trudering eingeschriebenen kolonialen Namenvergabepraktiken handelt es sich um ein jüngeres Kolonialcluster, das von Seiten kolonialrevisionistischer Interessenverbände eingefordert wurde, im Zuge dessen die älteren in der Zwischenkriegszeit verfügten kolonialen Benennungen zur Vermeidung von Straßennamendopplungen im 28. Bezirk getilgt wurden (vgl. Schulz und Ebert 2016: 377-378).

Die Überprüfung eines historischen Straßenverzeichnisses (vgl. Adressbuch München 1940 IV) ergab, dass noch im gleichen Jahr weitere SN-Token (wie bspw. Anecho- und Maerckerstraße, Kameruner Straße, Von-Erkert-Platz) für in nächster Nähe angelegte Straßenzüge in den öffentlichen Raum verfügt wurden, die noch nicht im Stadtplan verzeichnet sind. Zahlenmäßig übertrifft das Kolonialcluster mit 26 in nachweislich kolonial motivierter Motivik erfolgten Benennungen sogar das Cluster in Berlin-Wedding. Wenngleich die SN-Token Niobestraße, Mövestraße, Graf-Spee-Platz, Gorch-Fock-Straße und Admiral- 
Hipper-Straße für Straßenzüge in unmittelbarer Nähe verfügt wurden, sind keine kolonialen Benennungsmotiviken festzustellen. Die Namen wurden daher nicht ins Namenkorpus aufgenommen. ${ }^{166}$

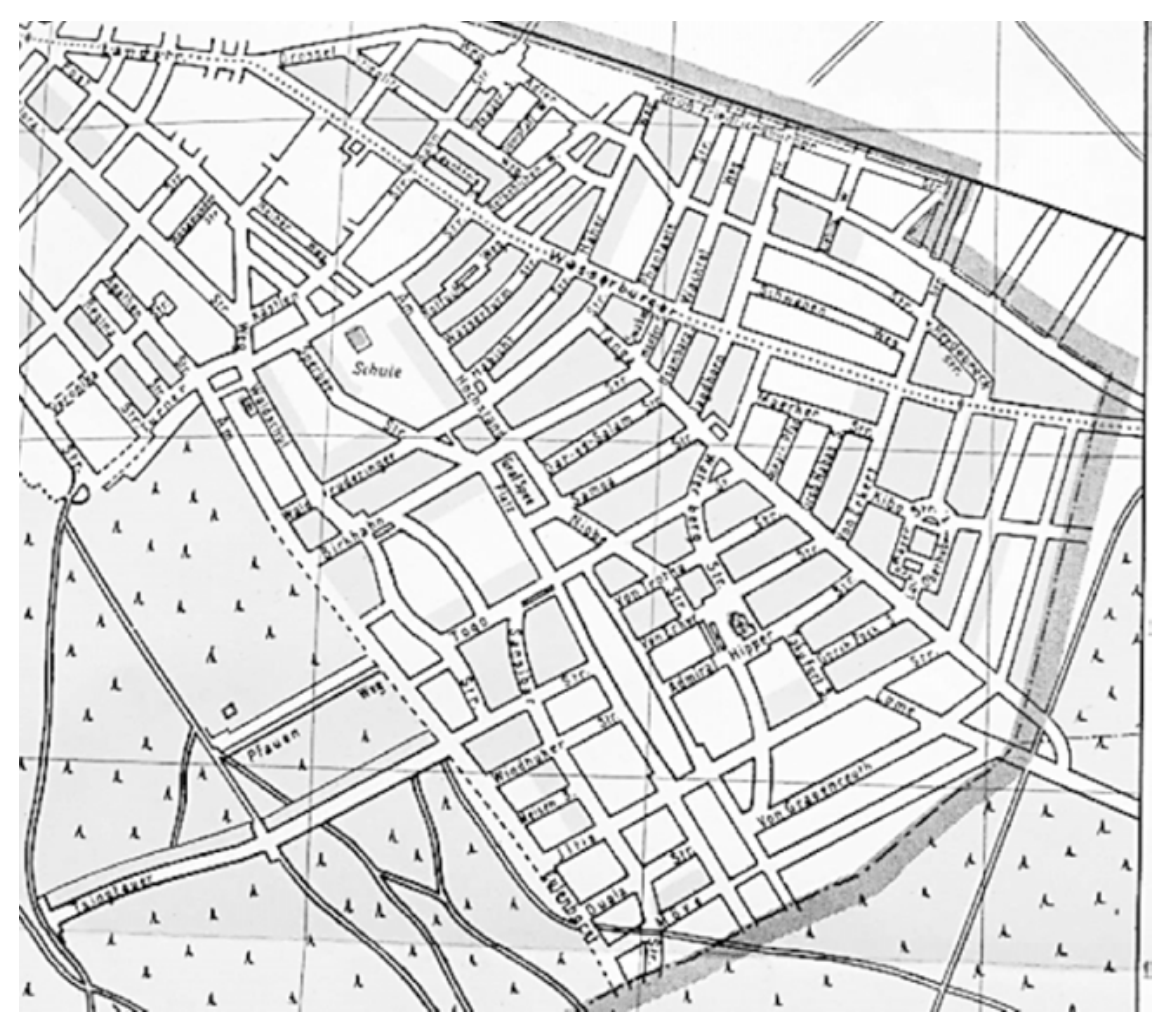

Abb. 23: Stadtplan München (1940), Ausschnitt Trudering.

166 Niobestraße: „Zur Erinnerung an das 1932 untergegangene Schulschiff Niobe, dessen Besatzung zum größten Teil den Tod in den Wellen fand.“ (Adressbuch München 1941 IV: 459) Mövestraße: „Zur Erinnerung an den Kaperkreuzer „Möwe“, der den englischen Handel empfindlich schädigte.“ (Adressbuch München 1941 IV: 445) Graf-Spee-Platz: „Max Graf v. Spee, Admiral, seit 1913 Chef d. deutschen Kreuzergeschwaders in Ostasien [...] gefallen am 8.12.1914 gegen überleg. engl. Streitkräfte bei den Falklandinseln.“ (Adressbuch München 1941 IV: 253) Gorch-Fock-Straße: „Gorch Fock. Schriftstellername [...] gefallen i. d. Seeschlacht b. Skagerrak; nach ihm ben. d. Ersatzbau des Schulschiffes Niobe.“ (Adressbuch München 1941 IV: 251) Admiral-Hipper-Straße: „Der Ritter von Hipper [...], Führer der leichten Seestreitkräfte in der Schlacht in Skagerrak, später Chef der Hochseeflotte und Admiral.“ (Adressbuch München 1941 IV: 49). 
Die zeitgleich als Kolonialcluster in München-Bogenhausen verfügten Namen für neu angelegte Straßenzüge weisen - entsprechend der offiziellen Regelungen (vgl. Runderlaß des Reichsministers des Innern 15.7.1939) - keine Übereinstimmungen hinsichtlich der Modifikator-Konstruktionen auf.

Um die Frage beantworten zu können, welche kolonisatorischen Wissenskonzepte mittels kolonial motivierter Straßenvergabepraktiken als Cluster versprachlicht werden sollten, werden die Namenviertel zuerst hinsichtlich ihrer gesellschaftspolitischen Verfügungszeiträume dargelegt. Sodann wird gezeigt, dass clusterbezogene Namenmuster auszumachen sind, die ortsübergreifendnationale Verwendung fanden. Auf Grundlage struktureller Prototypen soll herausgearbeitet werden, welche Diskursfunktionen von Seiten der Namengeber im Hinblick auf die damit versprachlichten kolonisatorischen Gewissheiten etabliert und im öffentlichen Alltagsraum der deutschen Metropole fixiert werden sollten.

\subsubsection{Diachrone Verteilungen der innerhalb von Clustern erfolgten Namenvergaben}

Im Hinblick auf die drei gesellschaftspolitischen Untersuchungszeiträume können für den Bestand der 60 Großcluster, die zwischen 1884 und 1945 in 48 Großund Mittelstädte verfügt wurden, zwei übergeordnete Typen voneinander unterschieden werden:

- Typ 1: Die innerhalb von Kolonialclustern zu verortenden Namen werden in diachronen Staffelungen verfügt.

- Typ 2: Die innerhalb von Kolonialclustern zu verortenden Namen werden zeitgleich verfügt.

Für Cluster des ersten Typs sind mindestens zwei gesellschaftspolitische Benennungsphasen festzustellen: In der ersten Phase werden entsprechende Benennungen erstmalig in den öffentlichen Raum verfügt, für die eindeutige koloniale Kommemorationen nachzuvollziehen sind. Stadtviertel, gerade solche in den Peripheriebereichen am Rande der Stadt, werden in jüngeren Zeiträumen erweitert. In der zweiten Phase werden im Zuge der neu angelegten Straßen koloniale Straßennamenmuster fortgeführt - das entsprach spätestens in nationalsozialistischer Zeit den reichsübergreifenden Vorgaben für Straßenvergabepraktiken (vgl. Runderlaß des Ministers des Innern 17.6.1933: 745-746). So sind die Benennungen der bis 1945 groß angelegten Kolonialcluster in DresdenRäcknitz/Zschertnitz (Kap. 3.4.1), Leipzig-Anger-Crottendorf und Berlin-Wedding sowohl in die faktische Kolonialzeit als auch in die 1920er und/oder 1930er Jahre zu verorten. Für Cluster dieses ersten Typs muss die von Werner (2008: 69) auf Basis gedächtnistheoretischer Aspekte dargelegte These der „besonders 
intensiv erhoffte[n] Wirkung “ für die jüngeren Namenvergaben in Frage gestellt werden, weil eben solche nicht zuletzt auch mit außersprachlichen Faktoren des infrastrukturellen Ausbaus der betreffenden Viertel und der Fortführung entsprechender Namenmuster zu begründen sind (vgl. Ebert angenommen). Cluster dieses ersten Typs spielen jedoch in ortsübergreifender Perspektive eine untergeordnete Rolle. Nur acht der bis 1945 erhobenen Kolonialviertel weisen diachrone Staffelungen der jeweiligen Namenvergaben auf:

Tab. 28: Zeithistorische Entstehung von Kolonialclustern.

Typ 1: Diachrone Staffelungen der

Typ 2: Zeitgleiche Benennungen

Benennungen

Anzahl an Clustern 8

52

Neben Berlin-Wedding, Leipzig-Anger-Crottendorf und Dresden-Räcknitz/ Zschertnitz sind derartige zeitliche Schichtungen für die in Hannover-SüdstadtBult bzw. Cuxhaven-Döse verfügten Kolonialcluster festzustellen: In der de factoKolonialzeit wurden die singulären Kolonialismen Karl-Peters-Platz (vgl. Hanke 2014: 230) bzw. Tsingtaustraße (vgl. Wolter 1997: 92) verfügt, die in den 1920er bzw. 1930er Jahren durch die Vergabe weiterer kolonialer SN-Token für Straßenzüge in unmittelbarer Nähe zu themenkohärenten Clustern erweitert wurden. ${ }^{167} \mathrm{In}$ Bremen-Oslebshausen, Gleiwitz [Gliwice]-Ratiborer Vorstadt sowie HamburgHamm und Horn erfolgten erstmalige koloniale Benennungen erst in der Zwischenkriegszeit. ${ }^{168}$ Im Zuge des infrastrukturellen Ausbaus der jeweiligen Viertel erfolgten weitere themenkohärente Namenverfügungen nach $1933 .{ }^{169}$

Von solchen ortsbezogenen Fällen ist der quantitativ dominante zweite Typ an zeitgleich verfügten Benennungen als groß angelegte Kolonialcluster abzu-

167 D. s. für Hannover-Südstadt-Bult: Am Karl-Peters-Platz (durch Umbenennung des SNTokens Haspelstraße), Wissmannstraße und Nachtigalstraße (vgl. Stadtplan Hannover 1924). D. s. für Cuxhaven-Döse: Lettow-Vorbeck-Straße, Leutweinstraße, Lüderitzstraße und Wißmannstraße (vgl. Adressbuch Cuxhaven 1939 III).

168 D. s. für Bremen-Oslebshausen: Kamerunstraße, Otavistraße, Südweststraße, Togostraße, Waterbergstraße und Windhukstraße (Abb. 24). D. s. für Gleiwitz [Gliwice]-Ratiborer Vorstadt: Lüderitzstraße und Wissmannstraße (vgl. Stadtplan Gleiwitz 1928). D. i. für Hamburg-Hamm und Horn: Emin-Pascha-Straße; man vgl. dazu die Anmerkung im Adressbuch Hamburg (1935 IV: 233): „[...] Emin Pascha oder Eduard Schnitzer (1840-92) [...] Ben. 1929“.

169 D. s. für Bremen-Oslebshausen: Dualaweg, Kribiweg, Togoplatz. D. s. für Gleiwitz [Gliwice]-Ratiborer Vorstadt: Lettow-Vorbeck-Straße, Petersweg, Windhukstraße. D. s. für HamburgHamm und Horn: Carl-Peters-Weg, Theodor-Weber-Reihe, Wissmannsweg (Abb. 18). 
grenzen: 52 der in den öffentlichen Raum von Groß- und Mittelstädten eingeschriebenen Namenviertel fallen hinsichtlich ihrer Verfügungszeitpunkte der betreffenden Namen in nur einen gesellschaftspolitischen Zeitraum. Damit kann die zeitgleich erfolgte, gebündelte Verfügung von drei und mehr Namen als Großcluster als ortsübergreifend-nationale Praxis kolonial motivierter Fixierungspraktiken herausgestellt werden. Die Kategorisierung dieser 52 Cluster hinsichtlich der gesellschaftspolitischen Verfügungszeitpunkte führt zu einem eindeutigen Ergebnis:

Tab. 29: Häufigkeitsverteilung zeitgleicher Benennungen als Kolonialcluster.

\begin{tabular}{llll}
\hline & $\begin{array}{l}\text { Faktische Kolonialzeit } \\
(1884-1919)\end{array}$ & $\begin{array}{l}\text { Weimarer Republik } \\
(1919-1933)\end{array}$ & $\begin{array}{l}\text { NS-Zeit } \\
(1933-1945)\end{array}$ \\
\hline Anzahl an Clustern & 3 & 3 & 46 \\
\hline
\end{tabular}

Für die faktische Kolonialzeit sind nur drei Cluster festzustellen, deren Benennungen allesamt bis 1919 verfügt wurden:

Berlin-Dahlem, Bremen-Waller Vorstadt, Köln-Ehrenfeld.

Die Nameninventare der bereits zur faktischen Kolonialzeit als Cluster verfügten kolonial motivierten Benennungen in Köln-Ehrenfeld und Berlin-Dahlem, die von der städtischen Administration in Berlin verfügt wurden (Kap. 4), überschneiden sich hinsichtlich ihrer Konstruktionen. Die Namenverfügungen wurden ebenfalls von Seiten der DKG kommentiert: „Köln weist auch eine TakuStraße und einen Taku-Platz sowie eine Iltis-Straße auf, die in Groß-Berlin wiederkehren auf dem Gelände von Dahlem, das auch eine Lans-Straße besitzt“ (DKZ 8.3.1913: 167). In beiden Städten beziehen sie sich auf die zeitgenössisch als Boxeraufstand titulierte Ostasiatische Expedition (vgl. Schnee 1920 II: 689).

Zur Erinnerung an die Kolonialisierung in Tsingtao und zur Glorifizierung der deutschen Intervention im sogenannten Boxeraufstand tragen einige Straßennamen im Zehlendorfor Stadtteil Dahlem bei. [...] Während des Boxeraufstandes beschoss am 17. Juni des Jahres 1900 das deutsch-kaiserliche Kanonenboot Iltis unter Leitung des Kapitäns Wilhelm von Lans den befestigten Vorhafen Taku der chinesischen Stadt Tientsin. (Honold 2003: 316)

Für die MOD-Types Taku(-Fort) und Iltis sind in ortsübergreifender Perspektive das zeigt auch Diagramm 1 in Kap. 6.3.1 - nur vier bzw. drei SN-Token festzustellen. Der MOD-Type Lans ist ausschließlich für die in Berlin-Dahlem und KölnEhrenfeld verfügten Kolonialcluster festzustellen. Etwaige weitere Kolonialclus- 
ter, die sich auf derartige Kommemorationen beziehen, erschienen offenbar nicht attraktiv.

Wenngleich die DKG als einflussreichster kolonialer Interessensverband im Deutschen Reich und in der Zwischenkriegszeit nachweislich weitere koloniale Fixierungspraktiken propagierte (Kap. 7.4), blieben ortsübergreifend-nationale Nachahmungspraktiken von kolonial motivierten Clusterverfügungen im Deutschen Reich bis 1933 aus. Für die Zwischenkriegszeit sind ebenfalls nur drei Kolonialcluster festzustellen, deren Benennungen allesamt nachweislich bis 1933 verfügt wurden:

Bochum-Ehrenfeld, Hamburg-Kleiner Grasbrook, München-28. Stadtbezirk.

Erst mit dem Beginn der nationalsozialistischen Machtübernahme ist ein ortsübergreifend-nationales administratives Interesse an der gebündelten Kommemoration von Kolonialakteuren und/oder kolonisierten Orten $\mathrm{u}$. dgl. durch die entsprechende Vergabe von 42 Großclustern in Groß- und Mittelstädten festzustellen, für die sich insbesondere die örtlichen Kreisverbände des durch Gleichschaltung an das NS-System angeschlossenen Reichskolonialbundes einsetzten (Kap. 7.4). 29 bzw. 17 Cluster wurden in folgende Viertel der jeweiligen Großbzw. Mittelstädte verfügt:

Braunschweig-Querum, Breslau [Wrocław]-Mochbern, Dessau-(heutiges) Handwerkerviertel, Duisburg-Huckingen und Buchholz, Düsseldorf-Golzheim, Düsseldorf-Urdenbach, Essen-Gerschede, Frankfurt am Main-Praunheim, Gelsenkirchen-Hüllen und Bismarck, Hamburg-Ottensen, Hamburg-Wandsbek-Ost, Hamburg-Wandsbek-West, Hamburg-Rahlstedt, Hannover-Badenstedt, Hindenburg O.S. [Zabrze]-Mathesdorf, Karlsruhe-Gartenvorstadt Grünwinkel, Kassel-Forstfeld, Kiel-Neumühlen-Dietrichsdorf, Köln-Nippes, Königsberg i. Pr. bzw. Königsberg (Pr.) [Kaliningrad]-Ratshof und Lawsken, Lübeck-Vorwerk, Ludwigshafen am Rhein- (heutige) Niederfeldsiedlung, Magdeburg-Neustädter Feld, Mannheim-Rheinau, Mühlheim an der Ruhr-Eppinghofen, München-Bogenhausen, München-Trudering, Stettin [Szczecin]-Braunsfelde, Stuttgart-Obertürkheim.

Bautzen-Thrombergsiedlung, Bottrop-Vonderort, Delmenhorst-Hasport und Annenheide, Eilenburg-Berg, Forst (Lausitz)-Süd (westlicher Teil), Heilbronn-Sontheim, HerfordOttelau, Koblenz-Pfaffendorf, Landsberg a. d. Warte [Gorzów Wielkopolski]-Zanziner Grund, Merseburg-Freiimfelde, Neustadt a. d. Haardt bzw. Weinstraße-West, Oranienburg-(heutiges) Ärzteviertel, Ravensburg-Südstadt, Recklinghausen-Suderwich, RiesaMerzdorf, Völklingen-Rammelter Schacht, Wolfenbüttel-Drei Linden.

Für den zahlenmäßig übergeordneten Bestand an Kolonialclustern, deren Benennungen erstmalig in gebündelter Form allesamt seit dem Beginn der nationalsozialistischen Machtübernahme in Groß- und Mittelstädte des Deutschen Reichs verfügt wurden, kann ein administratives Interesse an der Fixierung 
kolonialer Wissenskonzepte von Seiten der zeitgenössischen Administrationen nachgewiesen werden,

denn die benennende Macht ist sich dabei nicht nur über einen Einzelfall [kursiv im Original] einig geworden, sondern über viele Fälle - eben über eine ganze Thematik. Solche Cluster müssen also von einer breiten Willensbasis getragen sein [...]. (Werner 2008: 69)

\subsubsection{Clustertypen: Inventare}

Auf Grundlage der lexikologisch-onymischen Annotation der ModifikatorKonstruktionen erfolgte eine Kategorisierung der 389 SN-Token, die innerhalb von 60 Großclustern verfügt wurden:

- Typ 1:3 + x kolonial motivierte SN-Token mit ausschließlich toponymischen Modifikator-Konstruktionen

- Typ 2: 3 + x koloniale motivierte SN-Token mit ausschließlich anthroponymischen Modifikator-Konstruktionen

- Typ 3: 3 + x koloniale motivierte SN-Token mit toponymischen, anthroponymischen und ggf. weiteren Modifikator-Konstruktionen

Die Kategorisierung auf nur drei Clustertypen zeigt, dass die Form usueller kolonialer Clusterbenennung auch im Hinblick auf die innerhalb von solchen ortsübergreifend-nationalen Namenvierteln verfügten Konstruktionen von hoher Systematizität geprägt ist. So ist bspw. keine kolonial motivierte Clusterverfügung zu konstatieren, deren Benennungen ausschließlich Schiffe der Kaiserlichen Marine und/oder kolonisierte Bevölkerungsgruppen ehren und/oder würdigen sollten. Derartige Konstruktionen stellen Einzelphänomene dar, die innerhalb von Kolonialclustern des dritten Typs mitverfügt wurden. Für die drei Clustertypen sind eindeutige Distributionen festzustellen:

Tab. 30: Häufigkeitsverteilung der drei Clustertypen.

\begin{tabular}{llll}
\hline $\begin{array}{l}\text { Lexikologisch-onymische } \\
\text { Klassen der MOD-Token }\end{array}$ & Typ 1 & Typ 2 & Typ 3 \\
\hline Anzahl an Clustern & 6 & 30 & 24 \\
Anzahl an SN-Token & 34 & 134 & 221 \\
\hline
\end{tabular}

Ausschließlich mit toponymischen MOD-Types verfügte Clusterbenennungen (Typ 1) konnten nur für sechs Städte bzw. -viertel erhoben werden. Als ortsübergreifend-nationale Muster sind dagegen koloniale Verfügungspraktiken 
innerhalb groß angelegter Cluster für in unmittelbarer Nähe zueinander liegenden Straßenzügen des Typs 2 und 3 auszumachen, deren Konstruktionen ausschließlich anthroponymische MOD-Types (Typ 2) oder toponymische, anthroponymische und ggf. weitere Modifikator-Konstruktionen (Typ 3) aufweisen. Die absolute Anzahl an Namenvierteln mit toponymischen, anthroponymischen und ggf. weiteren lexikologisch-onymischen Modifikator-Konstruktionen des dritten Typs fällt etwas kleiner als die des zweiten Typs aus, sie sind aber hinsichtlich ihrer Inventare mit im Durchschnitt neun SN-Token größer angelegt. Alle drei Clustertypen werden im Folgenden inventarbezogen nach etwaigen Namenmustern untersucht, um anschließend sprachhistorische Aussagen über Formen der damit intendierten Raumbelegung und der damit versprachlichten kolonisatorischen Gewissheiten treffen $\mathrm{zu}$ können.

\section{a. Cluster mit ausschließlich toponymischen MOD-Types (Typ 1)}

Kolonialcluster mit ausschließlich toponymischen Benennungen konnten für die vier Großstädte Gelsenkirchen, Hamburg, Bremen und Stettin [Szczecin] erhoben werden; sie werden in der Tabelle inklusive ihrer Verortung dargelegt:

Tab. 31: Großcluster mit ausschließlich toponymischen MOD-Types.

\begin{tabular}{|c|c|c|}
\hline $\begin{array}{l}\text { Stadt, weitere Infos über } \\
\text { clusterbezogene Verortung }\end{array}$ & $\begin{array}{l}\text { Innerhalb der jeweiligen } \\
\text { Cluster verfügte Benennungen }\end{array}$ & Literaturangaben \\
\hline $\begin{array}{l}\text { Gelsenkirchen-Hüllen und } \\
\text { Bismarck }\end{array}$ & $\begin{array}{l}\text { Tangastr., Waterbergstr., } \\
\text { Windhukstr. }\end{array}$ & $\begin{array}{l}\text { Adressbuch Gelsenkirchen } \\
\text { (1941 III). }\end{array}$ \\
\hline Hamburg-Kleiner Grasbrook & $\begin{array}{l}\text { Kamerunweg, Kamerunkai, } \\
\text { Togokai, Windhukkai }\end{array}$ & Stadtplan Hamburg (ca. 1935). \\
\hline Hamburg-Ottensen & $\begin{array}{l}\text { Daressalamstr., Kamerunstr., } \\
\text { Otawiweg, Windhukstr. }\end{array}$ & Adressbuch Hamburg (1940 IV). \\
\hline Hamburg-Rahlstedt & $\begin{array}{l}\text { Kameruneck, Ostafrikadamm, } \\
\text { Somalikamp, Südwestkamp, } \\
\text { Tangastr., Togoweg, } \\
\text { Waterberg, Windhuker Stieg }\end{array}$ & $\begin{array}{l}\text { Stadtplan im Adressbuch } \\
\text { Hamburg (1940). }\end{array}$ \\
\hline Bremen-Oslebshausen & $\begin{array}{l}\text { Dualaweg, Kamerunstr., } \\
\text { Kribiweg, Otavistr., Südwest- } \\
\text { str., Togoplatz, Togostr., } \\
\text { Waterbergstr., Windhukstr. }\end{array}$ & Adressbuch Bremen (1942: III). \\
\hline $\begin{array}{l}\text { Stettin [Szczecin]- } \\
\text { Braunsfelde }\end{array}$ & $\begin{array}{l}\text { Kamerunstr., Lüderitzlandstr., } \\
\text { Tangastr., Togostr., } \\
\text { Waterbergstr., Windhuker Str. }\end{array}$ & $\begin{array}{l}\text { Stadtplan Stettin (ca. 1939), } \\
\text { Adressbuch Stettin (1941 II). }\end{array}$ \\
\hline
\end{tabular}


Das in Bremen verfügte Kolonialviertel mit ausschließlich detoponymischen Konstruktionen ist wie das Cluster in Hamburg-Kleiner Grasbrook in direkter Nähe zum Hafen zu verorten:

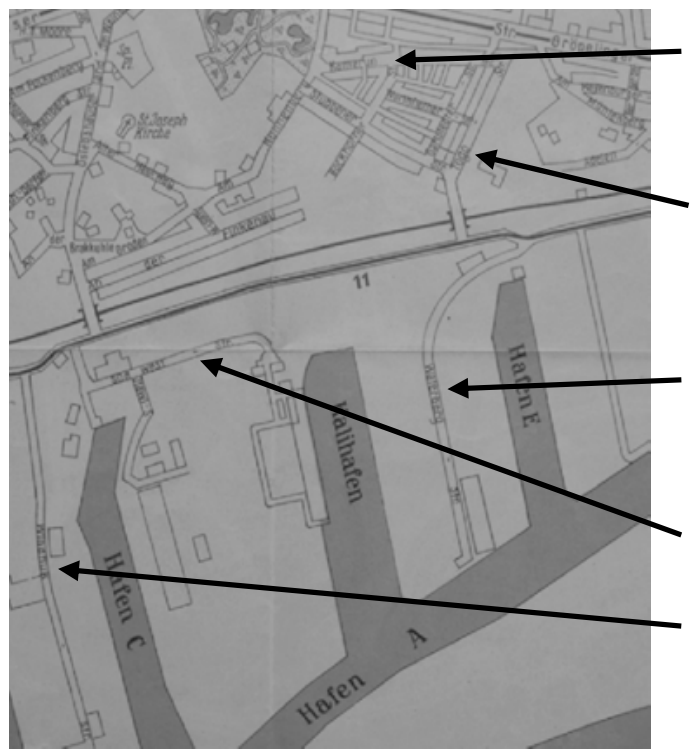

„Kamerunstraße [...] Br.-Oslebshausen. 1884-1918 deutsche Kolonie am Golf von Guinea." (Adressbuch Bremen 1939 III: 146)

„Togostraße [...] Br.-Oslebshausen. Ehem. Deutsches Schutzgebiet in Oberguinea an der Sklavenküste.“ (Adressbuch Bremen 1939 III: 283) „Waterbergstraße [...] (siehe HafenAnlagen) Berg und Siedlung im ehem. Deutsch-Südwestafrika.“ (Adressbuch Bremen 1939 III: 302)

Südwest-Str. (o. A. Bez.motivik) Otawi-Str. (o. A. Bez.motivik) „Windhukstraße: Ehemals Sitz der deutschen Verwaltung von DeutschSüdwestafrika." (Adressbuch 1939 III: 313)

Abb. 24: Hafenplan Bremen (1938).

Die im Stadtplan zu konstatierenden Benennungen fanden noch in der Zwischenkriegszeit statt. Ende der 1930er Jahre und Anfang der 1940er Jahre wurde das Cluster mit den weiteren dechoronymischen und deoikonymischen Benennungen Dualaweg, Kribiweg und Togoplatz (vgl. Adressbuch Bremen 1942: III) für Straßenzüge in nächster Nähe erweitert (Kap. 8.2.2.1). Sie beziehen sich ebenfalls auf den ehemaligen Kolonialbesitz des Deutschen Reichs in der Zeit des Kaiserreichs.

Die in Stettin [Szczecin] für neu angelegte Parallelstraßen verfügten Benennungen, die sich ebenfalls ausschließlich auf Orte in den Kolonialgebieten beziehen, sind nicht in nächster Nähe zu den dortigen Hafenanlagen, sondern in der „Villen-Kolonie Braunsfelde“ zu verorten (siehe Abb. 25).

Villenkolonien bzw. Villensiedlungen oder -viertel stellen gegründete Wohnsiedlungen in der Peripherie der mittelalterlichen Stadtkerne dar, die dem wohlhabenden Bürgertum und deren großzügig angelegten Anwesen zugutekommen sollten (vgl. Heineberg et al. 2014: 239). Eine Sichtung der Straßennamen in nächster Nähe zeigt, dass die Villenkolonie vom Zentrum kommend 
durch einen Straßenzug mit der Benennung Horst-Wessel-Allee im Westen abgegrenzt wurde. Aus der Peripherie gelangte man über Straßenzüge mit den SNToken Lothringer S., Elsässer S., Saar S., Malmedy S., Dirschauer S., Danziger S. u. dgl., die bereits vor 1933 verfügt wurden (Adressbuch Stettin 1932 II), zu den jeweiligen Parallelstraßen, die auf die Kolonien zur Zeit des Deutschen Kaiserreichs und auf Orte innerhalb solcher referieren sollten.

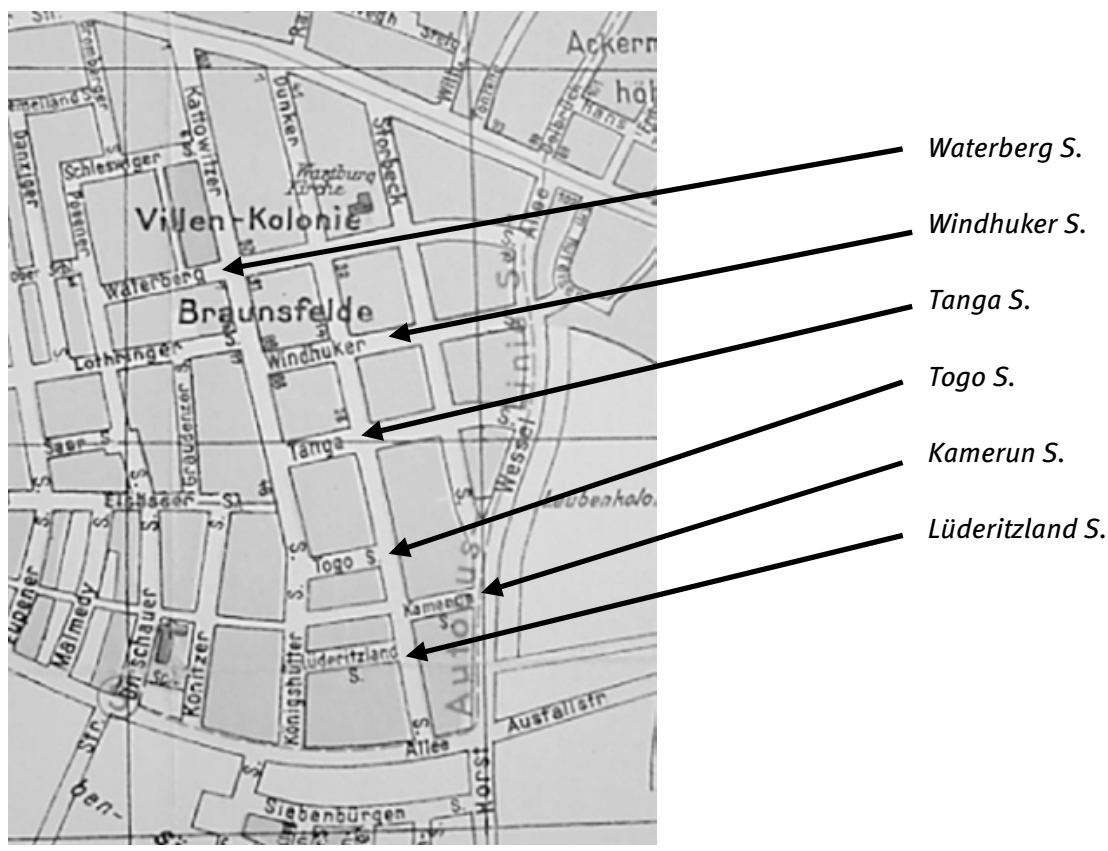

Abb. 25: Stadtplan Stettin (ca. 1939), Ausschnitt Braunsfelde.

Die Siedlung wurde offenbar in der Zwischenkriegszeit erschlossen und sodann im Nationalsozialismus mit weiteren Straßenzügen ausgebaut. Die Namenvergabepraktiken der in nationalsozialistischer Zeit erbauten Parallelstraßen, die sich auf den Kolonialbesitz in der Zeit des Deutschen Kaiserreichs beziehen, suggerieren die administrativ intendierte Verfügung eines Kolonialclusters. In Bezug auf die intendierte Kommemoration aller Benennungen in der Villenkolonie gehen die kolonial motivierten Benennungen in diesem Einzelfall solche Phänomene konnten bereits für koloniale Einzelbenennungen (Kap. 8.1.2) dargelegt werden - zugleich innerhalb der thematisch anders gelagerten Clusterbenennung auf. Das Thema Kolonialismus wird insofern kontextualisert, als dass sich alle in Braunsfelde verfügten Namen zum Zeitpunkt ihrer 
historischen Benennungen kommemorativ auf Gebiete und Städte beziehen sollten, die im Zuge der Bestimmungen des Versailler Vertrags seit 1920 der Kontrolle der Alliierten oder dem Völkerbund unterstellt wurden.

Die innerhalb der sechs Cluster verfügten Namenvergaben weisen hinsichtlich ihrer toponymischen Modifikator-Konstruktionen partielle Übereinstimmungen auf: Für alle sechs kolonialen Namenviertel sind Benennungen mit dem MOD-Type Windhuk auszumachen, der für das Gesamtinventar als hochfrequente Modifikator-Konstruktion herausgestellt wurde. Auch die weiteren verfügten toponymischen MOD-Types Togo, Kamerun sowie Tanga und Waterberg mit praxonymischen Anteilen fanden ortsübergreifende Verwendung. Die mit sechs bzw. acht SN-Token verfügten Kolonialcluster Bremen-Oslebshausen und Stettin [Szczecin]-Braunsfelde bzw. Hamburg-Rahlstedt weisen darüber hinaus Benennungen mit singulären Modifikatoren auf. Wenngleich der Modifikator der Lüderitzlandstraße nur ortsbezogen für Stettin [Szczecin] erhoben werden konnte, ist eine eindeutige koloniale Kommemoration nachzuweisen. Der Name referiert auf das gleichnamige Choronym, das ebenfalls als eigenes Lemma in Schnee (1920 II: 466) vertreten ist: „Diesen Namen erhielten die 1883 von Lüderitz [...] in Südwestafrika erworbenen Gebiete, die jetzt einen Bestandteil von Deutsch-Südwestafrika bilden“. Der Ausbau des in den 1920er Jahren angelegten Clusters in Bremen-Oslebshausen in nationalsozialistischer Zeit erfolgte unter anderem durch die Verfügung des SN-Tokens Kribiweg. Bei dem Ort handelte es sich in der faktischen Kolonialzeit um ein Zentrum des überseeischen Handels mit Kolonialwaren:

Kribi [...] bedeutender Hafenort und Sitz eines Bezirksamts an der Batangaküste in Kamerun. [...] In K. [d. i. Kribi] laufen zwei bedeutende Handelsstraßen zusammen, auf denen schon vor der Epoche der Besitznahme Kameruns Kautschuk, Öl, Elfenbein und die andern Erzeugnisse des Binnenlandes durch Zwischenhandel an die Küste gelangten. (Schnee 1920 II: 379)

Der Hafen spielte offenbar für die Hansestadt Bremen und deren überseeischen Handelsbeziehungen eine herausragende Rolle: Im historischen Straßenverzeichnis wird angegeben, dass mit der Benennung Kribiweg der „Bezirkshauptort unseres Schutzgebietes Kamerun“ (Adressbuch Bremen 1939 III: 162) geehrt und/oder gewürdigt werden sollte. Für den ausschließlich für HamburgRahlstedt zu verzeichnenden Modifikator der Benennung Somalikamp sind ähnlich wie für den ortsübergreifend verfügten MoD-Type Duala (Kap. 7.1.2.2 b) - polyreferenzielle Bezüge festzustellen, die jedoch eindeutig in einen kolonialen Kontext verortet werden können. Für diesen Einzelfall ist nicht ermittelbar, inwieweit eine Referenz auf die ,aus dem S.land [d. i. Somaliland] im nördlichen Ostafrika stammende[n] Eingeborene[n]“ (Schnee 1920 III: 370) oder eine 
Referenz auf die gleichnamige britische Kolonie vorgenommen werden sollte. Aus ähnlichen zeithistorischen sowie raumlinguistischen Gründen, die bereits für den MOD-Type Duala und für die Clusterbenennung in Bremen-Oslebshausen dargelegt wurden, ist es wahrscheinlicher, dass mit den innerhalb von Hamburg-Rahlstedt verfügten gebündelten Namen eine Kommemoration des Ortes intendiert wurde. Wenngleich der Modifikator der Lüderitzlandstraße nur ortsbezogen für Stettin [Szczecin] erhoben werden konnte, ist eine eindeutige koloniale Kommemoration nachzuweisen. Der Name referiert auf das gleichnamige Choronym, das ebenfalls als eigenes Lemma in Schnee (1920 II: 466) vertreten ist: „Diesen Namen erhielten die 1883 von Lüderitz [...] in Südwestafrika erworbenen Gebiete, die jetzt einen Bestandteil von Deutsch-Südwestafrika bilden.“.

\section{b. Cluster mit ausschließlich anthroponymischen MOD-Types (Typ 2)}

30 Kolonialcluster weisen ausschließlich deanthroponymische Konstruktionen auf. ${ }^{170}$ Sie werden in der Tabelle mit den jeweiligen Inventaren aufgelistet:

Tab. 32: Großcluster mit ausschließlich anthroponymischen MOD-Types.

\begin{tabular}{lll}
\hline $\begin{array}{l}\text { Stadt, weitere Infos über } \\
\text { clusterbezogene Verortung }\end{array}$ & $\begin{array}{l}\text { Innerhalb der jeweiligen Cluster ver- } \\
\text { fügte Benennungen }\end{array}$ & Literaturangaben \\
\hline Bautzen-Thrombergsiedlung & $\begin{array}{l}\text { Dr.-Peters-Str., Lüderitzstr., } \\
\text { Wissmannstr. }\end{array}$ & $\begin{array}{l}\text { Bestand 62011 Reper- } \\
\text { torium XI, Straßenum- } \\
\text { benennungen (1935- } \\
\text { Bochum-Ehrenfeld }\end{array}$ \\
& $\begin{array}{l}\text { Lüderitzstr., Petersstr., Wissmannstr. } \\
\text { 1942). }\end{array}$ & $\begin{array}{l}\text { Adressbuch Bochum } \\
\text { (1920 IV), Adressbuch }\end{array}$ \\
& $\begin{array}{l}\text { Bustav-Nachtigal-Str., Karl-Peters-Str., } \\
\text { Bottrop-Vonderort }\end{array}$ & $\begin{array}{l}\text { Adressbuch Bottrop (1938 } \\
\text { III), Stadtplan Bottrop }\end{array}$ \\
& $\begin{array}{l}\text { Lüderitzstr., Wissmannstr. } \\
\text { (1939), Weidner. }\end{array}$ \\
& $\begin{array}{l}\text { Gerhard-Rohlfs-Str., Leutweinplatz, Leut- } \\
\text { weinstr., Nachtigalstr., Wissmannstr. }\end{array}$ & $\begin{array}{l}\text { Adressbuch Bremen } \\
\text { (1905 II, 1919 II), Stadt- }\end{array}$ \\
& & plan Bremen (1927). \\
\hline
\end{tabular}

170 Nur das in Hamburg-Wandsbek-Ost verfügte Cluster weist neben fünf deanthroponymischen Konstruktionen eine singuläre deappellativische Konstruktion (d. i. Askaristieg) auf; da etwaige detoponymische Konstruktionen (vgl. Typ 3) nicht festzustellen sind, wurde das Cluster dem Typ 1 zugesprochen.

171 https://www.lwl.org/westfaelische-geschichte/nstopo/strnam/Kommune_37.html, Abruf am 28/06/2019. 


\begin{tabular}{|c|c|c|}
\hline $\begin{array}{l}\text { Stadt, weitere Infos über } \\
\text { clusterbezogene Verortung }\end{array}$ & $\begin{array}{l}\text { Innerhalb der jeweiligen Cluster ver- } \\
\text { fügte Benennungen }\end{array}$ & Literaturangaben \\
\hline $\begin{array}{l}\text { Delmenhorst-Hasport und } \\
\text { Annenheide }\end{array}$ & $\begin{array}{l}\text { Karl-Peters-Str., Lettow-Vorbeck-Str., } \\
\text { Leutweinstr., Lüderitzstr., Nachtigal- } \\
\text { str., Vogelsangstr., Wissmannstr. }\end{array}$ & $\begin{array}{l}\text { Grunding (1960: 750- } \\
763) .\end{array}$ \\
\hline $\begin{array}{l}\text { Dessau-(heutiges) Handwer- } \\
\text { kerviertel }\end{array}$ & $\begin{array}{l}\text { Lüderitzweg, Nachtigalweg, Petersweg, } \\
\text { Wissmannweg }\end{array}$ & $\begin{array}{l}\text { Adressbuch Dessau } \\
\text { (1940 II). }\end{array}$ \\
\hline Düsseldorf-Golzheim & $\begin{array}{l}\text { Lüderitzstr., Meyer-Waldeck-Str., } \\
\text { Petersstr., Sodenstr., Solfstr., } \\
\text { Trothastr., Woermannstr. }\end{array}$ & $\begin{array}{l}\text { Stadtplan Düsseldorf } \\
\text { (1937). }\end{array}$ \\
\hline Düsseldorf-Urdenbach & $\begin{array}{l}\text { Lüderitzstr., Meyer-Waldeck-Str., Peters- } \\
\text { str., Sodenstr., Solfstr., Woermannstr. }\end{array}$ & $\begin{array}{l}\text { Adressbuch Düsseldorf } \\
1940 \text { (III). }\end{array}$ \\
\hline Eilenburg-Berg & $\begin{array}{l}\text { Dr.-Nachtigal-Str., Dr.-Peters-Str., } \\
\text { Lüderitzstr. }\end{array}$ & $\begin{array}{l}\text { Eilenburger Geschichts- } \\
\text { und Museumsverein } \\
(2016) \text {. }\end{array}$ \\
\hline Hamburg-Hamm und Horn & $\begin{array}{l}\text { Carl-Peters-Weg, Emin-Pascha-Str., } \\
\text { Theodor-Weber-Reihe, Wissmannsweg }\end{array}$ & $\begin{array}{l}\text { Stadtplan Hamburg } \\
\text { (ca.1935). }\end{array}$ \\
\hline Hamburg-Wandsbek-Ost & $\begin{array}{l}\text { Askaristieg, Dominikweg, Erckertstr., } \\
\text { Estorffstr., Lettow-Vorbeck-Str., } \\
\text { Lüderitzweg }\end{array}$ & $\begin{array}{l}\text { Stadtplan i. Adress- } \\
\text { buch Hamburg (1940). }\end{array}$ \\
\hline Hamburg-Wandsbek-West & $\begin{array}{l}\text { Gustav-Nachtigal-Damm, Karl-Peters- } \\
\text { Weg, Wissmannsweg }\end{array}$ & $\begin{array}{l}\text { Stadtplan i. Adress- } \\
\text { buch Hamburg (1940). }\end{array}$ \\
\hline Hannover-Südstadt-Bult & $\begin{array}{l}\text { Am Carl-Peters-Platz, Carl-Peters- } \\
\text { Platz, Nachtigalstr., Wissmannstr. }\end{array}$ & $\begin{array}{l}\text { Stadtplan Hannover } \\
\text { (1931), Adressbuch } \\
\text { Hannover (1937 II). }\end{array}$ \\
\hline Herford-Ottelau & $\begin{array}{l}\text { Carl-Peters-Str., Gustav-Nachtigal-Str., } \\
\text { Hermann-von-Wissmann-Str. }\end{array}$ & Weidner. ${ }^{172}$ \\
\hline $\begin{array}{l}\text { Karlsruhe-Gartenvorstadt } \\
\text { Grünwinkel }\end{array}$ & $\begin{array}{l}\text { Karl-Peters-Str., Lettow-Vorbeck-Str., } \\
\text { Lüderitzstr., Wissmannstr. }\end{array}$ & $\begin{array}{l}\text { Stadtplan Karlsruhe } \\
\text { (1938), Adressbuch } \\
\text { Karlsruhe (1940 IV). }\end{array}$ \\
\hline $\begin{array}{l}\text { Kiel-Neumühlen- } \\
\text { Dietrichsdorf }\end{array}$ & $\begin{array}{l}\text { Carl-Peters-Str., Lettow-Vorbeck-Str., } \\
\text { Lüderitzstr., Nachtigalstr., Wissmann- } \\
\text { str., Woermannstr. }\end{array}$ & $\begin{array}{l}\text { Stadtplan Kiel (1940), } \\
\text { Adressbuch Kiel (1940 } \\
\text { II), Hilscher (2015). }\end{array}$ \\
\hline Koblenz-Pfaffendorf & $\begin{array}{l}\text { Gustav-Nachtigal-Str., Karl-Peters-Str., } \\
\text { Lüderitzstr., Wissmannstr., Woermannstr. }\end{array}$ & $\begin{array}{l}\text { Stadtarchiv Koblenz DB } \\
17(2016) .{ }^{173}\end{array}$ \\
\hline $\begin{array}{l}\text { Königsberg i. Pr. bzw. Kö- } \\
\text { nigsberg (Pr.) [Kaliningrad]- } \\
\text { Ratshof und Lawsken }\end{array}$ & $\begin{array}{l}\text { Karl-Peters-Str., Liebertstr., } \\
\text { Leutweinstr., Lüderitzstr., Rohlfsstr., } \\
\text { Woermannstr. }\end{array}$ & $\begin{array}{l}\text { Adressbuch Königsberg } \\
\text { (1941: II). }\end{array}$ \\
\hline
\end{tabular}

172 https://www.lwl.org/westfaelische-geschichte/nstopo/strnam/Kommune_92.html, Abruf am 28/06/2019.

173 https://www.edoweb-rlp.de/resource/edoweb:7003044/data, Abruf am 28/06/2019. 


\begin{tabular}{|c|c|c|}
\hline $\begin{array}{l}\text { Stadt, weitere Infos über } \\
\text { clusterbezogene Verortung }\end{array}$ & $\begin{array}{l}\text { Innerhalb der jeweiligen Cluster ver- } \\
\text { fügte Benennungen }\end{array}$ & Literaturangaben \\
\hline $\begin{array}{l}\text { Landsberg an der Warte } \\
\text { [Gorzów Wielkopolski]- } \\
\text { Zanziner Grund }\end{array}$ & $\begin{array}{l}\text { Lüderitzstr., Nachtigalstr., Petersstr., } \\
\text { Wissmannstr. }\end{array}$ & $\begin{array}{l}\text { Stadtplan Landsberg } \\
\text { an der Warte (nach } \\
\text { 1934). }\end{array}$ \\
\hline Lübeck-Vorwerk & $\begin{array}{l}\text { Karl-Peters-Str., Lettow-Vorbeck-Str., } \\
\text { Lüderitzstr. }\end{array}$ & $\begin{array}{l}\text { Adressbuch Lübeck } \\
\text { (1942 III). }\end{array}$ \\
\hline $\begin{array}{l}\text { Ludwigshafen am Rhein- } \\
\text { (heutige) Niederfeldsiedlung }\end{array}$ & Nachtigalstr., Petersstr., Wissmannstr. & $\begin{array}{l}\text { Adressbuch Ludwigsha- } \\
\text { fen am Rhein (1936 II). }\end{array}$ \\
\hline Mannheim-Rheinau & $\begin{array}{l}\text { Karl-Peters-Str., Gustav-Nachtigal-Str., } \\
\text { Leutweinstr., Lüderitzstr., Wissmannstr. }\end{array}$ & $\begin{array}{l}\text { Straßenverzeichnis im } \\
\text { Stadtplan Mannheim } \\
\text { (1936/37), Marchivum. }{ }^{174}\end{array}$ \\
\hline $\begin{array}{l}\text { Mühlheim an der Ruhr- } \\
\text { Eppinghofen }\end{array}$ & $\begin{array}{l}\text { Dr.-Karl-Peters-Str., Lüderitzstr., Von- } \\
\text { Lettow-Vorbeck-Str. }\end{array}$ & $\begin{array}{l}\text { Adressbuch Mühlheim } \\
\text { an der Ruhr (1940 II), } \\
\text { Meißner (1999). }\end{array}$ \\
\hline Bogenhausen & $\begin{array}{l}\text { Bennigsenstr., Dominikstr., Emin- } \\
\text { Pascha-Platz, Gröbenstr., Karl-Peters- } \\
\text { Str., Leutweinstr., Lüderitzstr., Nettel- } \\
\text { beckstr., Rohlfsstr., Wissmannstr. }\end{array}$ & $\begin{array}{l}\text { Adressbuch München } \\
\text { (1941: IV). }\end{array}$ \\
\hline $\begin{array}{l}\text { Neustadt an der Haardt bzw. } \\
\text { Weinstraße-Westen }{ }^{175}\end{array}$ & $\begin{array}{l}\text { Gustav-Nachtigal-Str., Karl-Peters-Str., } \\
\text { Lüderitzstr., Von-Wissmann-Str. }\end{array}$ & $\begin{array}{l}\text { Stadtplan Neustadt an } \\
\text { der Weinstraße (1957). }\end{array}$ \\
\hline Raver & $\begin{array}{l}\text { Gustav-Nachtigal-Weg, Lüderitzweg, } \\
\text { Petersweg }\end{array}$ & $\begin{array}{l}\text { StadtA RV Al } 2187, \\
2186, \text { Al } 2068 .\end{array}$ \\
\hline Recklinghausen-Suderwich & $\begin{array}{l}\text { Karl-Peters-Str., Gustav-Nachtigal-Str., } \\
\text { Lettow-Vorbeck-Str., Lüderitzstr., Von- } \\
\text { Wissmann-Str. }\end{array}$ & Weidner. ${ }^{176}$ \\
\hline Riesa-Merzdorf & $\begin{array}{l}\text { Dr.-Karl-Peters-Str., Dr.-Nachtigal-Str., } \\
\text { Lüderitzstr. }\end{array}$ & Stadtplan Riesa (1937). \\
\hline $\begin{array}{l}\text { Völklingen-Rammelter } \\
\text { Schacht }\end{array}$ & $\begin{array}{l}\text { Karl-Peters-Str., Lettow-Vorbeck-Str., } \\
\text { Lüderitzstr., Nachtigalstr., Wissmannstr. }\end{array}$ & $\begin{array}{l}\text { StadtA A2701, Isberner } \\
\text { und Kesternich (2012). }\end{array}$ \\
\hline Wolfenbüttel-Drei Linden & $\begin{array}{l}\text { Karl-Peters-Str., Lüderitzstr., Wiss- } \\
\text { mannstr. }\end{array}$ & $\begin{array}{l}\text { Adressbuch Wolfenbüt- } \\
\text { tel (1937 IV). }\end{array}$ \\
\hline
\end{tabular}

Die Verteilung auf die jeweiligen Ortstypen hält sich bei den Vergabepraktiken solcher Namenviertel zweiten Typs mit durchschnittlich vier bis fünf Benen-

174 https://www.marchivum.de/de/strassennamen, Abruf am 28/06/2019.

175 Die Frage, inwieweit bereits in nationalsozialistischer Zeit vom „Afrikaviertel“ (http://sm. geoview.info/neustadt_adweinstrasse_vom_afrika_viertel_aus_gesehen,6921403p, Abruf am 28/06/2019) in der Öffentlichkeit gesprochen wurde, konnte nicht geklärt werden.

176 https://www.lwl.org/westfaelische-geschichte/nstopo/strnam/Kommune_179.html, Abruf am 28/06/2019. 
nungen etwa die Waage: Sie konnten für 14 Groß- und für 13 Mittelstädte erhoben werden. Nur für Hamburg sind zwei Cluster dieses Typs festzustellen. Cluster mit nur drei Benennungen sind sowohl für Groß- als auch Mittelstädte zu konstatieren. Groß angelegte Namenviertel mit sechs und mehr deanthroponymischen Konstruktionen konnten dagegen ausschließlich für Großstädte (wie Bremen, Düsseldorf, Kiel, Königsberg in Pr. bzw. Königsberg (Pr.) [Kaliningrad] und München) erhoben werden.

Für den Bestand der mit drei und vier deanthroponymischen Benennungen verfügten Cluster sind prototypische Modifikator-Konstruktionen festzustellen, die sich mit den drei hochfrequenten anthroponymischen MOD-Types des erstellten Gesamtinventars decken (Diagramm 1, Kap. 6.3.1): So sollten bspw. die Benennungen Karl-Peters-, Lüderitz- und Wißmannstraße in der neu gegründeten Siedlung Drei Linden südöstlich der Wolfenbütteler Kernstadt genauso wie die SN-Token in Bautzen-Thrombergsiedlung und Bochum-Ehrenfeld in kommemorativer Intention auf die Kolonialakteure Carl Peters, Hermann von Wissmann und Adolf Lüderitz referieren:

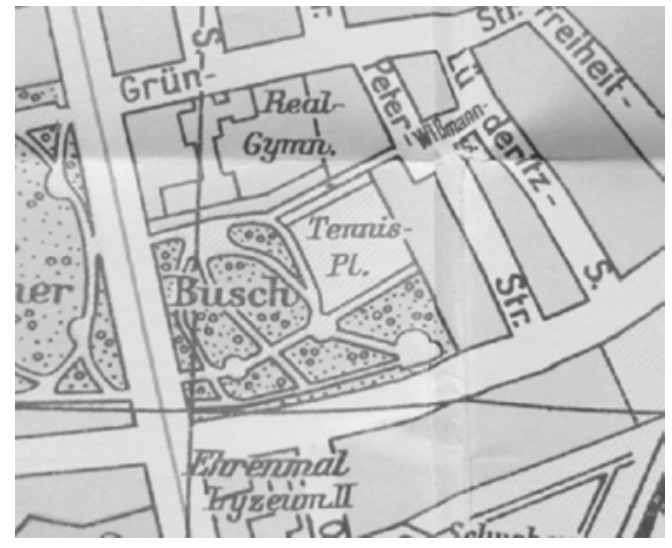

„Lüderitzstraße [...] Nach dem Begründer der deutschen Kolonie Deutsch-Südwestafrika [...].“ (Adressbuch Bochum 1924/25 IV: 115)

„Petersstraße [...] Nach dem Afrikaforscher Karl Peters [...].“ (Adressbuch Bochum 1924/25 IV: 136)

„Wißmannstraße [...] Nach dem Afrikaforscher Hermann von Wißmann [...].“ (Adressbuch Bochum 1924/25 IV: 184)

Abb. 26: Stadtplan Bochum (1938), Ausschnitt Ehrenfeld.

Bis auf eine Ausnahme sind für alle weiteren Cluster dieses zweiten Typs mit drei oder vier verfügten SN-Token die hochfrequenten MOD-Types Peters, Lüderitz, Wissmann, Nachtigal und Lettow-Vorbeck festzustellen. Nur für das in den aneinandergrenzenden Hamburger Stadtteilen Hamm und Horn verfügte Cluster mit vier deanthroponymischen Konstruktionen ist neben usuellen Konstruktionen das SN-Token Theodor-Weber-Reihe herauszustellen, dessen MOD-Type keine ortsübergreifende Verwendung fand. Folgende Auszüge aus historischen 
Straßenverzeichnissen zeigen koloniale Benennungsmotiviken für alle vier Namenvergaben auf:

Wissmannsweg (Hamm u. Horn). [...] benannt nach Hermann Wissmann [...] dem berühmten Afrikaforscher und Kolonialbeamten. (Adressbuch Hamburg 1943 IV: 900)

Carl-Peters-Weg (Horn) [...] benannt nach Dr. Carl Peters [...] dem hart umstrittenen genialen Kolonialpionier u. Reichskommissar in Ostafrika. (Adressbuch Hamburg 1935 IV: 164)

Emin-Pascha-Straße (Hamm und Horn) [...] Emin Pascha oder Eduard Schnitzer (18401892) ist als Afrikaforscher, Arzt und ägyptischer Regierungs-Beamter bekannt geworden. Ben. 1929. (Adressbuch Hamburg 1935 IV: 233)

Theodor-Weber-Reihe. (Horn) [...] benannt nach Theodor Weber (1844-1889) wirkte seit 1862 als Vertreter von J. C. Godeffroy und deutscher Konsul bahnbrechend auf den Samoa-, Fidschi- und Tongainseln. (Adressbuch Hamburg 1935 IV: 835)

Für den Bestand an Kolonialclustern zweiten Typs ist eine Art Attraktivitätsskala personenbezogener Kommemoration festzustellen: Die Kolonialakteure Carl Peters, Adolf Lüderitz, Hermann von Wissmann, Gustav Nachtigal und Paul von Lettow-Vorbeck sollten ortsübergreifend durch entsprechende Namenmuster für in unmittelbarer Nähe zueinander liegende Straßenzüge im öffentlichen (Alltags-)Raum geehrt und/oder gewürdigt werden. Bis 1945 stellen sie das personelle Zentrum von solchen gebündelten Fixierungspraktiken dar. Für Cluster mit einer großen Zahl an zu benennenden Straßenzügen in thematischer Kohärenz wurden neben solchen prototypischen Konstruktionen weitere Namen mit singulären anthroponymischen Modifikator-Konstruktionen verfügt. Dazu sind bspw. die Großcluster in Düsseldorf-Golzheim bzw. -Urdenbach zu zählen, für die neben usuellen Namenmustern auch Benennungen mit den ModifikatorKonstruktionen Meyer-Waldeck, Soden und Solf herauszustellen sind. Wenngleich es sich bei allen drei Personen um Kolonialakteure des Kaiserreichs handelt, erschienen sie als ortsübergreifend-nationale Namenmuster unattraktiv. Alfred Meyer-Waldeck wurde erst gegen Ende der Kolonialzeit zum Gouverneur von Kiautschou ernannt (vgl. Schnee 1920 II: 554). Eine etwaige ortsübergreifende Ehrung und/oder Würdigung von Wilhelm Solf und Julius Freiherr von Soden nach 1933 war schon aufgrund der ablehnenden Haltung der beiden Personen gegenüber Hitler und der NSDAP undenkbar (vgl. Erbar 2010: 549550). Solchen einzelortsbezogenen Namen, die innerhalb von groß angelegten Kolonialclustern neben usuellen Konstruktionen mitverfügt wurden, ist damit vorrangig eine auffüllende Funktion der noch zu benennenden Straßenzüge in thematischer Kohärenz zuzuschreiben.

Prototypisches Beispiel stellt das in München-Bogenhausen verfügte Kolonialcluster mit zehn deanthroponymischen SN-Token dar. Über die usuellen 
Namenmuster hinaus (Karl-Peters-, Leutwein-, Lüderitz-, Rohlfs- und Wißmannstraße) wurden weitere ortsbezogene Kommemorationen vorgenommen. Den Personen wurde durch entsprechende Benennungsmotiviken ein unmittelbarer und mittelbarer Verdienst an der deutschen Kolonialepoche zugesprochen:

Bennigsenstraße: Rudolf v. Bennigsen, 1. Gouverneur von Deutsch-Neuguinea. (Adressbuch München 1940 IV: 113)

Dominikstraße: Hans Dominik, verdient um die Erforschung und Befriedung der deutschen Kolonie Kamerun (1893-1910). (Adressbuch München 1940 IV: 168)

Emin-Pascha-Platz: Emin Pascha (Eduard Schnitzer), Afrikaforscher u. Arzt, hißt als Leiter einer Expedition z. Viktoriasee am 4.8.1890 in Tabora d. deutsche Flagge. (Adressbuch München 1940 IV: 187)

Gröbenstraße: Major Otto Friedrich von der Gröben gründete am 1.1.1683 die brandenburgische Festung Groß-Friedrichsburg an der afrikanischen Goldküste. (Adressbuch München 1940 IV: 265)

Nettelbeckstraße: Joachim Nettelbeck, Seefahrer, organisierte mit Schill und Gneisenau erfolgreich die Verteidigung der von den Franzosen 1806 belagerten Festung Kolberg; er weist als einer der ersten auf die Notwendigkeit hin, Kolonien zur Stützung der Landmacht zu erwerben. (Adressbuch München 1940 IV: 454) 177 $^{17}$

\section{c. Cluster mit toponymischen, anthroponymischen und ggf. weiteren MOD- Types (Typ 3)}

Cluster des dritten Typs weisen toponymische, anthroponymische und ggf. weitere Modifikator-Konstruktionen auf. Die rein quantitativ groß angelegten Cluster, die zwischen 1884 und 1945 mit durchschnittlich neun Benennungen in den öffentlichen Raum des Deutschen Reichs fixiert wurden, werden ebenfalls tabellarisch unter Angabe der Stadt und ihrer näheren Verortung dargelegt.

Tab. 33: Großcluster mit toponymischen, anthroponymischen und ggf. weiteren MOD-Types.

\begin{tabular}{lll}
\hline $\begin{array}{l}\text { Stadt, weitere Infos über } \\
\text { clusterbezogene Verortung }\end{array}$ & $\begin{array}{l}\text { Innerhalb der jeweiligen Cluster } \\
\text { verfügte Benennungen }\end{array}$ & Literaturangaben \\
\hline Berlin-Dahlem & Iltisstr., Lansstr., Takustr. & $\begin{array}{l}\text { Adressbuch Berlin (1921 V), } \\
\text { Honold (2003). }\end{array}$ \\
Berlin-Wedding & $\begin{array}{l}\text { Afrikanische Str., Damarastr., } \\
\text { Dualastr., Guineastr., Kameruner } \\
\text { Str., Kiautschoustr., Kongostr., }\end{array}$ & $\begin{array}{l}\text { Adressbuch Berlin (1942 } \\
\text { IV), Honold (2003). }\end{array}$ \\
\hline
\end{tabular}

177 Man vgl. dazu Kap. 3.4.3. 


\begin{tabular}{|c|c|c|}
\hline $\begin{array}{l}\text { Stadt, weitere Infos über } \\
\text { clusterbezogene Verortung }\end{array}$ & $\begin{array}{l}\text { Innerhalb der jeweiligen Cluster } \\
\text { verfügte Benennungen }\end{array}$ & Literaturangaben \\
\hline & $\begin{array}{l}\text { Lüderitzstr., Mohasistr., } \\
\text { Nachtigalplatz, Otavistr., Pekinger } \\
\text { Platz, Petersallee, Sambesistr., } \\
\text { Samoastr., Sansibarstr., Senegal- } \\
\text { str., Swakopmunder Str., Tangastr., } \\
\text { Togostr., Transvaalstr., Ugandastr., } \\
\text { Usambarastr., Windhuker Str. }\end{array}$ & \\
\hline Braunschweig-Querum & $\begin{array}{l}\text { Albert-Voigts-Weg, Carl-Peters-Str., } \\
\text { Hermann-Blumenau-Str., Kamerun- } \\
\text { str., Lettow-Vorbeck-Str., } \\
\text { Lüderitzstr., Otto-Finsch-Str., } \\
\text { Swakopmunder Str., Togoweg, } \\
\text { Windhuker Str., Wissmannstr. }\end{array}$ & $\begin{array}{l}\text { Adressbuch Braunschweig } \\
\text { (1940 III). }\end{array}$ \\
\hline Breslau [Wroctaw]-Mochbern & $\begin{array}{l}\text { Apiastr., Dualastr., Heinrich- } \\
\text { Schnee-Str., Karl-Peters-Str., } \\
\text { Lettow-Vorbeck-Str., Lüderitzstr., } \\
\text { Samoastr., Tangastr., Togostr., } \\
\text { Windhukstr., Wissmannstr. }\end{array}$ & $\begin{array}{l}\text { Stadtplan Breslau (etwa } \\
\text { 1941), Adressbuch Breslau } \\
\text { (1943 II). }\end{array}$ \\
\hline Cuxhaven-Döse & $\begin{array}{l}\text { Carsten-Niebuhr-Str., Lettow- } \\
\text { Vorbeck-Str., Leutweinstr., } \\
\text { Lüderitzstr., Tsingtaustr., Wiss- } \\
\text { mannstr. }\end{array}$ & $\begin{array}{l}\text { Adressbuch Cuxhaven } \\
\text { (1939 III). }\end{array}$ \\
\hline $\begin{array}{l}\text { Dresden-Räcknitz/ } \\
\text { Zschertnitz }\end{array}$ & $\begin{array}{l}\text { Godeffroystr., Karl-Peters-Str., } \\
\text { Leutweinstr., Lüderitzstr., } \\
\text { Nachtigalstr., Rohlfsstr., } \\
\text { Swakopmunder Str., Windhuker } \\
\text { Str., Wissmannstr., Woermannstr. }\end{array}$ & $\begin{array}{l}\text { Stadtplan Dresden (1939), } \\
\text { Adressbuch Dresden } \\
(1940 \text { V). }\end{array}$ \\
\hline $\begin{array}{l}\text { Duisburg-Huckingen- } \\
\text { Buchholz }\end{array}$ & $\begin{array}{l}\text { Kameruner Pfad, Kameruner Str., } \\
\text { Lüderitzallee, Otavistr., } \\
\text { Swakopmunder Pfad, } \\
\text { Swakopmunder Str., Windhuker } \\
\text { Pfad, Windhuker Str.. } \\
\text { Waterbergpfad, Waterbergstr. }\end{array}$ & $\begin{array}{l}\text { Stadtplan Duisburg (1940); } \\
\text { Mitteilung im Amtsblatt der } \\
\text { Stadt Duisburg (19.9.1944, } \\
\text { 27.9.1944). }\end{array}$ \\
\hline Essen-Gerschede & $\begin{array}{l}\text { Askaristr., Gustav-Nachtigal-Str., } \\
\text { Hansemannstr., Kamerunstr., Karl- } \\
\text { Peters-Str., Samoastr., Südseestr., } \\
\text { Tangabucht, Windhukweg }\end{array}$ & Stadtplan Essen (1942). \\
\hline $\begin{array}{l}\text { Forst (Lausitz)-Süd } \\
\text { (westlicher Teil) }\end{array}$ & $\begin{array}{l}\text { Karl-Peters-Str., Kamerunstr., } \\
\text { Lüderitzstr., Nachtigalstr., } \\
\text { Swakopmunder Str., Togostr., } \\
\text { Tangastr., Waterbergstr., Wiss- } \\
\text { mannstr., Woermannstr. }\end{array}$ & $\begin{array}{l}\text { Adressbuch Forst (Lausitz) } \\
\text { (1939 III), Stadtplan Forst } \\
\text { (Lausitz) (1940-1945). }\end{array}$ \\
\hline
\end{tabular}




\begin{tabular}{|c|c|c|}
\hline $\begin{array}{l}\text { Stadt, weitere Infos über } \\
\text { clusterbezogene Verortung }\end{array}$ & $\begin{array}{l}\text { Innerhalb der jeweiligen Cluster } \\
\text { verfügte Benennungen }\end{array}$ & Literaturangaben \\
\hline $\begin{array}{l}\text { Frankfurt am Main- } \\
\text { Praunheim }\end{array}$ & $\begin{array}{l}\text { Lettow-Vorbeck-Str., Neuguinea- } \\
\text { weg, Samoaweg, Tangastr., Togo- } \\
\text { weg }\end{array}$ & $\begin{array}{l}\text { Adressbuch Frankfurt am } \\
\text { Main (1941 II). }\end{array}$ \\
\hline $\begin{array}{l}\text { Gleiwitz [Gliwice]-Ratiborer } \\
\text { Vorstadt }\end{array}$ & $\begin{array}{l}\text { Lettow-Vorbeck-Str., Lüderitzstr., } \\
\text { Petersweg, Windhukstr., Wiss- } \\
\text { mannstr. }\end{array}$ & Stadtplan Gleiwitz (1938). \\
\hline Hannover-Badenstedt & $\begin{array}{l}\text { Kamerunstr., Lettow-Vorbeck-Allee, } \\
\text { Ostafrikastr., Rohlfsstr., Woer- } \\
\text { mannstr. }\end{array}$ & $\begin{array}{l}\text { Adressbuch Hannover } \\
\text { (1940 II), Zimmermann } \\
\text { (1992), Hanke (2014). }\end{array}$ \\
\hline Heilbronn-Sontheim & $\begin{array}{l}\text { Guineastr., Kamerunstr., Karl-Peters- } \\
\text { Str., Karolinenweg, Lüderitzstr., } \\
\text { Samoastr., Tangastr., Togostr., } \\
\text { Tsingtauer Str., Windhuker Platz }\end{array}$ & $\begin{array}{l}\text { Adressbuch Heilbronn } \\
\text { (1936), Stadtplan Heil- } \\
\text { bronn (1938). }\end{array}$ \\
\hline $\begin{array}{l}\text { Hindenburg O.S. [Zabrze]- } \\
\text { Mathesdorf }\end{array}$ & Lüderitzstr., Petersstr., Togostr. & $\begin{array}{l}\text { Stadtplan Hindenburg } \\
\text { (1936). }\end{array}$ \\
\hline Kassel-Forstfeld & $\begin{array}{l}\text { Lüderitzstr., Togoplatz, Togostr., } \\
\text { Windhukstr., Wissmannstr., Woer- } \\
\text { mannstr. }\end{array}$ & $\begin{array}{l}\text { Adressbuch Kassel } \\
\text { (1939 III). }\end{array}$ \\
\hline Köln-Nippes & $\begin{array}{l}\text { Carl-Peters-Str., Gustav-Nachtigal- } \\
\text { Str., Kamerunstr., Lüderitzstr., } \\
\text { Tangastr., Togostr. }\end{array}$ & $\begin{array}{l}\text { Adressbuch Köln (1937 IV), } \\
\text { Bechhaus-Gerst (2013). }\end{array}$ \\
\hline Köln-Ehrenfeld & Iltisstr., Lansstr., Takuplatz, Takustr. & $\begin{array}{l}\text { Adressbuch Köln (1937 IV), } \\
\text { Bechhaus-Gerst (2013). }\end{array}$ \\
\hline Leipzig-Anger-Crottendorf & $\begin{array}{l}\text { Lüderitzstr., Swakopmunder Str., } \\
\text { Windhuker Str., Waterbergstr. }\end{array}$ & $\begin{array}{l}\text { Adressbuch Leipzig } \\
\text { (1938 II). }\end{array}$ \\
\hline Magdeburg-Neustädter Feld & $\begin{array}{l}\text { Dualaweg, Daressalamer Weg, Ka- } \\
\text { meruner Weg, Kilimandscharoweg, } \\
\text { Leutweinweg, Lomeweg, } \\
\text { Massaiweg, Swakopmunder Weg, } \\
\text { Tangaweg, Togoweg, Waterberg, } \\
\text { Windhuker Weg, Woermannstr. }\end{array}$ & $\begin{array}{l}\text { Lageplan der Kleinsiedlung } \\
\text { am Milchweg (1938), } \\
\text { Adressbuch Magdeburg } \\
\text { (1940 II). }\end{array}$ \\
\hline Merseburg-Freiimfelde & $\begin{array}{l}\text { Lüderitzstr., Nachtigalweg, Peters- } \\
\text { str., Tangaweg, Togoweg, Windhuk- } \\
\text { weg, Wissmannweg, Woermannstr. }\end{array}$ & $\begin{array}{l}\text { Adressbuch Merseburg } \\
\text { (1940 II), Stadtplan Merse- } \\
\text { burg und Leuna (1947). }\end{array}$ \\
\hline München-28. Stadtbezirk & $\begin{array}{l}\text { Daressalamstr., Kamerunplatz, } \\
\text { Nachtigalplatz, Nachtigalstr., } \\
\text { Sansibarplatz, Samoaplatz, Togo- } \\
\text { str., Tsingtaustr. }\end{array}$ & $\begin{array}{l}\text { Adressbuch München } \\
\text { (1926 II), Stadtplan } \\
\text { München (1933). }\end{array}$ \\
\hline
\end{tabular}




\begin{tabular}{|c|c|c|}
\hline $\begin{array}{l}\text { Stadt, weitere Infos über } \\
\text { clusterbezogene Verortung }\end{array}$ & $\begin{array}{l}\text { Innerhalb der jeweiligen Cluster } \\
\text { verfügte Benennungen }\end{array}$ & Literaturangaben \\
\hline München-Trudering & $\begin{array}{l}\text { Anechostr., Askaripfad, } \\
\text { Daressalamstr., Dualastr., Groß- } \\
\text { friedrichsburger Str., Groß-Nabas- } \\
\text { Str., Iltisstr., Kameruner Str., } \\
\text { Kibostr., Lomeweg, Maerckerstr., } \\
\text { Samoastr., Sansibarstr., } \\
\text { Swakopmunder Str., Taku-Fort-Str., } \\
\text { Tangastr., Togostr., Tsingtauer Str., } \\
\text { Usambarastr., Von-Erkert-Platz, } \\
\text { Von-Erkert-Str., Von-Gravenreuth- } \\
\text { Str., Von-Heydebreck-Str., Von- } \\
\text { Trotha-Str., Waterbergstr., Windhu- } \\
\text { ker Str. }\end{array}$ & $\begin{array}{l}\text { Stadtplan München (1940), } \\
\text { Adressbuch München } \\
\text { (1941 IV). }\end{array}$ \\
\hline $\begin{array}{l}\text { Oranienburg-(heutiges) } \\
\text { Ärzteviertel }\end{array}$ & $\begin{array}{l}\text { Dualastr., Kamerunstr., } \\
\text { Lüderitzstr., Otavistr., } \\
\text { Swakopmunder Str., Taborastr., } \\
\text { Togostr., Transvaalstr., } \\
\text { Windhukstr. }\end{array}$ & $\begin{array}{l}\text { Stadtplan Oranienburg } \\
\text { (1938). }\end{array}$ \\
\hline Stuttgart-Obertürkheim & $\begin{array}{l}\text { Deutsch-Ostafrika-Str., Deutsch- } \\
\text { Südwestafrika-Str., Kameruner } \\
\text { Str., Lüderitzstr., Leutweinstr., } \\
\text { Neuguineastr., Otavistr., Peters- } \\
\text { str., Samoastr., Südseestr., } \\
\text { Togostr., Tangastr., Tsingtauer } \\
\text { Str., Windhuker Str., Wissmannstr. }\end{array}$ & $\begin{array}{l}\text { Adressbuch Stuttgart } \\
\text { (1940 III). }\end{array}$ \\
\hline
\end{tabular}

Die Vergabepraxis von derartigen Großclustern dritten Typs stellt ein weitgehendes Phänomen der Großstädte dar. Bis auf die vier Mittelstädte Cuxhaven (mit zeitlicher Schichtung der SN-Token, Kap. 8.2.2.1), Forst (Lausitz), Heilbronn und Oranienburg konnte die Fixierung solcher Namenviertel ausschließlich für Städte mit über 100.000 Einwohnern erhoben werden. Die folgende Abbildung zeigt einen historischen Stadtplanausschnitt von Heilbronn für ein neu angelegtes Baugebiet in unmittelbarer Nähe zum Neckar auf, in dem in der Mitte der 1930er Jahre entsprechende Namen in nachweislich kolonialer Motivik verfügt wurden. 


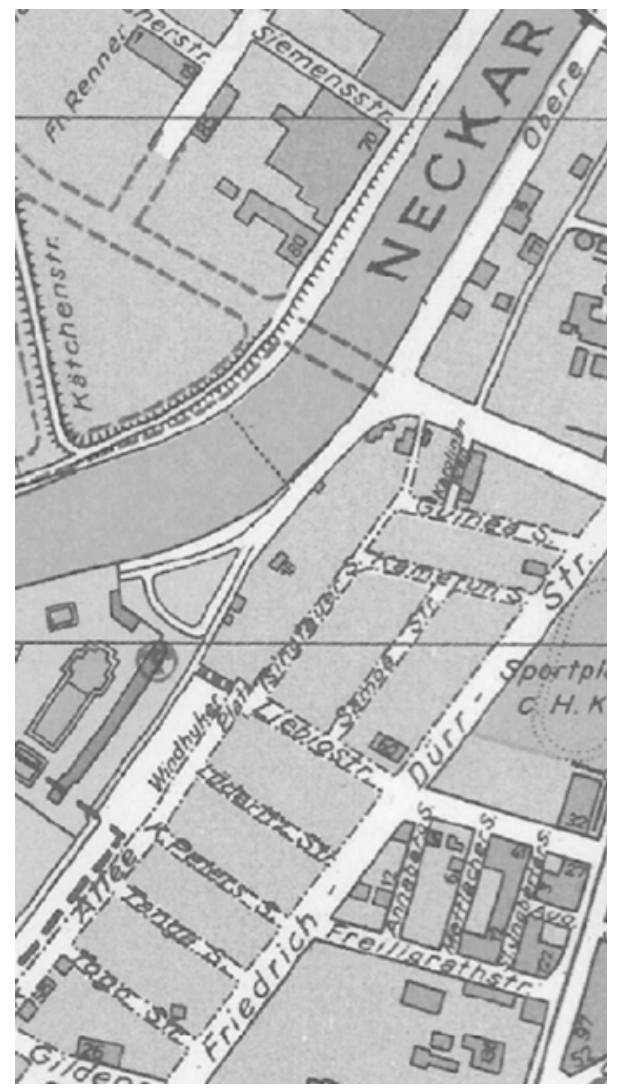

Karolinen Weg: „1936 nach den Karolineninseln in der Südsee, die bis 1919 deutsches Schutzgebiet waren.“ (Adressbuch Heilbronn 1936 III: 78)

Kamerun S.: „1936 nach der ehemaligen deutschen Kolonie Kamerun.“ (Adressbuch Heilbronn 1936 III: 73)

Windhuker Platz: „1936 nach der Hauptstadt des ehemaligen Deutsch-Südwestafrika.“ (Adressbuch Heilbronn 1936 III: 176)

Lüderitz S.: „1936 nach Franz Adolf Eduard Lüderitz (...), dem kaufmännischen Pionier des deutschen Kolonialbesitzes und Gründer der ehemaligen deutschen Kolonie Deutsch-Südwestafrika.“ (Adressbuch Heilbronn1936 III: 98)

K. Peters-S.: „1936 nach dem Afrikaforscher Karl Peters [...], der 1885 die deutsche Kolonie Deutsch-Ostafrika gründete.“ (Adressbuch Heilbronn 1936 III: 73)

Tanga S.: „1936 nach dem Hafen im ehemaligen Deutsch-Ostafrika. In der Schlacht bei Tanga am 4. November 1914 trug die Schutztruppe einen überwältigenden Sieg über einen weit überlegenen Gegner davon.“ (Adressbuch Heilbronn 1936 III: 159)

Togo S.: „1936 nach der ehemaligen deutschen Kolonie Togo.“ (Adressbuch Heilbronn 1936 III: 160) (außerdem: Guinea S., Samoa Str., Tsingtauer S.)

Abb. 27: Stadtplan Heilbronn (1938), Ausschnitt heutiges Ärzteviertel.

Die lexikologisch-onymischen Distributionen der MOD-Types, die für das ortsübergreifende Inventar an Benennungen als Großcluster des dritten Typs ausgemacht werden können, stimmen nur in Teilen mit den aufgezeigten Distributionen des Gesamtinventars (Kap. 7) überein:

Tab. 34: Konstruktionen innerhalb von Clustern (Typ 3).

\begin{tabular}{lll}
\hline Toponyme & Anthroponyme & SchiffsN, Appellativa, Adjektive u. dgl. \\
\hline 135 & 78 & 8 \\
\hline
\end{tabular}


Für Cluster des dritten Typs stellen detoponymische Konstruktionen das numerisch dominante Konstruktionsmuster dar: Mehr als die Hälfte der innerhalb solcher Cluster verfügten Namen referieren in kommemorativer Intention auf den kolonisierten Raum in Übersee. Sie übersteigen zahlenmäßig den Bestand an deanthroponymischen Konstruktionen, die Kolonialakteure ehren und/oder würdigen sollten. Für jene detoponymischen Konstruktionen sind hinsichtlich der jeweiligen Unterklassen folgende Distributionen zu verzeichnen:

Tab. 35: Distributionen toponymischer MOD-Types innerhalb von Clustern (Typ 3).

\begin{tabular}{lllll}
\hline Choronyme & Oikonyme & $\begin{array}{l}\text { Toponyme mit } \\
\text { praxonymischen Anteilen }\end{array}$ & Oronyme & Hydronyme \\
\hline 60 & 48 & 21 & 3 & 3 \\
\hline
\end{tabular}

Neben usuellen Benennungen mit choronymischen und oikonymischen MODTypes sowie die mit praxonymischen Anteilen verfügten detoponymischen Namenverfügungen sind innerhalb von Clustern des dritten Typs auch die für das Gesamtinventar aufgezeigten Einzelbenennungen mit oronymischen und hydronymischen Modifikatoren zu verorten, die sich auf naturräumliche Gegebenheiten im kolonisierten Raum beziehen.

Die betreffenden sechs singulären Modifikator-Konstruktionen Kibo, Kilimandscharo und Usambara bzw. Kongo, Mohasi und Sambesi sind den Kolonialclustern in Magdeburg-Neustädter Feld, München-Trudering und in BerlinWedding zuzuordnen, für die eine überdurchschnittliche Anzahl an kolonial motivierten SN-Token festzustellen ist. So werden bspw. in der Magdeburger Siedlung Am Milchweg am Ende der 1930er Jahre 13 Kolonialismen verfügt (vgl. Lageplan der Kleinsiedlung Milchweg 1938). Für die parallelen und/oder sich unmittelbar kreuzenden Straßen wurden usuelle Namenmuster mit choronymischen, oikonymischen (Duala, Kamerun, Lome, Swakopmund, Togo, Windhuk) sowie anthroponymischen (Leutwein, Wissmann, Woermann) Modifikatoren verfügt. Auch die sich auf Orte der dort stattgefundenen Kampfhandlungen beziehenden Modifikatoren (Tanga, Waterberg) entsprechen dem zeitgenössischen Usus kolonialer Namenvergabepraktiken. Über solche hochfrequenten MODTypes hinaus wurde die singuläre deoronymische Benennung Kilimandscharoweg verfügt, die sich auf den „Vulkanberg K. [d. i. Kilimandscharo] in DeutschOstafrika [...] als höchster Berg Afrikas“ (Schnee 1920 II: 294) bezieht. Und auch der Modifikator der Benennung Massaiweg, die auf die gleichnamige „große hamitische Völkergruppe“ „im nordöstlichen Deutsch-Ostafrika“ (Schnee 1920 II: 
521) referiert, fand eine nur einzelortsbezogene Verwendung innerhalb des Magdeburger Clusters.

Die mit jeweils über 20 SN-Token verfügten Kolonialcluster in BerlinWedding und München-Trudering weisen über usuelle Konstruktionen hinaus nicht nur deoronymische (Kibostraße in München-Trudering, Usambarastraße in Berlin-Wedding und München-Trudering) und dehydronymische (Kongo-, Mohasi- und Sambesistraße) auf, sondern auch weitere singuläre Konstruktionen: So ist bspw. ausschließlich für das Truderinger Cluster die singuläre dechoronymische Konstruktion Großfriedrichsburger Straße festzustellen, die auf die preußisch-brandenburgische Kolonie im heutigen Ghana referiert. Ihr wird im historischen Adressbuch eine Vorreiterrolle des späteren Kolonialerwerbs zugesprochen:

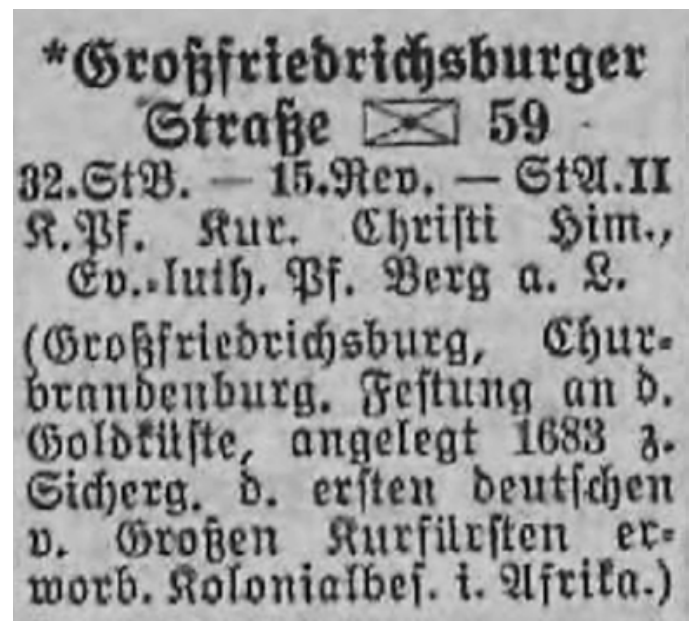

„Großfriedrichsburg, Churbrandenburg. Festung an d. Goldküste, angelegt 1683 z. Sicherg. d. ersten deutschen v. Großen Kurfürsten erworb. Kolonialbes. i. Afrika.“

Abb. 28: Adressbuch München (1941 IV: 256).

Auch die weiteren singulären Modifikator-Konstruktionen Anecho, Groß-Nabas, Maercker, Erkert, Gravenreuth und Heydebreck sind dem Großcluster in München-Trudering zuzuschreiben. Für alle einzelortsbezogenen Konstruktionen werden im zeitgenössischen Einwohnerbuch koloniale Benennungsmotiviken dargelegt:

Anechostraße: Anecho, Ort in Togo. (Adressbuch München 1941 IV: 66)

Groß-Nabas-Straße: Vom 2.-4.1.1905 fand bei Groß-Nabas in Deutsch-Südwestafrika ein Gefecht gegen den Großkapitän der Witboi-Hottentotten statt, an dem die Bayernkompanie hervorragend beteiligt war. (Adressbuch München 1941 IV: 313) 
Von-Maercker-Straße: Generalmajor Maercker, stationiert in Ost- und Südwestafrika, erster Präsident des deutschen Kolonialkriegerbundes. (Adressbuch München 1941 IV: 418)

Von-Erkert-Platz, Von-Erkert-Straße: Friedrich von Erkert, Hauptmann und erster Kamelreiterführer der Schutztruppe der sog. Bayernkompanie (1869-1908). (Adressbuch München 1941 IV: 668)

Von-Gravenreuth-Straße: Freiherr Karl von Gravenreuth, Hauptmann der Schutztruppe Kamerun, hervorgegangen aus dem Inf.-Leib.-Reg. (Adressbuch München 1941 IV: 668)

Von-Heydebreck-Straße: Oberstltn. Joachim von Heydebreck (1861-1914), Kommandeur der Schutztruppe Südwestafrika, siegte über die Engländer bei Sandfontein im September 1914. (Adressbuch München 1941 IV: 669)

Ebenso sind die singulären anthroponymischen Modifikator-Konstruktionen Voigts, Blumenau, Finsch, Niebhuhr und Schnee mit teilweise weiteren regionalbzw. lokalpatriotischen Kommemorationen für Großcluster des dritten Typs zu verorten. Auch Konstruktionen mit den choronymischen MOD-Types Sansibar und Transvaal, die auf Orte kolonialer Imaginationen in der Zeit des Deutschen Reichs referieren, sind auf Kolonialcluster des dritten Typs mit einer überdurchschnittlichen Anzahl an detoponymischen, deanthroponymischen und ggf. weiteren Namen beschränkt.

Damit ist auch für die Kolonialcluster dritten Typs eine Attraktivitätsskala orts-, personenbezogener und ggf. weiterer Kommemoration zu konstatieren. Neben usuellen Namenmustern werden innerhalb von Namenvierteln mit einer Vielzahl an $\mathrm{zu}$ benennenden Straßenzügen singuläre Konstruktionen mit oronymischen, hydronymischen, anthroponymischen und ggf. weiteren MODToken mitverfügt. Ihnen ist ebenfalls eine auffüllende Funktion der noch zu benennenden Straßenzüge in thematischer Kohärenz zuzuschreiben, der insbesondere am Beispiel von Kolonialclustern mit zeitlich gestaffelten Benennungen verdeutlicht werden kann: So ist für Berlin-Wedding festzustellen, dass die usuellen Namenmuster mit den MOD-Types Swakopmund, Nachtigal, Windhuk, Otavi, Duala, Tanga $\mathrm{u}$. dgl. in die faktische Kolonialepoche und in die Zwischenkriegszeit fallen, während Konstruktionen mit singulären MOD-Types (Sambesi, Senegal, Uganda, Mohasi, Damara, Usambara u. dgl.) erst Ende der 1920er und 1930er Jahre im Zuge der weiteren Erschließung des Baulandes verfügt wurden.

Nur für das groß angelegte „Kolonialviertel“ (Oberbürgermeister Braunschweig 18.01.1940) am Ende der 1930er Jahre in der Braunschweiger Neubausiedlung Wabenkamp in Querum sind davon abweichende Intentionen festzustellen: Die Namenmuster Carl-Peters-Straße, Kamerunstraße, Lettow-VorbeckStraße, Lüderitzstraße, Swakopmunder Straße, Togoweg, Windhuker Straße und Wissmannstraße wurden im November 1939 verfügt. Die ursprünglichen weiteren Namenvorschläge Tsingtauer Straße, Samoastraße und Guineastraße mit 
usuellen toponymischen MOD-Types wurden dagegen nicht genehmigt. Stattdessen wurden die drei deanthroponymischen SN-Token Albert-Voigts-Weg, Hermann-Blumenau-Straße und Otto-Finsch-Straße verfügt, die Kolonialakteure ehren und/oder würdigen sollten und zugleich einen lokalen Bezug zur Stadt Braunschweig aufweisen (Kap. 7.3.1). In der „Zusammenfassung der Beigeordnetensitzung vom 17.11.1939 zur Straßennamensgebung in Braunschweig“ findet sich dazu folgender Vermerk „Für die unter Ziff. 4, 5, und 6 aufgeführten Namen sind andere Straßenbezeichnungen zu wählen, bei denen vor allen Dingen in der kolonialen Geschichte bekannte Braunschweiger berücksichtigt werden sollen“.

Für Cluster solchen dritten Typs sind darüber hinaus quantitative Abweichungen usueller anthroponymischer Modifikator-Konstruktionen herauszustellen: Während diese im ortsübergreifend-inventarbezogenen Zugriff in der Verbindung gängiger Klassifikatoren als hochfrequente deanthroponymische Namenmuster herausgestellt wurden (Diagramm 1), fällt die Anzahl an entsprechenden Konstruktionen innerhalb solcher Namenviertel auffällig gering aus:

Tab. 36: Distributionen anthroponymischer MOD-Types innerhalb von Clustern (Typ 3).

\begin{tabular}{lllll}
\hline Lüderitz & Peters & Wissmann & Nachtigal & Lettow-Vorbeck \\
\hline 16 & 12 & 9 & 8 & 6 \\
\hline
\end{tabular}

Für 16 der 24 Cluster sind entsprechende Benennungen zu konstatieren, die Adolf Lüderitz ehren und/oder würdigen sollten. „Kaufmann [...] Gründer der deutschen Kolonie Deutsch-Südwestafrika. Ertrank auf einer Forschungsfahrt 1886 an der Mündung des Oranje-Flusses“ (Adressbuch Köln 1937 II: 447). Auffällig ist dagegen die kleine Zahl an Benennungen innerhalb des Clusters des dritten Typs, die auf die Kolonialakteure Carl Peters, Hermann von Wissmann, Gustav Nachtigal und Paul von Lettow-Vorbeck referieren. Solche ortsübergreifend zu konstatierenden Divergenzen sind nicht gänzlich mit den in einigen Orten neben Kolonialclustern verfügten deanthroponymischen Einzelbenennungen zu erklären, deren MOD-Types in solchen etwaigen Fällen für Konstruktionen in den jeweiligen Namenvierteln nicht mehr zur Verfügung standen (Tab. 25); nur für Einzelorte wie bspw. Berlin (Wissmannstraße), Düsseldorf (Wissmannstraße), Köln (Lettow-Vorbeck-Straße), Heilbronn (Lettow-Vorbeck-Straße) und Leipzig (Wissmannstraße) kann festgestellt werden, dass die zuvor aufgezeigten anthroponymischen MOD-Types bereits durch entsprechende Einzelbenennungen in die jeweiligen städtischen (Alltags-)Räume verfügt wurden. Für 
die weiteren betreffenden Städte ist dies jedoch nicht der Fall. Dieses Ergebnis bestätigt weiterhin die Hypothese, dass gerade die Kolonialakteure Carl Peters und Paul von Lettow-Vorbeck in nationalsozialistischer Zeit desemantisiert wurden. Mit den als Großcluster mit toponymischen, anthroponymischen und ggf. weiteren Modifikatoren verfügten kolonialen Namenvergabepraktiken zielte die zeitgenössische Administration nicht vorrangig auf die Kommemoration eben jener Personen als spezifische Kolonialakteure ab; sie wurden - das zeigen auch entsprechende Fälle, in denen derartige Konstruktionen als Einzelbenennungen mit weiteren die deutschen Militärs $\mathrm{zu}$ ehrenden und/oder würdigenden Namen für Straßenzüge in nächster Nähe verfügt wurden (Kap. 8.1.2) nicht mehr ausschließlich in den spezifisch kolonialen Kontext als ,Kolonialhelden' verortet, sondern zum Teil als ,deutsche Helden' vergangener Kaiserreichzeiten und/oder im Ersten Weltkriegs (um-)stilisiert.

\subsubsection{Ergebnisse: Strukturmuster und Diskursfunktionen kolonialer Clusterbenennung}

Die themenkohärente Benennung von Straßenzügen für parallele, sich kreuzende und/oder in unmittelbarer räumlicher Nähe zueinander liegende Straßenzüge stellt ein von Seiten der neuzeitlichen Administration erwünschtes und praktiziertes Muster dar, mit dem die Straßen ganzer Stadtviertel thematisch gebündelt werden können. Solche Vergabepraktiken führen zum Aufbau themenkohärenter Cluster. Auch die in vorliegender Arbeit untersuchten kolonial motivierten Straßennamen wurden vorrangig in der Form von groß angelegten Namenvierteln mit drei und mehr Benennungen verfügt. Dabei konnten durch die Sichtung zeitgenössischer Stadtpläne, Straßenverzeichnisse u. dgl. 60 Kolonialcluster für Groß- und Mittelstädte erhoben werden. Die administrative Praxis der gebündelten Verfügung kolonialer Straßennamen als „Kolonialviertel“ (Winzer 1907/10: 2) wurde von den jeweiligen städtischen Administrationen ${ }^{178}$ angestrebt und kann einzelortsbezogen auch in zeitgenössischen Quellen für

178 Man vgl. dazu auch die Anmerkung des Bürgermeisters in Völklingen am 22.12.1938: „Die Stadtverwaltung beabsichtigt dem Herrn Polizeipräsidenten folgende Strassenbezeichnungen vorzuschlagen [...] 3.) Siedlung Rammelter Schacht. Hier handelt es sich um die Benennung von 4 Strassen. [...] Nachdem der erste Bauabschnitt mit Lüderitzstrasse bereits die Bezeichnug [sic!] eines Kolonialpioniers erhalten, sollen die übrigen Strassen ebenfalls Namen von um die Kolonialgeschichte verdienten Männern erhalten [...]“ (StadtA A Nr. 2701). Auch in der „Zusammenfassung der Beigeordnetensitzung vom 17.11.1939 zur Straßennamensgebung in Braunschweig“ ist vom „Kolonial-viertel-Wabenkamp“ die Rede. 
die Kolonialbewegung nachgewiesen werden. ${ }^{179}$ Koloniale Clusterbenennung ist hinsichtlich der damit intendierten zeitgenössischen Kommemorationen als „ein probates Mittel im kolonialen und postkolonialen Diskurs“ (Stolz und Warnke 2015: 111) zu beschreiben: „Sie ist effektives Werkzeug der Administration zur Sichtbarmachung kolonialzeitlicher und/oder kolonialzeitbezogener Machtverhältnisse [...]“ (Ebert 2018: 112). Die gebündelte Fixierung kolonialer Kommemoration im öffentlichen Raum stellt diesen als eindeutigen Ort symbolischer Raumaneignung heraus, ihm ist eine eindeutig deklarative Funktion zuzusprechen (vgl. Busse und Warnke 2014: 527).

Mithilfe der drei strukturellen Prototypen an Kolonialclustern sollten in ortsübergreifend-nationaler Perspektive folgende kolonisatorische Gewissheiten in den öffentlichen (Alltags-)Raum fixiert werden:

- Typ 1: Ehrung und/oder Würdigung der kolonisierten Räume

- Typ 2: Ehrung und/oder Würdigung der Kolonialakteure

- Typ 3: Ehrung und/oder Würdigung der kolonisierten Räume, der Kolonialakteure und ggf. Weiteres

Für die jeweiligen Typen konnten eindeutige Distributionen festgestellt werden: Die gebündelte Kommemoration der in der Kaiserzeit kolonisierten Räume (Typ 1) beschränkt sich auf wenige städtische Viertel. Mit jeweils 30 bzw. 24 Cluster stellen Kolonialviertel des zweiten und dritten Typs das ortsübergreifendnationale Muster kolonialer Fixierungspraktiken dar, mit denen die (diskursiv-) funktionalen Parameter Personalität (Typ 2) bzw. Personalität, Lokalität und ggf. Weiteres (Typ 3) im (Alltags-)Raum der deutschen Gesellschaft versprachlicht werden sollten. Die ortsbezogenen Cluster mit ausschließlicher Kommemoration der kolonisierten Gebiete (Typ 1) sind als ein Phänomen nach der de facto-Kolonialzeit zu beschreiben: Die Namenvergaben finden allesamt erst nach der faktischen Kolonialzeit statt. Sie werden entweder zeitgleich in der Zwischenkriegszeit (Hamburg-Kleiner Grasbrook), in nationalsozialistischer Zeit (Gelsenkirchen-Hüllen und Bismarck, Hamburg-Ottensen, Hamburg-Rahlstedt, Stettin [Szczecin]-Braunsfelde) oder in diachronen Staffelungen in den 1920er und 1930er Jahren (Bremen-Oslebshausen) verfügt. Die ortsübergreifend-

179 So schlug der Chemnitzer Kreisverband (27.8.1936) bspw. die Tilgung der SN-Token Rosenstraße und Rosenplatz von zwei sich kreuzenden Straßenzügen am Chemnitzer Südbahnhof (vgl. Stadtplan Chemnitz 1920) zur Verfügung der kolonial motivierten Benennungen Tangaplatz und Lettow-Vorbeck-Straße vor. Jenes vorgeschlagene Kleincluster sollte, auch wenn es nicht zur administrativen Namenvergabe kam, offenbar die aus zeitgenössischer Sicht heldenhafte Verteidigung der gleichnamigen Stadt und dessen militärischen Anführer gegen alliierte Truppen im Ersten Weltkrieg ehren und/oder würdigen. 
nationale Ehrung und/oder Würdigung von Kolonialakteuren durch entsprechend gebündelte deanthroponymische Benennungen (Тyp 2) in einer vergleichbaren Anzahl an Groß- und Mittelstädten findet maßgeblich in nationalsozialistischer Zeit statt: Ausschließlich die zeitgleich in Bremen-Waller Vorstadt und Bochum-Ehrenfeld verfügten deanthroponymischen Benennungen sind noch in die Kaiserzeit bzw. in die unmittelbare Nachkriegszeit zu verorten. Alle weiteren Clusterverfügungen erfolgten im Nationalsozialismus. Auch die überdurchschnittlich groß angelegten Cluster dritten Typs, deren Benennungen kolonisierte Räume, Kolonialakteure und ggf. Weiteres (Typ 3) ehren und/oder würdigen sollten, wurden maßgeblich nach 1933 verfügt. Obgleich also auch der dritte Clustertyp als ein ortsübergreifend-nationales Phänomen des Nationalsozialismus beschrieben werden kann, ist zumindest eine nennenswerte Anzahl an Namenverfügungen für den Zeitraum der faktischen Kolonialepoche herauszustellen. Die Clusterverfügungen in Berlin-Dahlem und Köln-Ehrenfeld erfolgten noch vor Beginn des Ersten Weltkriegs. Auch für die in diachronen Staffelungen verfügten Kolonialcluster in Vierteln neu aufzuschließender Peripheriebereiche der Großstädte Berlin, Leipzig und Dresden sind bereits bis 1919 drei und mehr als drei detoponymische und/oder deanthroponymische Namen zu konstatieren, die in den 1920er und/oder 1930er Jahren durch weitere kolonialzeitbezogene Namen für Straßenzüge in unmittelbarer Nähe erweitert wurden. Überhaupt beschränken sich Kolonialcluster des dritten Typs mit einer Vielzahl an Benennungen weitestgehend auf Großstädte, in denen neben usuellen Namenmustern auch singuläre Konstruktionen verfügt wurden, die als eine Art Auffüllmaße beschrieben wurden. Jene Auffüllmaße folgte je nach Ort unterschiedlichen Vorlieben. So ist bspw. für die in MünchenTrudering und Braunschweig-Querum verfügten Großcluster festzustellen, dass neben usuellen Namenmustern singuläre deanthropoynymische Benennungen mitverfügt wurden, die weitere Kolonialakteure mit spezifisch lokalen Bezügen ehren und/oder würdigen sollten. Auch einzelne dehydronymische und deoronymische Konstruktionen konnten innerhalb solcher Großcluster herausgestellt werden. Zusammenfassend kann festgehalten werden, dass die für das Gesamtinventar herausgestellten singulären Modifikator-Konstruktionen für diejenigen Kolonialviertel festzustellen sind, die - Selbiges konnte in Einzelfällen bereits für Cluster des ersten und zweiten Typs aufgezeigt werden - eine überdurchschnittliche Anzahl an SN-Token aufweisen. Die innerhalb von Kolonialclustern mitverfügten Einzelphänomene können damit erklärt werden, dass innerhalb solcher aufzuschließender Viertel der städtischen Peripheriebereiche eine offenbar große Anzahl an Straßenzügen angelegt wurden; dementsprechend hoch war auch der Benennungsbedarf an Namen, der hinsichtlich der Motiviken möglichst kohärent ausfallen sollte. 
Neben der Rekonstruktion der mit solchen Fixierungspraktiken versprachlichten Gewissheiten von Seiten der Namengeber ist auch von einer Rezeption kolonialer Benennungen von Seiten der Bewohnerinnen und Bewohner, allein schon durch deren Orientierungsfunktion, auszugehen: „So wirken sie mit bei der Ausformung von Makro- und Mikrobereichen und dienen im urbanen Großraum nicht zuletzt als Leit- und Orientierungssysteme“ (Werner 2008: 68). Es ist $\mathrm{zu}$ vermuten, dass sich die als Großcluster verfügten usuellen Straßennamenvergaben durch die Produktion eben solcher Muster in die unmittelbare Raumdeskription auf die Rezeption jener administrativ intendierten kolonialen Kommemorationen durch die Bewohnerinnen und Bewohner ausgewirkt haben vorausgesetzt, dass der Aspekt der Kommemoration aus sprachhistorischer Perspektive verstanden wurde. Dass sich neben der erleichterten Memorierbarkeit der Namen zu Gunsten der Nutzerinnen und Nutzer (vgl. Heuser 2008: 602) auch die kommemorativen Aspekte durch kolonial motivierte Straßenvergaben innerhalb von themenkohärenten Clustern weiter stabilisieren ließen, ist anzunehmen. Das ist zumindest die Hoffnung derjenigen kolonialen Interessensgruppen, die derartige Benennungsformen zwischen 1884 und 1945 fordern.

Für den ortsbezogenen Fall des in nationalsozialistischer Zeit angelegten kolonialen Großclusters in Magdeburg-Neustädter Feld ist festzustellen, dass die Wahrnehmung der von Seiten der lokalen Administration damit intendierten kommemorativen Funktionen mit weiteren visuellen Formen in der öffentlichen Raumdeskription vorangetrieben werden sollte. Regelungen im Nationalsozialismus zur Beschriftung der Straßennamenschilder zur etwaigen Ausgestaltung der Schilder ließen wenig bis kaum Spielraum zu (vgl. Runderlaß des Reichsministers des Innern und des Preußischen Ministers des Innern 01.11.1934). Die in Roeder (1995: 61, Abb. 50) abgedruckten zeitgenössischen Fotografien aus dem Jahresbericht des Vereins für Kleinwohnungswesen (1938) zeigen, dass die koloniale Kommemoration der jeweiligen Benennungen stattdessen in anderer Form in der unmittelbar visuellen Raumdeskription fixiert wurde: 


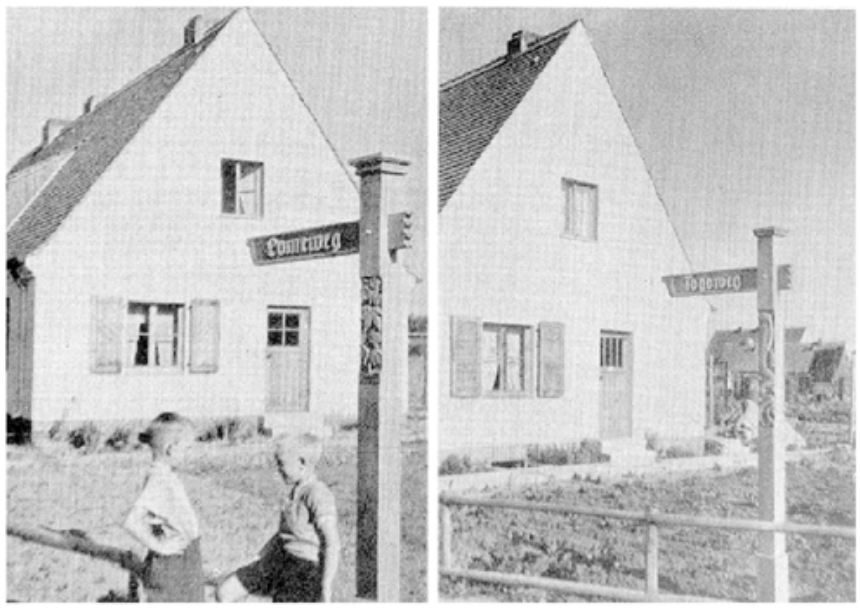

Abb. 29: Lome- und Togoweg in Magdeburg, Neustädter Feld (Milchweg).

Im historischen Jahresbericht wurde an gleicher Stelle zudem Folgendes vermerkt: „Die Straßen in der Kleinsiedlung am Milchweg sind nach unseren Kolonien benannt; dementsprechend wurde die kunsthandwerkliche Ausbildung [Fettdruck im Original] der Wegweiser ausgeführt.“ Die Straßenpfähle aus Holz weisen im oberen Bereich Schnitzarbeiten von Pflanzen und Tieren der kolonisierten Gebiete auf. Für die Benennungen Lome- und Togoweg sind auf den Fotografien bspw. Schnitzereien von Palmen und eine Schlange zu erkennen. Hinweise auf eine etwaige ortsübergreifende Praxis solcher kunsthandwerklichen Ausgestaltungen von Schildern kolonialer Straßennamen liegen nicht vor. ${ }^{180}$ Es konnten keine Hinweise für eine etwaige ortsübergreifende Praxis gefunden werden, in der solche kunsthandwerklichen Ausgestaltungen der kolonial motivierten Benennungen Erwähnung fanden. Daher kann nur vermutet werden, dass es sich bei den für die kolonialen Namenvergabepraktiken in Magdeburg-Neustädter Feld zu konstatierenden Schnitzarbeiten um singuläre Phänomene handelte.

180 Man vgl. dazu das Bildarchiv des Deutschen Dokumentationszentrums für Kunstgeschichte (https://www.bildindex.de/, Abruf am 28/06/2019), in dem unter anderem auch historische Fotografien von Straßenschildern zu finden sind. Die Aufnahmen von kolonial motivierten Straßenbenennungen stammen weitestgehend aus der Zeit nach 1945. Für sie sind keine derartigen kunsthandwerklichen Verzierungen festzustellen. 


\subsubsection{Clusterbezogene Georeferenzierungen}

Dass der Einbezug georeferenzierender Perspektiven der jeweiligen Namenverfügungen durch die Berücksichtigung raumlinguistischer Musterhaftigkeiten weitere Einsichten der mit kolonialen Clustervergabepraktiken versprachlichten Gewissheiten gewähren, wurde in Ebert (2018: 110) am Beispiel der als Großcluster verfügten Namen im Leipziger Stadtteil Anger-Crottendorf dargelegt: Alle vier als Kolonialcluster des dritten Typs (Tab. 33) verfügten Benennungen Lüderitzstraße, Swakopmunder Straße, Waterbergstraße und Windhuker Straße referieren in räumlicher Hinsicht direkt bzw. indirekt auf die Kolonie DeutschSüdwestafrika, die aus Sicht der deutschen Kolonialverwaltung noch bis zum Beginn des Ersten Weltkriegs als die einzig unbestrittene Siedlungskolonie galt (Kap. 7.3.2.2 b) Mit den zwei deoikonymischen und dem (mit praxonymischen Anteilen) verfügten detoponymischen Namen sollten die Verwaltungs- und Handelszentren Swakopmund und Windhuk und der aus Sicht der deutschen Kolonisatoren erfolgreiche Kolonialkrieg gegen die indigenen Bevölkerungsgruppen der Herero und Nama am Waterberg kommemoriert werden. Auch für die deanthroponymische Benennung kann insofern eine indirekte räumliche Bezugnahme auf Deutsch-Südwestafrika festgestellt werden, als dass Adolf Lüderitz an der Inbesitznahme dieser ersten Kolonie maßgeblich beteiligt war. ${ }^{181}$ Für den Teilbestand detoponymischer Benennungen wurde eine maßgebliche Georeferenzierung von Deutsch-Südwestafrika herausgestellt (Diagramm 3), die aufgrund ihres zeitgenössischen Charakters als einzige Siedlungskolonie begründet werden konnte. In einer clusterbezogenen Perspektive stellt die alleinige (direkte und indirekte) Kommemoration Deutsch-Südwestafrikas durch entsprechende gebündelte Namenvergabepraktiken allerdings kein ortsübergreifendes Muster dar. Es sind keine weiteren Kolonialcluster festzustellen, deren Benennungen sich - wie im Leipziger Fall - ausschließlich auf Orte (Typ 1) oder Orte, Personen und ggf. Weiteres (Typ 3) der deutschen Kolonialgeschichte in Deutsch-Südwestafrika beziehen. Nur zwei weitere Cluster des dritten Typs referieren direkt und indirekt auf einen bestimmten kolonisierten Raum: Die sich hinsichtlich ihrer Modifikator-Konstruktionen Taku, Lans und Ittis überschneidenden Clusterverfügungen in Berlin-Dahlem und Köln-Ehrenfeld dienten der Kommemoration der deutschen Beteiligung an der zeitgenössisch als Boxeraufstand titulierten Ostasiatischen Expedition (vgl. Schnee 1920 II: 689)

181 In diesem Zusammenhang ist auch auf die von Rohlfs verfasste Schrift „Angra Pequena. Die erste deutsche Kolonie in Afrika“ (ca. 1885) zu verweisen: Die Publikation verzeichnet nicht nur ein „Bildnis Lüderitz's“ auf dem Titelblatt, sondern enthält maßgebliche biographische Anteile seiner Tätigkeiten in Südwestafrika. Teil der DSDK. 
um die Jahrhundertwende. ${ }^{182}$ Für die beiden Fälle ist damit keine unmittelbare Georeferenzierung auf die Kolonie Kiautschou, wohl aber auf den ostasiatischen Raum zu konstatieren. Für alle weiteren verfügten kolonialen Namenviertel ersten und dritten Typs sind keine räumlichen Bezugnahmen auf nur eine Kolonie festzustellen. Stattdessen ist koloniale Clusterbenennung, deren Namen sich direkt und indirekt auf den kolonisierten Raum in zwei und mehr Kolonialgebieten des Deutschen Reichs beziehen sollten, als ortsübergreifendes Muster erfassbar und hinsichtlich seiner clusterbezogenen kommemorativen Georeferenzierung als weitgehend unspezifisch $\mathrm{zu}$ beschreiben. In diskursfunktionaler Perspektive sollten mit gebündelten kolonial motivierten Namenvergaben nicht die Geschichte einer bestimmen Kolonie versprachlicht werden; vielmehr sollten narrative Muster dieser nur etwa 30 Jahre andauernden Kolonialepoche in den öffentlichen (Alltags-)Raum des Deutschen Reichs fixiert werden, die nicht von spezifischem Wissen über die Geschichte der einzelnen Kolonien abhängig gemacht wurde.

Für über die Hälfte der Kolonialviertel ersten und dritten Typs sind, wenngleich sich die entsprechenden clusterbezogenen Namen auf zwei oder mehrere Kolonien beziehen, dennoch raumbezogene Präferenzen festzustellen: Die sich entweder auf die kolonisierten Gebiete (Typ 1) oder auf die kolonisierten Gebiete, die beteiligten Kolonialakteure und ggf. Weiteres (Typ 3) beziehenden gebündelten Namenvergabepraktiken von 16 Clustern nehmen Kommemorationen der deutschen Kolonialzeit in Afrika vor. Sie wurden im öffentlichen Raum folgender Städte bzw. städtischen Viertel verfügt:

Bremen-Oslebshausen, Dresden-Räcknitz/Zschertnitz, Duisburg-Huckingen-Buchholz, Forst (Lausitz)-Süd (westlicher Teil), Gelsenkirchen-Hüllen und Bismarck, Gleiwitz [Gliwice]Ratiborer Vorstadt, Hamburg-Kleiner Grasbrook, Hamburg-Ottensen, Hamburg-Rahlstedt, Hannover-Badenstedt, Kassel-Forstfeld, Köln-Nippes, Magdeburg-Neustädter Feld, Merseburg-Freiimfelde, Oranienburg-(heutiges) Ärzteviertel, Stettin [Szczecin]-Braunsfelde.

Neben den sechs ausschließlich mit toponymischen Modifikator-Konstruktionen verfügten Kolonialcluster in Bremen, Gelsenkirchen, Hamburg und Stettin [Szczecin] ist eine räumliche Bezugnahme auf die deutsche Kolonialepoche

182 Man vgl. dazu auch Bechhaus-Gerst (2013: 238): „Das „Chinesenviertel“ mit Takuplatz, Lans- und Iltisstraße, erhielt 1902 und 1914 seine Straßennamen. [...] Die drei Straßen bilden ein Ensemble, das an die deutsche Kolonialaggression in China erinnert. [...] Zu den Angreifern gehörte das deutsche Kanonenboot „Iltis“ unter Führung von Kapitän Wilhelm Lans. Der Angriff markiert den Beginn eines blutigen Kolonialkriegs, der in Deutschland als „Niederschlagung des Boxeraufstands“ erinnert wird“. 
in Afrika mittels gebündelter Namenvergabepraktiken für weitere zehn Cluster des dritten Typs als ein ortsübergreifendes Muster herauszustellen. So beschränkt sich bspw. auch das in Duisburg-Huckingen-Buchholz verfügte Kolonialviertel in nationalsozialistischer Zeit auf die Ehrung und/oder Würdigung der deutschen Kolonialepoche auf dem afrikanischen Kontinent. Im Stadtplan von 1942 sind für das Neubauviertel erst fünf der zehn SN-Token verzeichnet.

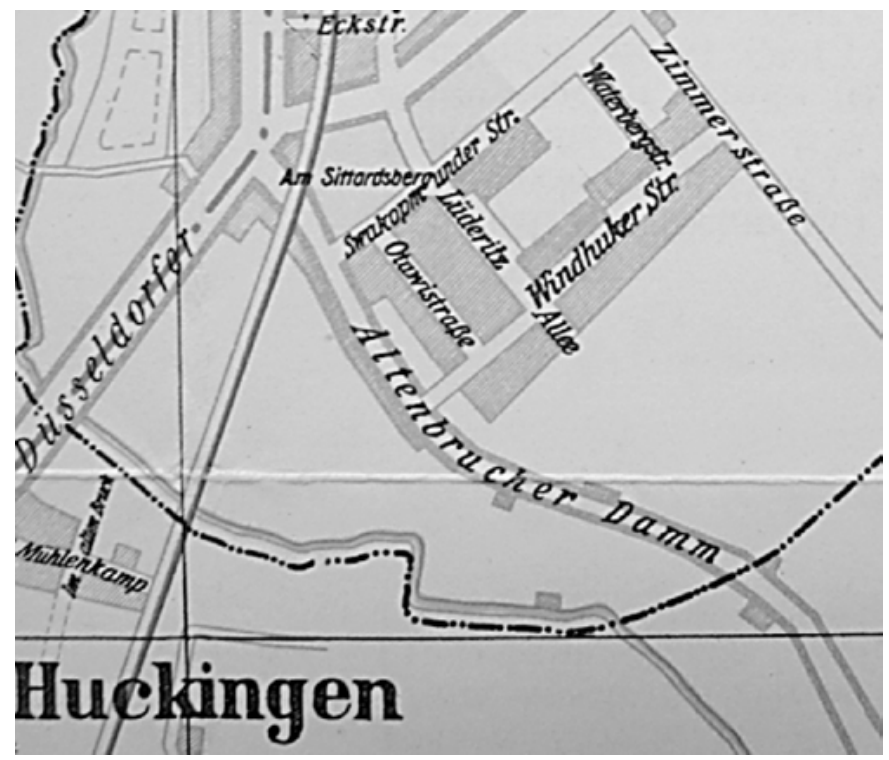

Abb. 30: Stadtplan Duisburg (1942), Ausschnitt Huckingen-Buchholz.

Wie im Leipziger Fall ist bis 1942 ein Cluster zu konstatieren, dessen SN-Token sich auf ausgebaute administrative und/oder wirtschaftlichen Zentren in Deutsch-Südwestafrika (Otawistraße, Swakopmunder Str., Windhuker Str.), auf den Ort des von Seiten der Kolonialmacht unterdrückten Aufstandes der indigenen Bevölkerung (Waterbergstr.) sowie auf Adolf Lüderitz als maßgeblich an der Gründung der Kolonie beteiligten Kolonialakteur (Lüderitz Allee) beziehen sollte. Erst 1944 wurden die weiteren Benennungen Waterbergpfad, Swakopmunder Pfad und Windhuker Pfad sowie Kameruner Straße und Kameruner Pfad für neu errichtete schmale Straßenzüge verfügt (vgl. Mitteilung im Amtsblatt der Stadt Duisburg 19.9.1944, 27.9.1944). Sie führten zu Behelfsbauten für Einwohnerinnen und Einwohner, die durch kriegsbedingte Luftangriffe ihre Wohnungen verloren hatten. 
Das Duisburger Beispiel zeigt, dass erst aufgrund der zeitgenössischen Kriegsumstände eine Clustererweiterung in jüngerer Zeit erfolgte, mit der das ursprüngliche sich auf Orte, Ereignisse und Kolonialakteure in DeutschSüdwestafrika bezogene Namenviertel sodann auch auf Kamerun als weitere Kolonie in Afrika referieren sollte. Im Ergebnis wurden bis 1945 kolonialzeitbezogene Wissenskonzepte der deutschen Kolonialgeschichte in Afrika im öffentlichen (Alltags-)Raum fixiert - eine ursprünglich kommemorativ-raumbezogene Präferenz für Deutsch-Südwestafrika ist für diesen ortsbezogenen Fall dennoch herauszustellen.

Alle innerhalb von Kolonialclustern ersten und zweiten Typs gebündelten Namenvergaben, für die kommemorative Georeferenzierungen auf den kolonisierten Raum in Afrika festzustellen sind, wurden in der Zeit nach der faktischen Kolonialepoche, insbesondere nach der nationalsozialistischen Machtübernahme, verfügt. Dieser Befund ist damit zu erklären, dass sich die kolonialagitatorische Propaganda nach 1919/20 ausschließlich auf Afrika konzentrierte, „nachdem die früheren deutschen Kolonien in der Südsee und in China (Kiautschou) bereits in der Weimarer Zeit aus dem Rückgabekatalog verschwunden waren“ (Gründer 1999: 333). Auch der Kolonialrevisionismus im Nationalsozialismus, vorrangig vertreten durch Propagandaarbeit des RKB, konzentriert sich maßgeblich auf Afrika. Dies wird unter anderem an dem seit 1933 genutzten populären Motiv, das unter anderem vom RKB als Werbemaßnahme zur Mitgliedergewinnung genutzt wurde, deutlich: Der mit Verbzweitstellung als Aufforderung zu verstehende Ausrufesatz „Auch hier liegt deutsches Land!“ und dem Untertitel „Werde Mitglied im Reichskolonialbund“ (vgl. Schöfert 2012: 100-101, 191) ziert ein Motiv, das ausschließlich den afrikanischen Kontinent (mit farblicher Markierung der Kolonialgebiete zur Kaiserzeit) abbildet. Dies zeigt die von Seiten des RKB behauptete Zugehörigkeit der ehemaligen Kolonien Afrikas zur deutschen Metropole, die 1919 an die Mandatsträger des Völkerbundes übergingen. Das in zeitgenössischen Quellen als „Mittelafrika“ (Linne 2008: 7) bezeichnete Kolonialprojekt

sollte [...] nicht nur Kamerun, den französischen Kongo und Deutsch-Ostafrika zusammenschließen, sondern durch eine Vereinbarung über Belgisch-Angola auch DeutschSüdwestafrika mit diesem deutschen mittelafrikanischen Großreich verbinden. Vorstellungen von einem im mittleren Afrika zu schaffenden kolonialen Großreich als einem ,deutschen Indien` in Afrika waren bereits bei der vorkolonialen Propaganda aufgetaucht. (Gründer 1999: 179)

Mit der massiven nationalsozialistischen Propagierung eines solchen mittelafrikanischen Kolonialreichs schloss man an argumentative Muster im vorkolonialen Deutschland an (vgl. Zantop 1999). Damit ist auch die ortsübergreifend- 
nationale Vergabepraxis kolonialzeitbezogener Clusterverfügung nachzuvollziehen, deren Namen direkt und indirekt auf Orte, Ereignisse, Akteure und ggf. Weiteres der afrikanischen Kolonien referieren sollten.

\subsection{Exkurs: Kolonialcluster in Lodz bzw. Litzmannstadt (tódź), Pabianitz [Pabianice] und Königshütte [Chorzów] - fragliche Fälle?}

Koloniale Cluster für Städte der am Ende der 1930er Jahre erfolgten Annexionen sind auf drei singuläre Orte der ehemals polnischen Gebiete beschränkt: Nur für die Städte Lodz bzw. Litzmannstadt [€ódź] und Pabianitz [Pabianice] im von Seiten des Deutschen Reichs eingerichteten Gau Wartheland sowie für Königshütte [Chorzów] in (Ost-)oberschlesien konnten gebündelte Benennungen als groß angelegte Kolonialcluster erhoben werden. Für jene drei koloniale Namenviertel, deren SN-Token in zeitgenössischen Stadtplänen und Adressbüchern zusammengetragen werden konnten, soll diskutiert werden, inwieweit mit den jeweiligen Konstruktionen vergleichbare bzw. anders gelagerte koloniale Gewissheiten versprachlicht werden sollten.

Mit dem Überfall auf Polen wurden die betreffenden drei Städte von nationalsozialistischer Seite besetzt und dem Deutschen Reich gewaltsam eingegliedert. Ziel der NS-Politik gegenüber Polen war unter anderem eine „Entnationalisierung - die Vernichtung eines politischen und kulturellen Eigenlebens [...]“ (Harten 1996: 86). Aus historischen Quellen wird ersichtlich, dass es der nationalsozialistischen Stadtverwaltung vor Ort darum ging, die Vorherrschaft des nationalsozialistischen Deutschen Reichs im öffentlichen Raum mittels der Sprachenwahl sichtbar zu machen. Dieser Prozess ging mit einer aggressiven Marginalisierung des Polnischen einher. Dass sich die NS-Politik dabei auch massiv der Straßennamen bemächtigte, wird in folgendem Auszug aus dem von Seiten des NSDAP-Oberbürgermeisters in Auftrag gegebenen Stadtbuchs für Königshütte ersichtlich:

Eine der wichtigsten Aufgaben der Stadtverwaltung war es, die früher so deutsche Stadt, die in der Polenzeit sehr stark entnationalisiert worden war, wieder zum Deutschtum zurückzuführen. Das konnte zunächst nur in äusserlicher Beziehung geschehen. So wurde die deutsche Sprache als einzige Amtssprache sofort eingeführt. In einer „Anordnung betreffend Strassenbenennung “ forderte der Oberbürgermeister am 12. September die Bevölkerung auf, mit der Umbenennung der Strassen gleichzeitig auch alle polnischen Inschriften an den Häusern und Läden soweit möglich, baldigst durch deutsche zu ersetzen [...]. Zunächst sind 15 Strassen umbenannt worden. Am 16. September folgten die anderen fast 
300 Strassen nach. Die neuen Strassennamen hat Ratsherr Max Muschol in mühevoller Arbeit mit orts- und heimatkundigen Männern zusammengestellt. (Schmidt 1941: 176)

Auch in den polnischen Gebieten, die als „Reichsgau Wartheland“ dem Deutschen Reich angeschlossen wurden, fanden Umbenennungen von polnischen Stadt- und Landkreisnamen sowie von Straßennamen in den Städten statt, bei denen es sich zum Großteil nicht um reine Übersetzungen handelte (vgl. Urban 2006: 52).

Ziel der nationalsozialistischen Besatzer war nicht allein die Schaffung eines von Deutschen bewohnten Landstriches, sondern die ,Eindeutschung' des gesamten Raumes: In einem halben Dutzend Erlassen ordnete der Reichsinnenminister in Zusammenarbeit mit den Verwaltungsbehörden des Reichsgaus die Umbenennung von Städten und Landkreisen an, von denen die Namensänderung von „Lodz“ in „Litzmannstadt“ sicherlich die bekannteste ist. (Lemmen 2014)

In Lodz bzw. Litzmannstadt [€ódź] sollte „ein deutscher Stadtkern geschaffen [werden], in dem Volksdeutsche und Baltendeutsche angesiedelt werden“ (OB Schiffer 1940, zit. nach Teunissen 2016). Die polnischsprachigen Namen, die noch ein Jahr vor der Annexion anhand des Lodzer Stadtplans (Górski ca. 1938) für das südliche Stadtviertel Chojny nachvollzogen werden können, tauchen allesamt, auch in den jeweiligen Peripheriebereichen, im „Plan von Litzmannstadt“ (Thiem 1942) nicht mehr auf. Auch die betreffenden am Anfang der 1940er Jahre in Auftrag gegebenen Stadtpläne von Königshütte [Chorzów] (1941) und Pabianitz [Pabianice] (1943) weisen sowohl für die Stadtkerne als auch für die jeweiligen Viertel in der städtischen Peripherie ausschließlich deutschsprachige Straßenbenennungen auf. Dass bei derartigen Umbenennungsprozessen auch kolonialzeitbezogene Namenvergaben als groß angelegte Cluster Verwendung fanden, zeigt, dass das koloniale Narrativ offenbar aus zeitgenössischer Sicht als ein Teil des propagierten „Deutschtum[s]“ (Schmidt 1941: 176) angesehen wurde: Für die betreffenden drei Städte sind eine Vielzahl an Namen zu verzeichnen, die usuell entsprechend der Namenvergabepraktiken in die Großund Mittelstädte des Deutschen Reichs als Cluster in die Viertel der jeweiligen städtischen Peripheriebereiche verfügt wurden.

Für Pabianitz [Pabianice] können acht koloniale SN-Token konstatiert werden. Die SN-Token Kamerun-, Lüderitz-, Samoa-, Togo-, Nachtigal- und Wissmannstraße sowie Karl-Peters- und Lettow-Vorbeck-Straße stellen allesamt Umbenennungen für Parallelstraßen am südlichen Stadtrand dar: 


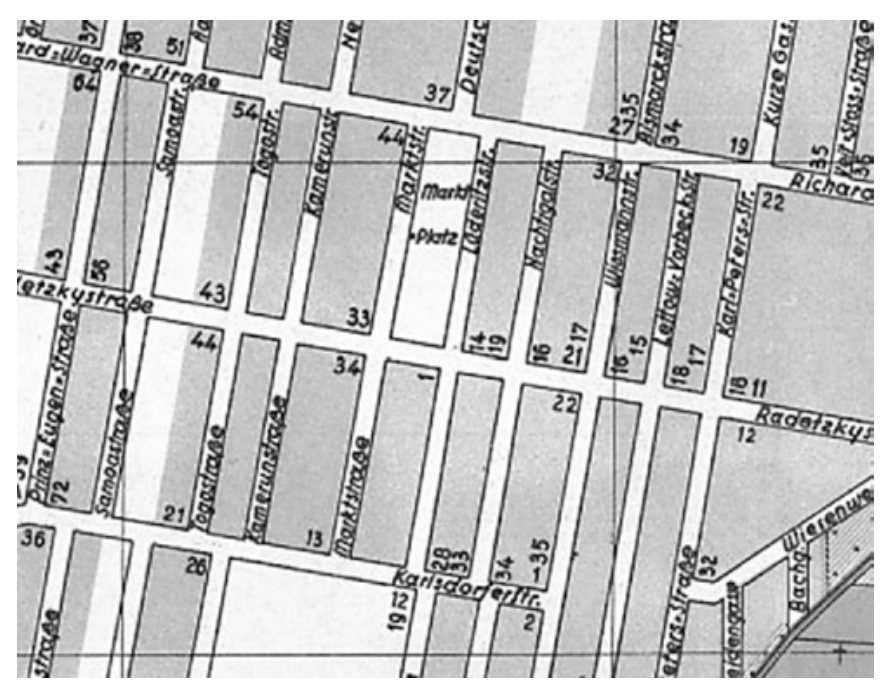

Abb. 31: Stadtplan Pabianitz [Pabianice] (1943), Ausschnitt südlicher Stadtrand.

Die jeweiligen deanthroponymischen und detoponymischen Konstruktionen stimmen mit den für das erstellte Gesamtinventar aufgezeigten hochfrequenten MOD-Types überein. Im Ergebnis kann für Pabianitz [Pabianice] eine koloniale Clusterverfügung dritten Typs konstatiert werden, deren gebündelte Benennungen in kommemorativer Intention auf Orte und Kolonialakteure der Kolonialzeit referieren sollten. Das Kolonialcluster in Pabianitz [Pabianice] entspricht hinsichtlich der großen Anzahl an Benennungen, der jeweiligen Konstruktionen und der damit intendierten unspezifischen Georeferenzierung dem Usus kolonialzeitbezogener Namenvergabepraktiken in der Zeit des Nationalsozialismus. Auffällig ist dagegen die Verortung des kolonialen Namenviertels: Während Kolonialcluster in Groß- und Mittelstädten vorrangig in Neubaugebiete der städtischen Peripheriebereiche verfügt wurden, sind die betreffenden kolonialzeitbezogenen Straßennamen im Stadtplan von 1943 für Straßenzüge in unmittelbarer Nähe des MarktPlatz[es] festzustellen. Die Frage, ob tatsächlich ein solcher Marktplatz bereits in polnischer Zeit existierte oder erst im Zuge der Annexion von nationalsozialistischer Seite angelegt oder sogar ausschließlich für den betreffenden Stadtplan konstruiert wurde, muss angesichts der derzeitigen Quellenlage offen bleiben.

Dass die deutschsprachigen Namen nicht nur im betreffenden Stadtplan, sondern auch in zeitgenössischen Alltagstexten festzustellen sind und seit dem Zeitpunkt ihrer Verfügung im Raum selbst sicht- und lesbar waren, zeigt der Eintrag in der Litzmannstädter Zeitung vom 6.12.1942, in dem der Oberbürgermeister die „Anmeldung zum Bezug von Gemüsekonserven“ mitteilt: „Wer tief- 
gefrorenes Obst und Gemüse $\mathrm{zu}$ beziehen wünscht, hat sich in nachfolgenden Geschäften einzutragen“:

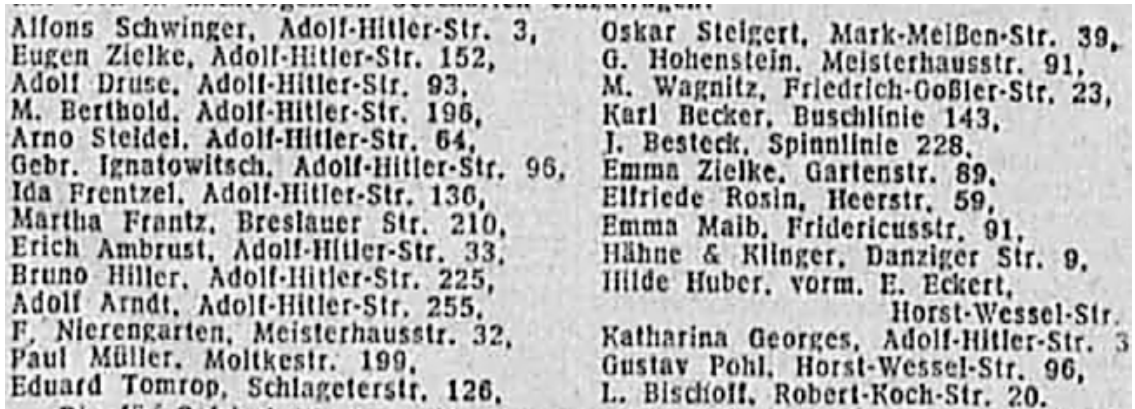

Abb. 32: Litzmannstädter Zeitung (6.12.1942).

Auch die jeweiligen deutschsprachigen kolonialen Umbenennungen wurden offenbar durch entsprechende Beschilderung in der unmittelbaren Raumdeskription verfügt: In der Litzmannstädter Zeitung vom 22.03.1942 wird berichtet, dass die Bewohnerin Emma Hübscher folgenden Verlust zu verzeichnen hat: „VERLOREN (Majuskeln im Original) [...] Dritte Reichskleiderkarte [...] der Emma Hübscher, Pabianice, Lüderitzstraße 38, verloren.“.

Die für Königshütte [Chorzów] erhobenen kolonialzeitbezogenen SN-Token Kamerunstr., Kolonialstr., Lettow-Vorbeck-Str. und Lüderitzstr. sind für das Viertel Bismarck am südlichen Stadtrand festzustellen:

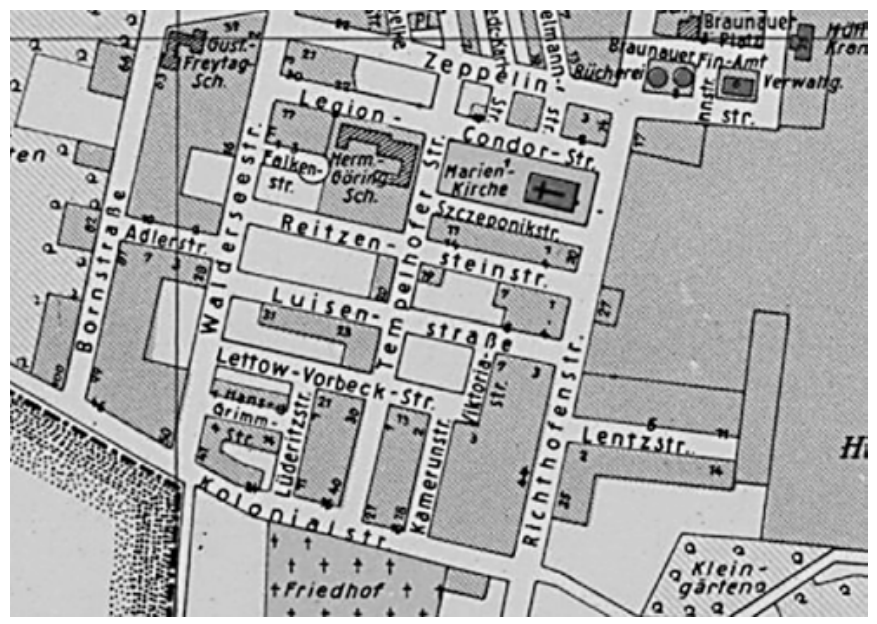

Abb. 33: Königshütte [Chorzów] (1941), Ausschnitt Bismarck. 
Obwohl alle Namen für aneinandergrenzende Quer- und Parallelstraßen festzustellen sind, ist eine genaue Abgrenzung explizit kolonialer Kommemoration gegenüber weiteren kommemorativen Namenverfügungen in nächster Nähe nur in Ansätzen möglich. So bleibt bspw. die Frage ungeklärt, inwieweit das SNToken Walderseestraße in nachweislich kolonialer Intention verfügt wurde oder sich das SN-Token wie die Benennung der Richthofenstr. im Osten für einen Straßenzug gleicher Länge auf Generäle des Ersten Weltkriegs beziehen sollten.

Zeitgenössische Adressbücher mit etwaigen Benennungsmotiviken sind nicht verfügbar. Auffällig ist darüber hinaus die Benennung Hans-Grimm-Str. für eine Straße, die parallel bzw. kreuzförmig zu den Straßenzügen der usuellen kolonialen Konstruktionen Lüderitzstr. und Lettow-Vorbeck-Str. verläuft. Inwieweit man dem Schriftsteller Hans Grimm eine Relevanz innerhalb des zeitgenössischen kolonialrevisionistischen Diskurses zusprechen wollte, kann, wenn überhaupt, nur mit seinem in der Zwischenkriegszeit publizierten Roman „Volk ohne Raum“ (Grimm 1926) begründet werden.

Die Ideologie war nicht eigentlich nationalsozialistisch, aber enthielt zahlreiche Elemente und Topoi des völkischen Blut-und-Boden-Denkens. Vor allem lieferte der Titel Volk ohne Raum [kursiv im Original] der nationalsozialistischen Agitation ein wirkungsvolles Sichtwort, das fortan [...] für Überbevölkerungsängste, Versailles-Revisionismus und Ostraumexpansion genutzt werden konnte. (Speitkamp 2005a: 169)

Bezieht man auch weitere in Königshütte [Chorzów]-Bismarck verfügten deutschsprachigen Umbenennungen (bspw. Richthofenstr., Zeppelin-str., Legion-CondorStr.) mit ein, liegt die Vermutung nahe, dass dort alle solche Namen Verwendung fanden, die sich aus zeitgenössischer Sicht auf erfolgreiche oder gewünscht erfolgreiche Expansion beziehen sollten. Die spezifisch kolonialen Namenmuster, die auf Orte der kolonisierten Gebiete und Kolonialakteure referieren, werden innerhalb dieses thematisch übergeordneten Clusters mitverfügt.

Dass die nationalsozialistischen Verwaltungsbehörden binnen weniger Wochen nach der Annexion der ehemals polnischen Gebiete den Straßennamenbestand ganzer Städte tilgten und mit deutschsprachigen Umbenennungen auffüllten, die zugleich das nationalsozialistische Narrativ des „Deutschtum[s]“ (Schmidt 1941: 176) propagandistisch verdeutlichen sollten, führte in Lodz bzw. Litzmannstadt [Łódź] offenbar zu einer zeitgenössischen Benennungsnot. Die Umbenennung der Stadt erfolgte im April 1940, in deren Zusammenhang man auch den Namen der Lodzer Zeitung bzw. Lodscher Zeitung in Litzmannstädter Zeitung änderte. Die Umbenennung wurde auf der Titelseite von Seiten des Gauleiters und Reichstatthalters A. Greiser folgendermaßen bekanntgegeben: 
Befehl des Führers: Lodsch heißt jetzt Litzmannstadt. Telegramm des Gauleiters und Reichsstatthalters an den Führer. [...] Mein Führer! Ich melde mich Ihnen in Ausführung Ihres Befehles, daß ich soeben in Ihrem Auftrage, der von deutschen Handwerkspionieren gegründeten und von deutschen Arbeitern und Kaufleuten besiedelten großen Industriestadt Lodsch den Namen Litzmannstadt gegeben habe. [...] Wir gedenken in Dankbarkeit und Ehrfurcht hierbei der entscheidenden Waffentat eines Ihrer treuesten Gefolgsmänner von dieser Stadt, des Generals Litzmann. (Litzmannstädter Zeitung 12.04.1940)

Offenbar gingen die deutschsprachigen Straßennamen für Lodz bzw. Litzmannstadt [Łódź] in einem noch stärkeren Ausmaß mit dem nationalsozialistischen Ziel der „De-Kulturation und Germanisierung“ (Harten 1996) Polens einher: Allein im vorherigen Zitat wird das Deutsche zwei Mal als historische Legitimation (von deutschen Handwerkspionieren gegründet[en], „,von deutschen Arbeitern und Kaufleuten besiedelt[en]) für deren Annexion und Namensänderung erwähnt.

Vermutlich herrschte, wenn eine Stadt in kürzester Zeit auf dem Reißbrett deutschsprachige Namen bekommen sollte, eine Art Benennungsnot vor. Auf dem Anfang der 1940er Jahre veröffentlichten Stadtplan (vgl. Thiem 1942) sind Imitationen themenkohärenter Namenmuster festzustellen, wie sie im Deutschen Reich schon im 19. Jahrhundert üblich waren. Innerhalb solcher Cluster können darüber hinaus Konstruktionen ausgemacht werden, die hinsichtlich ihrer Modifikatoren für keine andere deutsche Stadt festzustellen sind. So sind bspw. die ModifikatorKonstruktionen Wunderlampe, Zinnsoldat, Goldelse und Entlein eines mit vielen weiteren Namen angelegten themenkohärenten Namenviertels, das offenbar kommemorativen Bezug auf berühmte (vorrangig deutschsprachige) Märchenund Romanliteratur nehmen sollte, heute nirgends festzustellen:

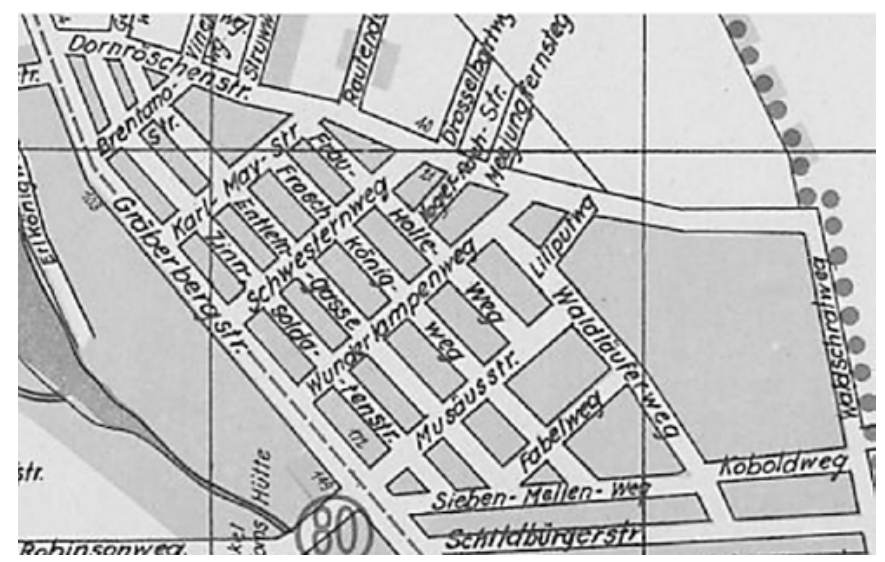

Abb. 34: Lodz bzw. Litzmannstadt [tódź] (1942). 
Die zeitgenössische Benennungsnot, die sich im Zuge der zügigen Vergabe deutschsprachiger Straßennamen für eine ganze Stadt ergab, ist auch anhand der kolonial intendierten Namenvergabepraktiken festzustellen, die für das Viertel Effinghausen abseits des Stadtkerns erhoben werden konnten: Die kolonialen Namenvergabepraktiken sind nicht nur aufgrund der über das übliche Maß hinausgehenden Anzahl an nahezu 30 SN-Token (Kap. 6.1) als Sonderfall herauszustellen, sondern auch bezüglich der jeweiligen Modifikator-Konstruktionen (Kap. 7.1.1).

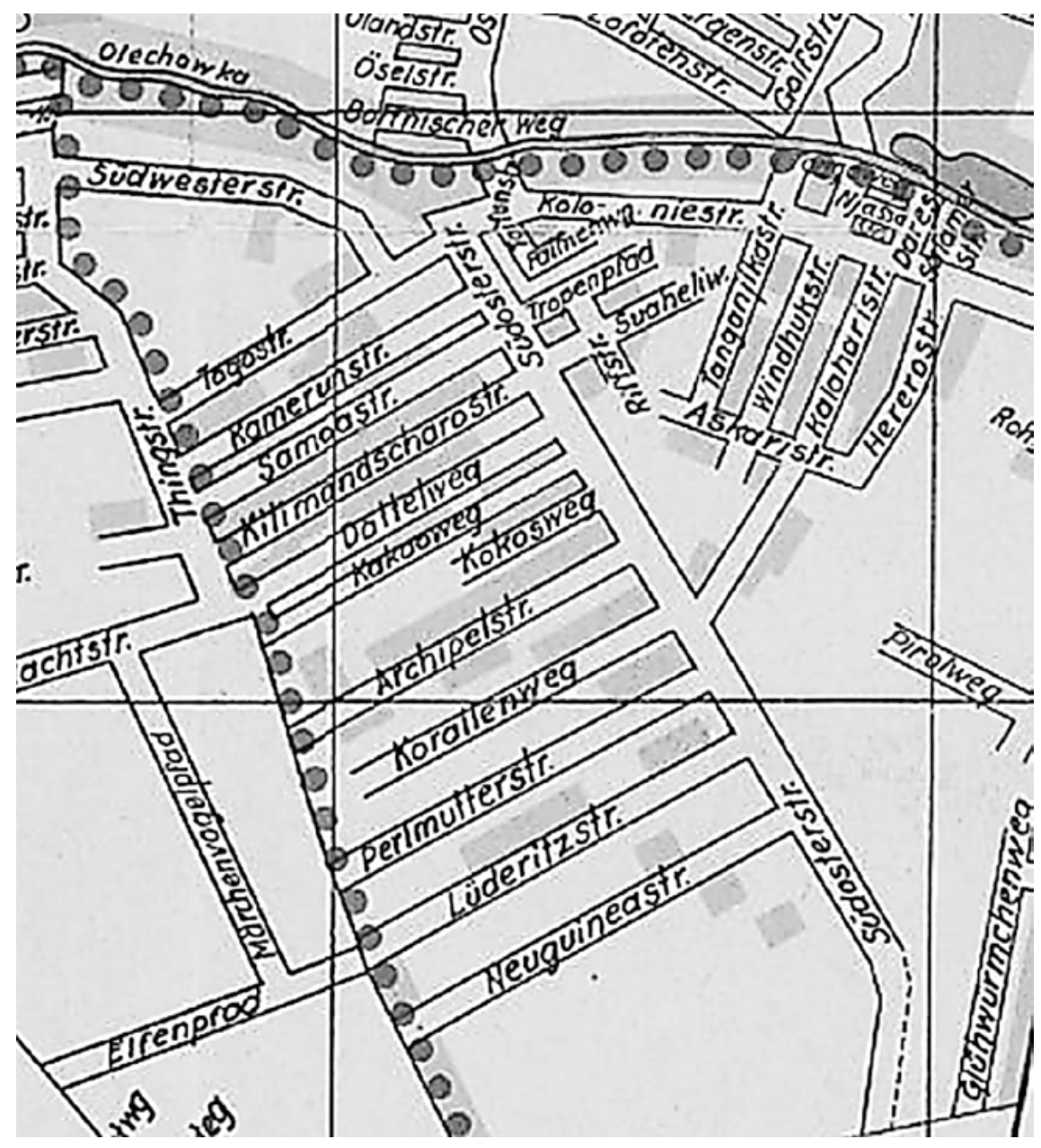

Abb. 35: Lodz bzw. Litzmannstadt [tódź] (1942), Ausschnitt Effinghausen. 
Alle Namen sind auch im ein Jahr zuvor herausgegebenen Straßenverzeichnis (vgl. Oberbürgermeister von Litzmannstadt \& Statistisches Amt 1941) als Umbenennungsprodukte früherer polnischsprachiger Namen $\mathrm{zu}$ verzeichnen, für die erwartungsgemäß keinerlei Bezug zur deutschen Kolonialgeschichte aufzuweisen ist. Neben Konstruktionen mit usuellen MoD-Types (bspw. Askaristr., Daressalamer Str., Kamerunstr., Lüderitzstr., Neuguineastr., Samoastr., Südwesterstr., Tangaweg, Togostr., Windhukstr.), die bereits als ortsübergreifend-nationale Konstruktionsmuster dargelegt wurden, sind auch Benennungen festzustellen, deren hydronymische (Njassastr., Tanganjikastr.) und appellativische (Herero, Suaheli) Modifikatoren nur ortsbezogen für das Effinghausener Namenviertel erhoben werden konnten. Trotzdem sind die vier Modifikator-Konstruktionen im Koloniallexikon durch entsprechende Lemmata verzeichnet (vgl. Schnee II: 654-356, III: 455-457, II: 57-59, III: 432). Darüber hinaus weicht die große Zahl an Benennungen mit linksköpfigen appellativischen Modifikatoren (Archipel, Dattelweg, Kakaoweg, Kokosweg, Korallenweg, Palmenweg, Perlmutterstr., Taifun, Tropfenpfad u. dgl.) von den usuellen kolonialen Konstruktionsmustern ab. ${ }^{183}$ Offenbar kam man mit den prototypischen Modifikatoren aufgrund der derart hohen Zahl an umzubenennenden polnischsprachigen Straßennamen in thematischer Kohärenz nicht aus, was zu weiteren Konstruktionen aus Assoziationsketten wie Kolonialprodukten bis hin zu Wirbelstürmen, die in den Raum der kolonisierten Gebiete zu verorten sind, führte. Solche Assoziationsketten führten bei Benennungen, die sich auf den kolonisierten Raum beziehen sollten, aber auch zu Fehlern (Südosterstr.). Die Einmaligkeit (und Kuriosität) an deutschsprachigen Straßennamen für die im Zuge des Polenfeldzugs annektierten Stadt Lodz bzw. Litzmannstadt [Łódź] ist damit auch hinsichtlich der damit versprachlichten Gewissheiten herauszustellen.

183 Eine bundesweite Suche ergibt, dass einige Konstruktionen auch im deutschsprachigen Raum ortsübergreifende Verwendung fanden, diese jedoch nicht innerhalb von Kolonialclustern verortet werden können: So ist in Riedenberg bei Stuttgart das SN-Token Dattelweg für einen Straßenzug zu konstatieren, der in unmittelbarer Nähe zu weiteren Straßen mit den Benennungen Melonenstr., Mandarinenweg, Feigenweg und Olivenstr. zu verorten ist. Auch für Nürnberg ist der Straßenname auffindbar, und zwar in Nachbarschaft zu Straßenzügen mit den SN-Token Olivenweg, Zitronenweg, Kastanienweg und Zedernweg. 